Universidade de São Paulo

Instituto de Física

\title{
Defeitos em Nanofitas de Grafeno zigzag
}

\author{
Alberto Torres Riera Junior \\ Orientador: Antônio José Roque da Silva
}

Dissertação apresentada ao Instituto de Física

da Universidade de São Paulo para a obtenção do título de Mestre em Ciências.

Banca examinadora: Rodrigo Barbosa Capaz (IF/UFRJ)

Helena Maria Petrilli (IF/USP)

Antônio José Roque da Silva (IF/USP)

São Paulo 
FICHA CATALOGRÁFICA

Preparada pelo Serviço de Biblioteca e Informação do Instituto de Física da Universidade de São Paulo

Riera Junior, Alberto Torres

Defeitos em Nanofitas de Grafeno zigzag - 2008

Dissertação (Mestrado) - Universidade de São Paulo. Instituto de Física - Depto. de Física dos Materiais

Orientador: Prof. Dr. Antônio José Roque da Silva

Área de Concentração: Física

Unitermos: 1. Física da Matéria Condensada;

2. Física Teórica; 3. Propriedades dos Sólidos. 


\section{Agradecimentos}

Agradeço a minha família por todo o suporte e apoio. A minha namorada, Vilmara, pela compreensão. E a todo o pessoal do grupo SAMPA, especialmente ao Rodrigo Amorim.

Em especial, gostaria de agradecer ao meu orientador, Antônio José Roque da Silva, por ter me orientado durante o meu mestrado e me ensinado a pensar como físico.

Agradeço à CNPq pelo suporte financeiro. 



\section{Resumo}

Grafeno e nanofitas de grafeno vêm, cada vez mais, atraindo o interesse da comunidade científica devido as suas notáveis propriedades. Neste trabalho realizou-se um estudo sistemático da estabilidade de defeitos do tipo divacância, vacância e Stone-Wales em grafeno e nanofitas de grafeno com bordas zigzag.

Para tal, fizeram-se cálculos de primeiros princípios, baseados em teoria do funcional da densidade (DFT) na aproximação GGA com o uso de pseudopotenciais ultrasoft e uma base de ondas planas. Também foram feitas simulações de imagens de STM para os defeitos nas nanofitas.

Além disso, foram encontrados dois novos defeitos, não publicados em nenhum outro lugar (até onde vai o conhecimento do autor), com energia de formação muito baixa. 


\section{Abstract}

Graphene and graphene nanoribbons have been attracting a lot of interest from the scientific community because of their novel properties.

In this work, a systematic research has been done on the stability and energetics of divacancy, vacancy and Stone-Wales defects in graphene and zigzag graphene nanoribbons.

With this goal in mind, ab initio density functional calculations within the GGA approximation, using ultrasoft pseudopotentials and a plane wave basis were done. Also, STM images were simulated for some selected defects.

Besides, two new defects, not published elsewhere (to the best knowledge of the author), with very low formation energy are reported. 


\section{Sumário}

1 Introdução $\quad 9$

2 Grafeno $\quad 11$

2.1 Nanofitas ............................. 14

3 Modelos teóricos $\quad 18$

3.1 Teoria do Funcional da Densidade . . . . . . . . . . . . . 20

3.1.1 Teoremas de Hohenberg-Kohn . . . . . . . . . . . . 21

3.1.2 Ansatz de Kohn-Sham . . . . . . . . . . . . . . 22

3.1.3 Aproximação da Densidade Local (LDA) . . . . . . . . . 25

3.1.4 Aproximações Generalizadas de Gradiente (GGA) . . . . . . 26

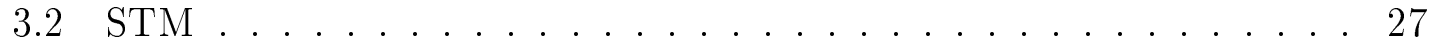

3.2.1 Modelo de Tersoff-Hamann . . . . . . . . . . . . 28

4 Simulação computacional $\quad 30$

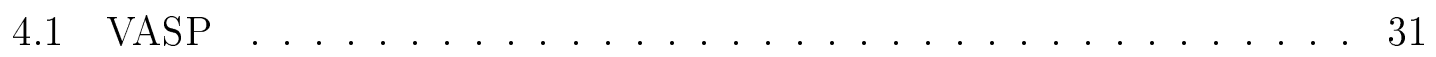

4.2 Detalhes dos cálculos . . . . . . . . . . . . . . . 31

$\begin{array}{lll}5 & \text { Resultados } & 33\end{array}$

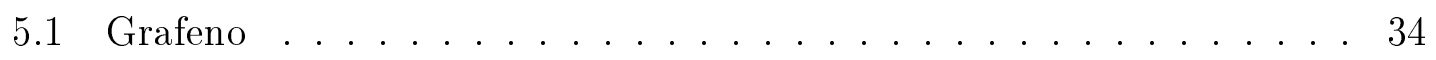

5.1 .1 Divacância $(\mathrm{V} 2) \ldots \ldots . \ldots . \ldots . \ldots . \ldots 34$

5.1 .2 Monovacância (V1) .................. 36

5.1 .3 Stone-Wales $(\mathrm{SW}) \ldots \ldots \ldots \ldots$ 
5.1 .4 Discussão . . . . . . . . . . . . . . . . 38

5.2 Nanofitas ............................. 40

5.2 .1 Pristina ......................... 41

5.2 .2 Divacância . . . . . . . . . . . . . . 43

5.2 .3 Monovacância .................... 53

5.2 .4 Stone-Wales . . . . . . . . . . . . . . . 59

5.2 .5 Discussão . . . . . . . . . . . . . . 69

6 Conclusão $\quad 72$

$\begin{array}{ll}\text { A Aproximação de Born-Oppenheimer } & 74\end{array}$

$\begin{array}{ll}\text { B Otimização de parâmetros } & 77\end{array}$

B.1 Energia de Corte . . . . . . . . . . . . . . 77

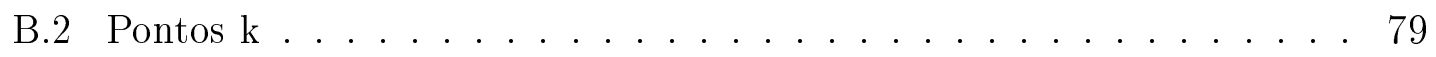

B.3 Parâmetro de rede . . . . . . . . . . . . . . . . . 80

$\begin{array}{ll}\text { C Pseudopotenciais } & 82\end{array}$

D Aproximação de Supercélula $\quad 84$

$\begin{array}{lr}\text { Referências Bibliográficas } & 86\end{array}$ 


\section{Capítulo 1}

\section{Introdução}

Desde a descoberta dos fulerenos em 1985 por Kroto [1], e a dos nanotubos de carbono em 1991 por Iijima [2], materiais grafíticos de baixa dimensionalidade tem recebido uma crescente atenção por parte da comunidade científica da matéria condensada. Este interesse se justifica devido à riqueza de novos fenômenos apresentados por estes sistemas[3] e ao grande potencial para aplicações nas mais diversas áreas (micro e nanoeletrônica, sensores, etc.).

Em particular, apesar do grafeno ser conhecido teoricamente há mais de 60 anos (grafite 2D) [4] , foi a partir de 2004, quando o grafeno foi isolado pela primeira vez [5], que o número de trabalhos investigando o grafeno e suas propriedades começou a crescer exponencialmente. Hoje em dia, o grafeno é um dos tópicos mais "quentes" na área de matéria condensada.

Grafeno e nanofitas de grafeno, que podem ser vistas como tiras formadas a partir do corte do grafeno, possuem uma quantidade imensa de possíveis aplicações. Não é a toa que o grafeno é hoje um dos candidatos à substituição da tecnologia do silício. Entre os vários dispositivos que já foram demonstrados e sugeridos, temos sensores ultrasensíveis [6, 7, 8], células solares [9], transistores de efeito de campo [10, 11], dispositivos de memória [12, 13], dispositivos spintrônicos [14, 15, 16, 17], materiais compostos [18] entre outros.

Grande parte desses dispositivos é baseada em nanofitas de grafeno. Assim, é de fundamental importância conhecer quais são os tipos de defeitos mais estáveis 
em nanofitas e saber como a presença destes defeitos alteraram suas propriedades. A presença de defeitos, que dependendo do tipo de aplicação em vista pode ser benéfica ou prejudicial, pode ser resultado dos procesos de fabricação (por exemplo, das técnicas empregadas para a obtenção do grafeno e de corte das fitas) ou até, se desejada, de irradiação por elétrons ou ions, da mesma forma como é feito com nanotubos de carbono [19, 20, 21].

É sabido que em nanotubos (que são sistemas similares a nanofitas) a presença de defeitos altera drasticamente as propriedades eletrônicas e de transporte [19, 20], e que os defeitos mais estáveis são divacâncias, monovacâncias e Stone-Wales.

Neste trabalho, faremos um estudo das propriedades estruturais e energéticas de defeitos do tipo divacância, monovacância e Stone-Wales em nanofitas de grafeno com bordas zigzag e apresentaremos simulações de imagens STM.

Esta dissertação está organizada da seguinte forma: no capítulo dois apresentamos a teoria básica e propriedades do grafeno e de nanofitas de grafeno. Nos capítulos três e quatro, descrevemos o método usado para realizar os cálculos, a Teoria do Funcional da Densidade, e o código empregado (VASP). A seguir, no capítulo cinco detalhamos os resultados obtidos. Por último apresentamos as conclusões atingidas e perspectivas futuras. 


\section{Capítulo 2}

\section{Grafeno}

Desde sua descoberta, o grafeno tem sido alvo de intensa pesquisa, tendo se tornado um dos candidatos à substituição da tecnologia do silício e sendo, hoje em dia, um dos tópicos mais "quentes" na área de física da matéria condensada. Entre as várias propriedades que tornam o grafeno tão interessante, pode-se ressaltar a alta mobilidade dos portadores de carga (a maior já medida até hoje) [22], a maior resistência mecânica entre os materias [23] e uma condutividade térmica duas vezes maior que a do diamante [24].

O grafeno, uma forma alotrópica do carbono constituída por uma camada de átomos dispostos numa estrutura hexagonal, pode ser considerado como o bloco de construção de todos os outros materiais grafíticos [3]. Ele pode ser embrulhado para formar fulerenos 0D, enrolado em nanotubos 1D ou empilhado, resultando em grafite 3D (Fig. 2.1).

A estrutura hexagonal do grafeno não é uma rede de Bravais, mas pode ser vista como uma rede triangular com dois átomos na base (formando duas sub-redes, A e B), conforme ilustrado na figura 2.2. Os vetores de rede são dados por

$$
\mathbf{a}_{1}=\sqrt{3} a_{C C}\left(\frac{\sqrt{3}}{2}, \frac{1}{2}\right)
$$




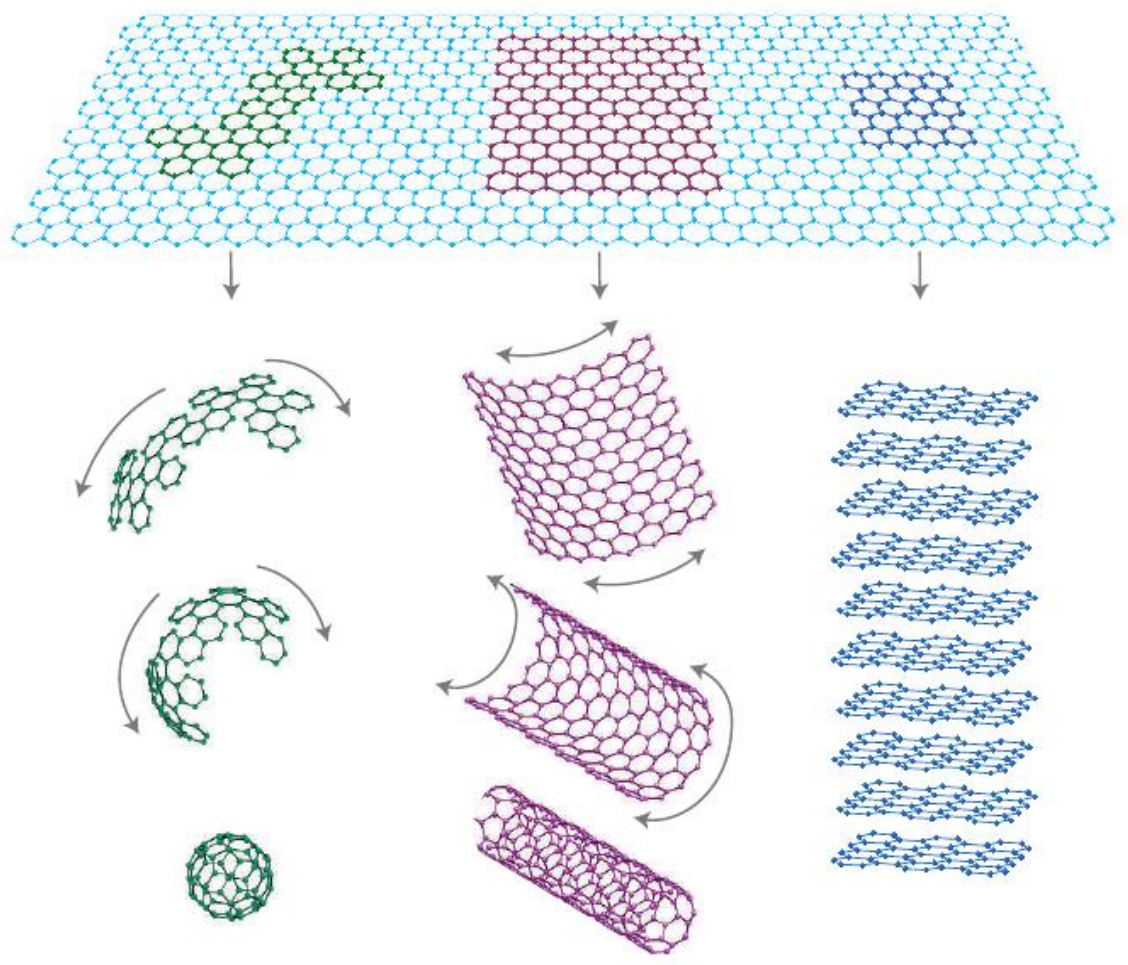

Figura 2.1: O grafeno pode ser embrulhado para formar fulerenos 0D, enrolado em nanotubos 1D ou empilhado, resultando em grafite 3D. Figura retirada da Ref. [3].

$$
\mathbf{a}_{2}=\sqrt{3} a_{C C}\left(\frac{\sqrt{3}}{2},-\frac{1}{2}\right)
$$

onde $a_{C C}=1.42 \AA$ é a distância carbono-carbono experimental ${ }^{1}$ e $\left|\mathbf{a}_{1}\right|=\left|\mathbf{a}_{2}\right|=$ $\sqrt{3} a_{C C}=2.46 \AA$ são os pâmetros de rede (veja o apêndice B). Sua zona de Brillouin é então definida pelos vetores

$$
\begin{aligned}
& \mathbf{b}_{1}=\frac{2 \pi}{\sqrt{3} a_{C C}}\left(\frac{1}{\sqrt{3}}, 1\right) \\
& \mathbf{b}_{2}=\frac{2 \pi}{\sqrt{3} a_{C C}}\left(\frac{1}{\sqrt{3}},-1\right)
\end{aligned}
$$

onde $\left|\mathbf{b}_{1}\right|=\left|\mathbf{b}_{2}\right|=4 \pi / 3 a_{C C}$.

A estrutura de bandas do grafeno (Fig. 2.3) revela que este é um semicondutor de gap zero com um cruzamento linear no ponto K. Portanto, perto do ponto K,

\footnotetext{
${ }^{1}$ Que é igual ao valor encontrado nos cálculos neste trabalho (apêndice B
} 
a)

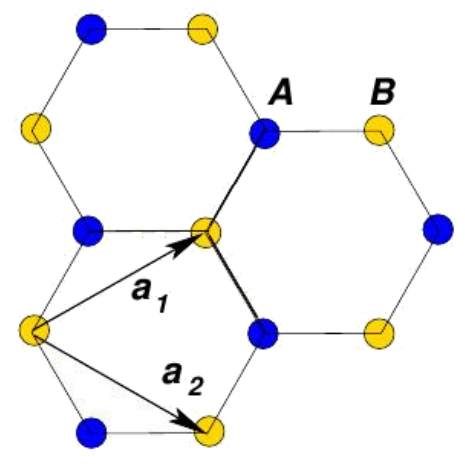

b)

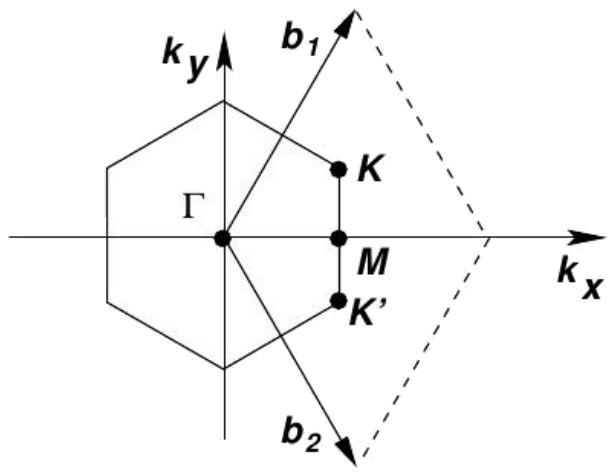

Figura 2.2: (a) Rede do grafeno, seus vetores de rede, $\mathbf{a}_{1}$ e $\mathbf{a}_{2}$ e as duas subredes, A (azul) e B (amarelo). (b) Primeira zona de Brillouin (hexágono), seus pontos de alta simetria e os vetores da rede recíproca, $\mathbf{b}_{1}$ e $\mathbf{b}_{2}$.

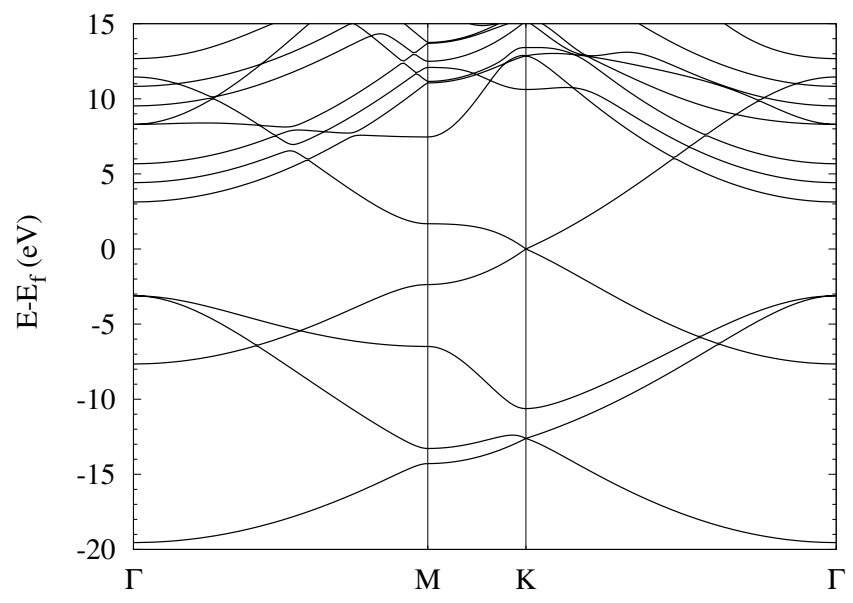

Figura 2.3: Estrutura de bandas do grafeno. Note o cruzamento linear no ponto K.

onde a relação de dispersão é linear, os elétrons apresentam uma massa efetiva nula, o quedá origem a várias propriedades interessantes [3].

Os átomos de carbono (valência $2 s^{2} 2 p^{2}$ ) no grafeno apresentam hibridização $s p^{2}$, formando ligações $\sigma$ no plano. Já os orbitais $p_{z}$ não hibridizados, que apontam para fora do plano do grafeno, formam ligações $\pi$ deslocalizadas. As ligações $\sigma$ são ligações covalentes fortes, majoritariamente responsáveis pelas propriedades mecânicas e elásticas do grafeno, enquanto que as ligações $\pi$ são responsáveis pelas propriedades eletrônicas [25]. 
(a)

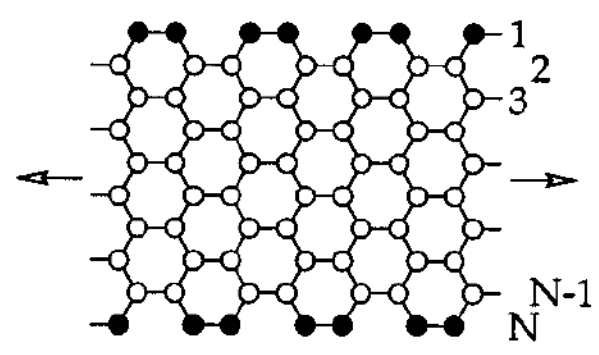

(b)

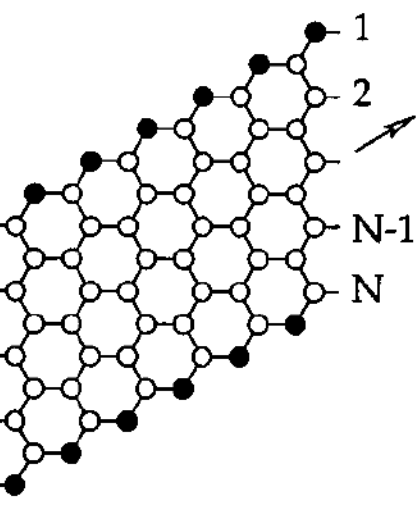

Figura 2.4: Exemplos da estrutura de nanofitas do tipo armchair (a) e zigzag (b). Figura retirada da Ref. [26].

\section{$2.1 \quad$ Nanofitas}

Nanofitas de grafeno (Graphene Nano-Ribbons - GNR) são formadas através do corte do grafeno. Dependendo da direção na qual o corte é feito são obtidas fitas com diferentes tipos de bordas. Na figura 2.4 podemos ver os dois tipos básicos de bordas. GNRs com bordas como as da Fig. 2.4a são chamadas de armchair e podem ser vistas como se fossem um nanotubo zigzag aberto. Se forem como as da Fig. 2.4b, são denominadas zigzag, estas podem ser vistas como se fossem um nanotubo armchair aberto. Misturas entre estes tipos de bordas também são possíveis.

O tipo de borda é uma característica importante, pois é ela que determina as propriedades eletrônicas das fitas. Diferentemente dos seus nanotubos correspondentes, GNRs armchair são sempre semicondutoras [27] (enquanto nanotubos zigzag podem ser condutores ou semicondutores), e GNRs zigzag, podem ser condutoras ou semicondutoras [28, 29, 27] (nanotubos armchair são sempre condutores). Os estados mais estáveis de GNRs zigzag apresentam magnetismo e, dependendo do alinhamento dos momentos magnéticos das bordas, são condutoras ou semicondutoras $[25,29,28,27]$.

Além disso, fitas zigzag apresentam estados localizados nas bordas com energias próximas ao nível de Fermi. Na figura 2.5 podem-se ver duas imagens de STM, 

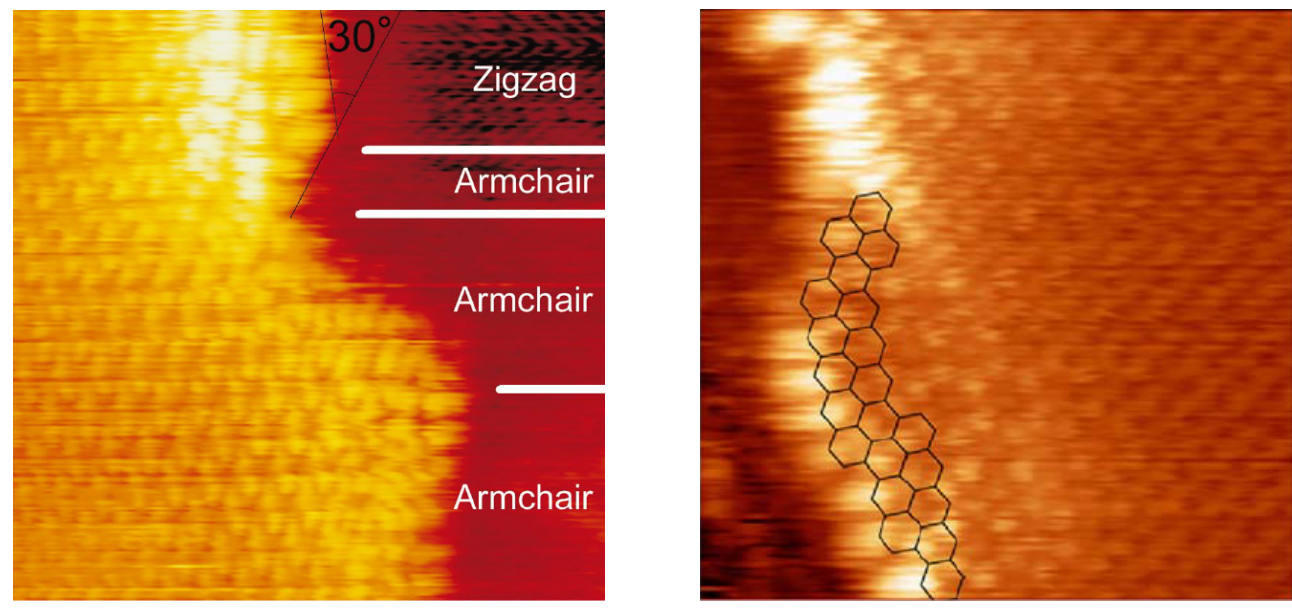

Figura 2.5: Imagens de STM em modo de corrente constante $\left(V_{s}=0.02 \mathrm{~V}\right.$ e $I=$ $0.7 n A$ ) de superfícies de grafeno com bordas hidrogenadas em HPOG. As regiões mais claras indicam uma maior densidade local de estados. Figuras retiradas das refs. [30, 31].

realizadas por Kobayashi et al. [30, 31], mostrando a presença de estados localizados em superfícies de grafeno com bordas hidrogenadas em grafite pirolítico altamente orientado (Highly Oriented Pyrolitic Graphite - HOPG), que aparecem como regiões mais brillantes nas imagens.

Devido as suas incríveis propriedades, o grafeno abriu um novo horizonte pra possíveis aplicações. Entre os vários dispositivos que já foram demonstrados experimentalmente temos transistores de efeito de campo (Field Effect Transistors FET) [10, 11], transistores de um único elétron (Single Electron Transistor - SET) [32, 33, 34], dispositivos de memória [12, 13], sensores ultra-sensíveis [6, 7, 8], células foto-voltáicas [9], mateirais compostos [18], dispositivos spintrônicos [14, 15, 16, 17] e qubits de spin $[35,36]$.

A maioria dos dispositivos acima citados são baseados em nanofitas de grafeno. Portanto, é importante do ponto de vista de aplicações que seja possível produzir fitas estreitas e com bordas bem definidas (lembre que o tipo de borda define as propriedades eletrônicas da fita). Atualmente, estes objetivos já são alcançados em laboratório (embora não sempre ao mesmo tempo). Na figura 2.6, podem-se ver imagens AFM de nanofitas de até $20 \mathrm{~nm}$ com bordas bem definidas produzidas por 

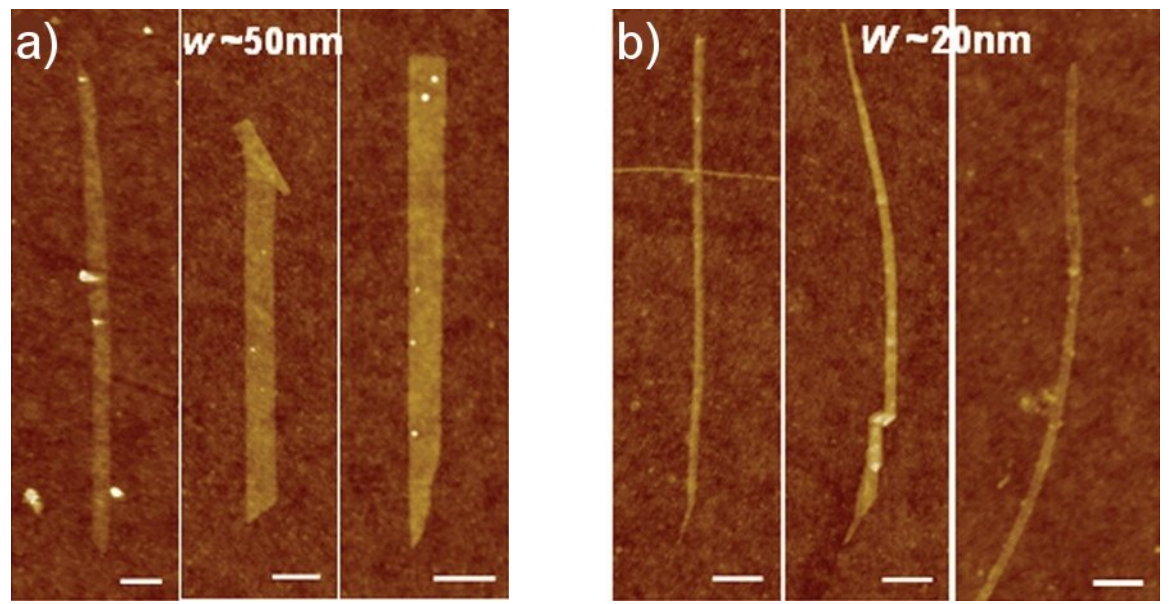

Figura 2.6: Imagens AFM de nanofitas de grafeno produzidas por meios químicos. A fitas em (a) possuem uma, duas e duas camadas respectivamente. Em (b), possuem de três a uma (direita). Todas as barras de escala indicam $100 \mathrm{~nm}$. Figuras retiradas da Ref. [37]
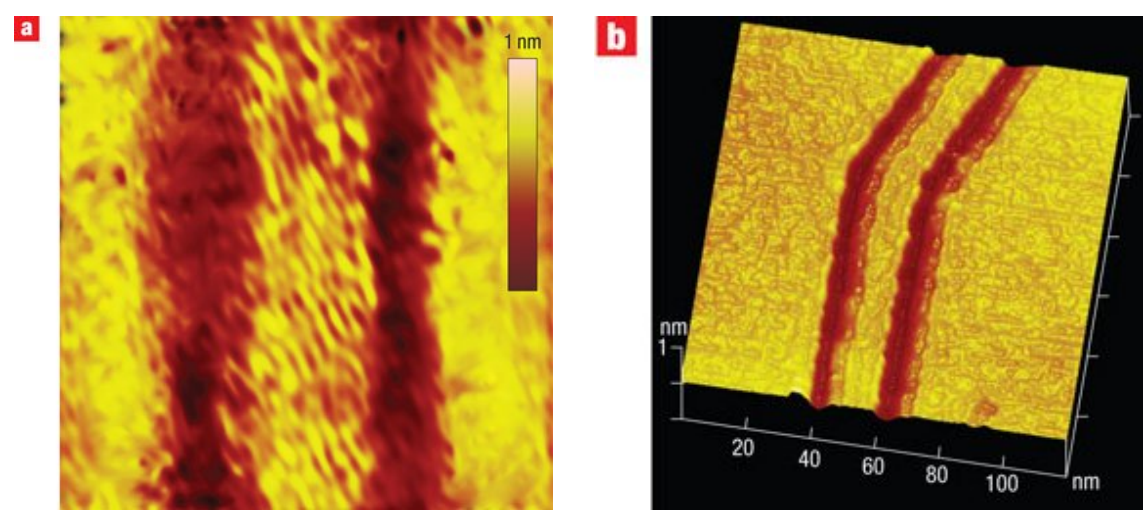

Figura 2.7: Imagens STM de (a) uma nanofita de grafeno armchair de $2.5 \mathrm{~nm}$ de largura e (b) de uma junção de uma fita armchair com uma zigzag, com largura de $8 \mathrm{~nm}$. Fitas produzidas por litografia STM. Figuras retiradas da Ref. [38].

meios químicos [37]. Já na figura 2.7a tem-se uma fita armchair de aproximadamente $2.5 \mathrm{~nm}$ produzida por litografia STM (esta não apresenta bordas suaves).

Outra questão importante é a presença de defeitos, que podem alterar as propriedades eletrônicas do grafeno e das nanofitas. Em geral, as mostras de grafeno produzidas em laboratório apresentam boa qualidade cristalina [3]. Apesar disso, Hashimoto et al. [21] e Meyer et al. [39] mostraram a existência de defeitos em grafeno através de imagens obtidas por microscopia eletrônica de transmissão (Fig. 2.8). Também, defeitos podem vir a ser criados por bombardeamento de elétrons 

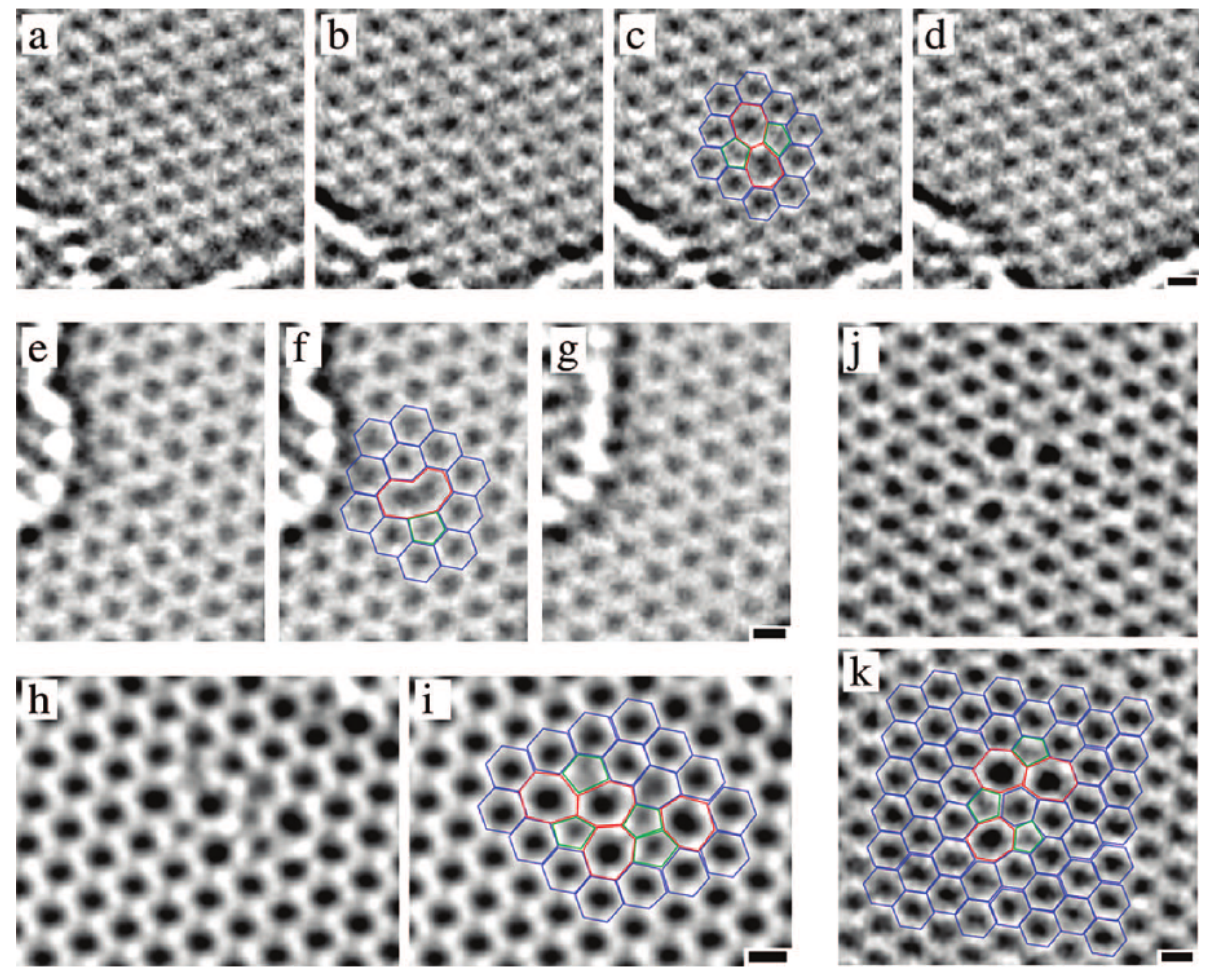

Figura 2.8: Defeitos encontrados em seqüencias de imagens HRTEM. (a-d) Aparecimento de um defeito Stone-Wales (SW): (a) a rede não-perturbada, (b) defeito SW, (c) mesma imagem com a configuração atômica sobreposta e (d) relaxação para a rede não-perturbada (após $4 \mathrm{~s}$ ). (e-g) Monovacância reconstruída: (e) e (f) monovacância sem e com a geometria sobreposta e (g) a rede não-perturbada (4 s depois). (h-i) Imagem de um defeito com quatro pentágonos e heptágonos. (j-k) Defeito com três pentágonos e heptágonos. Todas as barras tem 2 A. Figura da Ref. [39].

ou íons [19, 21]. Assim, saber quais são os defeitos mais estáveis em grafeno e em nanofitas de grafeno e como eles alteram suas propriedades é de vital importância para a engenharia de dispositivos.

Entre os defeitos que já foram observados em grafeno estão: divacâncias e monovacâncias, por Hashimoto et al., e monovacâncias e Stone-Wales, por Meyer et al. (Fig. 2.8).

Assim como em nanotubos de carbono, os defeitos mais estáveis (e mais estudados) no grafeno são do tipo divacância [40, 41, 42, 43], monovacância [40, 43, 44, 45] e Stone-Wales [40, 43, 46]. Dada a semelhança entre esses sistemas e nanofitas de grafeno é de se esperar que estes tipos de defeitos também sejam os mais estáveis nas nanofitas. 


\section{Capítulo 3}

\section{Modelos teóricos}

Nosso conhecimento da estrutura eletrônica da matéria é baseado em modelos quânticos e estatísticos. Para obter estas propriedades deve-se resolver a equação de Schrödinger. Assim, desde o surgimento da mecânica quântica, resolver a equação de Schrödinger para um sistema de muitos corpos interagentes tem se constituído um problema de grande relevância, e ao mesmo tempo, de difícil solução.

A hamiltoniana para um sistema composto de elétrons e núcleos é dada por

$$
H=T_{e}+V_{e N}+V_{e e}+T_{N}+V_{N N},
$$

onde o termo

$$
T_{e}=-\frac{\hbar}{2 m_{e}} \sum_{i} \nabla_{i}^{2}
$$

é a energia cinética dos elétrons,

$$
V_{e N}=-\sum_{i, I} \frac{Z_{I} e^{2}}{\left|\mathbf{r}_{i}-\mathbf{R}_{I}\right|}
$$

representa a interação entre elétrons e núcleos,

$$
V_{e e}=-\frac{1}{2} \sum_{i \neq j} \frac{e^{2}}{\left|\mathbf{r}_{i}-\mathbf{r}_{j}\right|},
$$


a interação inter-eletrônica,

$$
T_{N}=-\sum_{I} \frac{\hbar}{2 M_{I}} \nabla_{I}^{2}
$$

é a energia cinética devida aos núcleos e, por último,

$$
V_{N N}=-\frac{1}{2} \sum_{I \neq J} \frac{Z_{I} Z_{J} e^{2}}{\left|\mathbf{R}_{i}-\mathbf{R}_{j}\right|},
$$

é a interação entre núcleos.

Usando a aproximação de Born-Oppenheimer (apêndice A), podemos considerar os núcleos como sendo fixos e reescrever o hamiltoniano como

$$
H_{B O}=T_{e}+V_{e e}+V_{e x t},
$$

onde as posições dos núcleos são consideradas parâmetros agora, e

$$
V_{e x t}=-\sum_{i, I} V_{I}\left(\left|\mathbf{r}_{i}-\mathbf{R}_{I}\right|\right)=V_{e N}
$$

é o potencial externo ${ }^{1}$, identificado como $V_{e N}$ (Eq. 3.3).

Assim, para obter a estrutura eletrônica para esse sistema, é necessário resolver a equação de Schrödinger (independente do tempo) com o hamiltoniano ${ }^{2}$ (3.7),

$$
H|\Psi\rangle=\left(T_{e}+V_{e e}+V_{e x t}\right)|\Psi\rangle=E|\Psi\rangle .
$$

É interessante notar que os termos $T_{e}$ e $V_{e e}$ são sempre iguais para qualquer sistema, isto é, são universais. Desta forma, o problema é especificado pelo potencial externo $V_{\text {ext }}$.

A grande dificuldade em resolver esta equação reside no termo $V_{e e}$ (Eq. 3.4),

\footnotetext{
${ }^{1}$ No sentido de ser externo aos elétrons.

${ }^{2}$ Daqui em diante o subscrito BO será abandonado.
} 
que acopla o conjunto de variáveis $\left\{\mathbf{r}_{i}\right\}$, e faz com que seja extremamente difícil encontrar soluções analíticas. Diversos métodos de primeiros princípios, i.e. sem parâmetros ajustáveis, foram idealizados para conseguir resolver a Eq. (3.8), como a aproximação de Hartree-Fock, Interação de Configurações e Coupled Cluster [47].

Estes métodos empregam aproximações para a função de onda a fim de resolver o problema de muitos corpos. Uma vez obtidas as funções de onda, todos os observáveis podem ser calculados. No entanto, como a função de onda é função de $3 \mathrm{~N}$ variáveis, o custo computacional para tratar sistemas grandes é muito alto, tornando-se inviável.

A teoria do funcional da densidade (Density Functional Theory - DFT), por outro lado, parte de uma abordagem completamente diferente. Na DFT, a variável básica não é mais a função de onda, mas a densidade eletrônica, uma função de 3 coordenadas. Todos os observáveis podendo ser obtidos, em princípio, através desta.

\subsection{Teoria do Funcional da Densidade}

As primeiras tentativas para formular uma teoria do funcional da densidade para sistema quânticos começaram em 1927, com os trabalhos de Thomas [48] e Fermi [49], que propuseram uma aproximação para calcular a energia cinética dos elétrons em função da densidade, enquanto que a interação inter-eletrônica era tratada classicamente. O funcional de energia de Thomas-Fermi é

$$
E_{T F}[n]=T_{T F}[n]+U_{\text {Hartree }}[n]+V_{\text {ext }}[n],
$$

onde

$$
\begin{aligned}
U_{\text {Hartree }}[n] & =\frac{1}{2} \int d \mathbf{r} v_{\text {Hartree }}(\mathbf{r}) n(\mathbf{r}) \\
& =\frac{1}{2} \int d \mathbf{r} d \mathbf{r}^{\prime} \frac{n(\mathbf{r}) n\left(\mathbf{r}^{\prime}\right)}{\left|\mathbf{r}-\mathbf{r}^{\prime}\right|}
\end{aligned}
$$


é a energia de Hartree $\left(v_{\text {Hartree }}\right.$ é o potencial ${ }^{3}$ de Hartree), o termo clássico da interação entre elétrons, e é usada uma aproximação de densidade local (Local Density Approximation - LDA) para a energia cinética,

$$
T_{T F}[n]=\int d \mathbf{r} t_{s}^{h o m}(\mathbf{r}) n(\mathbf{r})=\frac{3}{10}\left(3 \pi^{2}\right)^{(2 / 3)} \int d \mathbf{r} n(\mathbf{r})^{(5 / 3)},
$$

isto é, considera-se que a densidade de energia cinética num dado ponto do espaço do sistema original é igual à de um gás homogêneo de elétrons, $t(\mathbf{r}) \approx t^{\text {hom }}(\mathbf{r})$.

Posteriormente, Dirac estendeu o modelo, incluindo um termo de troca usando, também, a aproximação LDA. Também foram propostas correções para levar em conta inomogeneidades na densidade. No entanto, o modelo de Thomas-Fermi emprega aproximações muito "cruas", fornecendo resultados não muito bons na maioria dos casos [50]. O maior mérito deste modelo foi o de usar a densidade como variável básica, sugerindo que seria possível sair de um problema de $3 \mathrm{~N}$ coordenadas (funções de onda) para um de apenas 3 (densidade).

\subsubsection{Teoremas de Hohenberg-Kohn}

Os teoremas de Hohenberg-Kohn (HK) [51] estabeleceram a fundamentação teórica da DFT. Em sua versão original, eles foram derivados para sistemas com estado fundamental não-degenerado e sem polarização de spin. Contudo, existem extensões para tratar sistemas com spin e com degenerescências no estado fundamental [50].

O primeiro teorema garante que a densidade eletrônica do estado fundamental, $n_{0}(\mathbf{r})$, determina univocamente (a menos de uma constante) o potencial externo ${ }^{4}$ $V_{\text {ext }}$. Conseqüentemente, como $V_{\text {ext }}$ determina o hamiltoniano, e este, todas as funções de onda, temos que todas as propriedades do sistema são completamente determinadas pela densidade do estado fundamental $n_{0}(\mathbf{r})$.

\footnotetext{
${ }^{3}$ Usaremos letras maiúsculas para denotar energias e minúsculas para potenciais.

${ }^{4} \mathrm{O}$ teorema é válido apenas para densidades $n_{0}$ que correspondem a algum potencial externo $V_{\text {ext }}$. Densidades deste tipo são ditas $v$-representáveis.
} 
O segundo teorema nos diz que a energia é um funcional da densidade, $E[n]$, e que este, para um dado potencial externo $V_{\text {ext }}$, possui um mínimo global para a densidade do estado fundamental $n_{0}(\mathbf{r})$, ou seja, $E\left[n_{0}\right]<E\left[n^{\prime}\right]$ para qualquer densidade $n^{\prime} \neq n_{0}$. Uma conseqüência direta deste teorema é que o funcional de densidade $E[n]$ é suficiente para determinar a densidade do estado fundamental $n_{0}$ e sua energia, $E_{0} \equiv E\left[n_{0}\right]$.

Assim, sabemos que existe um funcional da densidade,

$$
E_{H K}[n]=T[n]+V_{e e}[n]+V_{e x t}[n],
$$

com o qual podemos obter $n_{0}$ e $E_{0}$ por métodos variacionais. No entanto, os teoremas de HK apenas nos informam da existência deste funcional, não fornecendo nenhuma pista sobre como construí-lo na prática.

\subsubsection{Ansatz de Kohn-Sham}

DFT é, hoje em dia, o método mais usado e um dos mais bem sucedidos para cálculos de estrutura eletrônica. Isto se deve graças à proposta feita por Kohn e Sham [52] em 1965, sem a qual a DFT, apesar de ser muito interessante do ponto de vista teórico, não teria muita utilidade na prática. A idéia principal de seu esquema consiste em mapear o problema de muitos corpos interagentes em um problema não-interagente.

A dificuldade em se calcular o funcional de energia de HK é que não se conhecem expressões gerais para $T_{e}[n]$ e $V_{e e}[n]$. No entanto sabemos calcular a energia cinética através das funções de onda (da forma usual),

$$
T=\langle\Psi|\hat{T}| \Psi\rangle
$$

e a parte clássica da interação inter-eletrônica (Eq. 3.10).

Considere então um sistema auxiliar de $\mathrm{N}$ partículas não-interagentes ${ }^{5}$ sujeitos $^{-}$

\footnotetext{
${ }^{5}$ Usaremos o subscrito s (do inglês, single) para denotar o sistema não-interagente.
} 
Schrödinger

Difícil

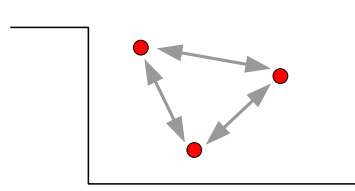

- elétron

- potencial externo
DFT Kohn-Sham

"Fácil"

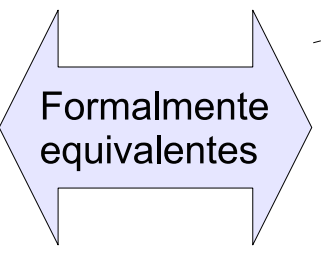

- partícula não-interagente potencial efetivo

Figura 3.1: Ilustração esquemática do método de Kohn-Sham. O sistema de elétrons interagentes (esquerda) é mapeado num sistema de partículas não interagentes num potencial efetivo (direita).

a um potencial externo $\hat{V}_{s}$. A hamiltoniana deste sistema é

$$
\hat{H}_{s}=\hat{T}_{s}+\hat{V}_{s}=-\frac{\hbar}{2 m} \sum_{i} \nabla_{i}^{2}+\hat{V}_{s}
$$

e sua solução é um determinante de Slater formado pelos orbitais obtidos das soluções de

$$
\left(-\frac{\hbar}{2 m} \nabla^{2}+v_{s}(\mathbf{r})\right) \varphi_{i}(\mathbf{r})=\epsilon_{i} \varphi_{i}(\mathbf{r})
$$

Do teorema de HK, sabemos que existe um funcional de energia único para este sistema,

$$
E_{s}[n]=T_{s}[n]+V_{s}[n]
$$

Comparando com a Eq. (3.12) percebemos que se substituirmos $V_{s}[n]$ por um potencial efetivo

$$
V_{e f f}^{K S}[n]=U_{\text {Hartree }}[n]+V_{e x t}[n]+E_{x c}[n]
$$

onde definimos $E_{x c}[n]$, chamado de funcional de troca e correlação, como a diferença das energias cinética e de interação inter-eletrônica entre os sistemas interagente e não-interagente,

$$
E_{x c}[n]=\left(T[n]-T_{s}[n]\right)+\left(V_{e e}[n]-U_{\text {Hartree }}[n]\right)
$$


na Eq. 3.16 teremos

$$
\begin{aligned}
E_{s}[n] & =T_{s}[n]+V_{e f f}^{K S}[n] \\
& =T_{s}[n]+U_{\text {Hartree }}[n]+V_{\text {ext }}[n]+E_{x c}[n] \\
& =T[n]+V_{e e}[n]+V_{\text {ext }}[n] .
\end{aligned}
$$

Ou seja, através da substituição de $V_{s}$ por $V_{e f f}^{K S}$ (que inclui efeitos de interação) no funcional de energia do sistema não-interagente (Eq. 3.16), recuperamos o funcional de energia do sistema interagente (Eq. 3.12).

Assim, o ansatz de Kohn-Sham consiste em assumir que a densidade do estado fundamental do sistema de muitos corpos interagentes, além de ser $v$-representável, também é não-interagente- $v$-representável, ou seja, que a densidade do estado fundamental, além de ser representada pelo potencial $V_{e x t}$, também é representada por um potencial não-interagente, isto é, que $n_{0}(r)=n_{s}(r)$. Também, para que seja possível calcular a energia cinética $T_{s}$, utilizam-se as funções de onda (orbitais), dadas pelas soluções de

$$
\left(-\frac{\hbar}{2 m} \nabla^{2}+v_{e f f}^{K S}(\mathbf{r})\right) \varphi_{i}^{K S}(\mathbf{r})=\epsilon_{i}^{K S} \varphi_{i}^{K S}(\mathbf{r})
$$

Nestas equações, o potencial efetivo depende da densidade, e portanto, elas são resolvidas de forma auto-consistente. É importante ressaltar que as autofunções $\varphi_{i}^{K S}$ e os autovalores $\epsilon_{i}^{K S}$ (chamados de orbitais e energias Kohn-Sham) que aparecem em (3.20) são as funções de onda e energias do sistema auxiliar não-interagente, introduzido como um artifício matemático para possibilitar o cálculo da densidade do sistema interagente. Assim, estes são descarecidos de significado físico ${ }^{6}$, fornecendo apenas a densidade e energia do estado fundamental corretas. Apesar disso, a experiência tem mostrado que, muitas vezes, os orbitais e energias Kohn-Sham fornecem

\footnotetext{
$[50]$.

${ }^{6} \mathrm{Com}$ exceção do último autovalor ocupado, que corresponde ao negativo da energia de ionização
} 
boas aproximações para as funções de onda e energias das excitações elementares do sistema interagente.

A grande vantagem da abordagem de Kohn-Sham está no fato de isolar num termo separado, o funcional $E_{x c}$, os efeitos de muitos corpos (a troca e correlação), que são difíceis de calcular. Tipicamente, este termo é pequeno em comparação a $T_{s}$, $V_{\text {Hartree }}$ e $V_{\text {ext }}$. Logo, espera-se que mesmo aproximações razoáveis para o funcional de troca e correlação forneçam bons resultados.

\subsubsection{Aproximação da Densidade Local (LDA)}

A primeira aproximação para o termo de troca e correlação também foi sugerida por Kohn e Sham [52] no mesmo artigo no qual propuseram o método que hoje leva seus nomes. Esta, da mesma forma que no caso da energia cinética no modelo de Thomas-Fermi (Eq. 3.11), aproxima localmente a energia de troca e correlação do sistema pela de um gás de elétrons homogêneo com a mesma densidade.

A expressão da energia de troca para um gás de elétrons homogêneo é conhecida analiticamente $^{7}$,

$$
\begin{aligned}
E_{x}^{L D A}[n] & =\int d \mathbf{r} \varepsilon_{x}^{h o m}(n(\mathbf{r})) n(\mathbf{r}) \\
& =-\frac{3 e^{2}}{4}\left(\frac{3}{\pi}\right)^{\frac{1}{3}} \int d \mathbf{r} n(\mathbf{r})^{4 / 3}
\end{aligned}
$$

O mesmo não acontece para a energia de correlação. No entanto, Ceperley e Alder (CA) realizaram cálculos precisos [53], baseados em métodos de Monte Carlo quântico, da energia de correlação do gás uniforme de elétrons. Cálculos modernos usam parametrizações dos dados publicados por CA para calcular $\varepsilon_{c}^{\text {hom }}$ [54].

\footnotetext{
${ }^{7}$ Adicionando o termo $E_{x}^{L D A}[n]$ ao modelo de Thomas-Fermi obtem-se o funcional de ThomasFermi-Dirac.
} 
Assim, temos que o funcional de troca e correlação na aproximação LDA é

$$
E_{x c}^{L D A}[n]=\int d \mathbf{r}\left[\varepsilon_{x}^{h o m}(n(\mathbf{r}))+\varepsilon_{c}^{h o m}(n(\mathbf{r}))\right] n(\mathbf{r})
$$

Por ser baseado num gás homogêneo, espera-se que a aproximação LDA funcione melhor para sistemas mais homogêneos (como metais), com densidades que variam lentamente, do que para átomos ou moléculas, onde há grandes variações da densidade.

De forma geral, a LDA tende a superestimar energias de ligação em moléculas e de coesão em sólidos e subestimar comprimentos de ligação. Apesar disso, surpreendentemente (devido a sua simplicidade) a LDA fornece bons resultados mesmo em casos onde há grandes variações da densidade.

\subsubsection{Aproximações Generalizadas de Gradiente (GGA)}

O sucesso da LDA impulsionou o desenvolvimento de funcionais de troca e correlação que, além do valor da densidade em um ponto do espaço, levassem em conta informações sobre a variação da mesma ${ }^{8}$, de forma a melhorar a descrição de sistemas onde há grandes variações da densidade. Estas aproximações para $E_{x c}[n]$, chamadas de aproximações generalizadas de gradiente, são dadas, na sua forma genérica, por

$$
E_{x c}^{G G A}[n]=\int d \mathbf{r} \varepsilon_{x c}^{G G A}(n, \nabla n) n(\mathbf{r})
$$

Diferentemente da LDA, cujo funcional é universal (há apenas variações na forma de parametrizar os dados de CA), há uma grande variedade de funcionais GGA. Os mais usados em química quântica costumam ser ajustados por algum conjunto de dados experimentais, sendo chamados de semi-empíricos. Já os mais usados em física costumam ser baseados em vínculos e limites assintóticos exatos. Entre os funcionais mais usados podemos citar os propostos por Perdew, Burke e Erzenhof

\footnotetext{
${ }^{8} \mathrm{Na}$ prática, nenhum sistema é uniforme como o gás homogêneo.
} 
(PBE) [55], Perdew e Wang (PW91) [56] e o BLYP [57, 58] (que é semi-empírico).

Genericamente, embora não de forma sistemática, os funcionais GGA melhoram a descrição das energias atômicas, de ligação e coesão, e comprimentos e ângulos de ligação.

Além do funcionais LDA e GGAs existem os chamados funcionais híbridos, que misturam a troca e correlação de funcionais LDA, GGA e a troca exata de HartreeFock, em geral ajustando dados experimentais. Um exemplo de funcional híbrido muito usado atualmente é o B3LYP [50]. Outro tipo de funcionais são os metaGGAs, que incluem informação sobre o laplaciano da densidade, $\nabla^{2} n$, além da própria densidade e seu gradiente.

\section{$3.2 \mathrm{STM}$}

A microscopia de tunelamento por varredura (Scanning Tunneling Microscopy STM) é uma técnica poderosa e muito útil para a caracterização de superfícies, sendo, hoje em dia, amplamente utilizada para a obtenção de imagens. Desenvolvida em 1981 por G. Binnig e H. Rohrer [59] nos laboratórios da IBM, rendeu aos mesmo o prêmio Nobel de Física em 1986.

O conceito de funcionamento do STM é bem simples [60] (veja Fig. 3.2): Quando uma ponta metálica é aproximada de uma superfície condutora (ou semicondutora) e uma voltagem $V$ é aplicada entre ambas, surge uma corrente devido ao tunelamento de elétrons entre a ponta e a amostra. Esta corrente fornece uma medida da densidade local de estados (Local Density of States - LDOS) da superfície.

Dentre os vários modos de operação do STM [60] ressaltarei dois:

- Modo de altura constante

Neste modo, a distância entre a ponta e a amostra é mantida constante e se registram as variações na corrente de tunelamento à medida que é feita a varredura sobre a superfície (Fig. 3.2b). 
a)

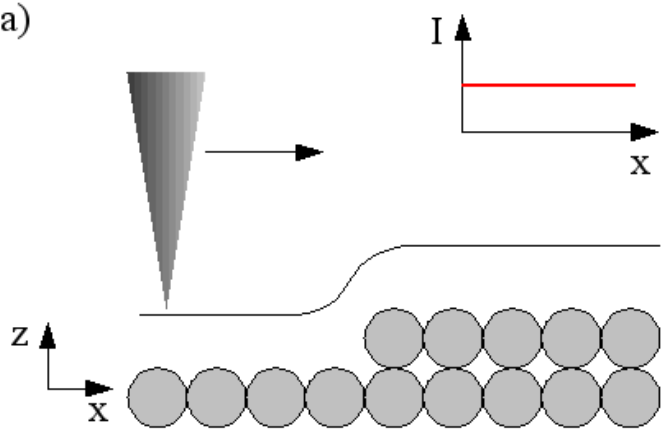

b)
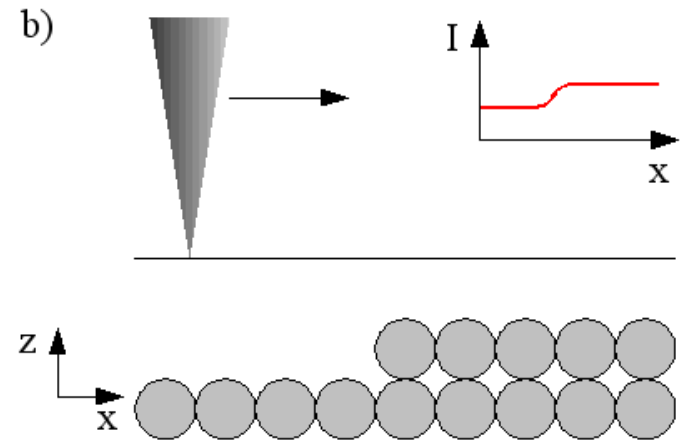

Figura 3.2: Representação esquemática dos modos de operação de um STM: no modo de corrente constante (a) a distância entre a ponta e a superfície é ajustada de forma a manter a corrente (inset) constante; no modo de altura constante (b) a distância é mantida fixa enquanto a corrente varia. Em ambos os casos deve haver uma voltagem aplicada entre a ponta e a superfície.

- Modo de corrente constante

A corrente de tunelamento é mantida constante. Isto é feito ajustando-se a distância ponta-amostra durante o escaneamento (Fig. 3.2a).

\subsubsection{Modelo de Tersoff-Hamann}

Em 1961 Bardeen resolveu, empregando teoria de perturbação em primeira ordem, o problema do tunelamento unidimensional entre dois eletrodos separados por um isolante [61]. Dentro de seu formalismo, a corrente de tunelamento $I_{t}$ é dada por

$$
I=\frac{2 \pi e}{\hbar} \sum_{\mu, \nu} f\left(E_{\mu}\right)\left[1-f\left(E_{\nu}+e V\right)\right]\left|M_{\mu \nu}\right|^{2} \delta\left(E_{\mu}-E_{\nu}\right)
$$

onde $f(E)$ é a função de Fermi-Dirac, $V$ é a diferença de potencial entre os eletrodos, $\mu$ e $\nu$ se referem, respectivamente, a estados da ponta e da superfície, e a matriz de tunelamento é

$$
M_{\mu \nu}=\frac{\hbar}{2 m} \int_{z=z_{0}}\left(\psi_{\mu}^{*} \frac{\partial \psi_{\nu}}{\partial z}-\psi_{\nu} \frac{\partial \psi_{\mu}^{*}}{\partial z}\right) d S
$$

Tersoff e Hamann, partindo da solução de Bardeen, demonstraram [62] que, no limite de baixas voltagens e temperaturas, e assumindo que as funções de onda da ponta têm simetria esférica (ou seja, são considerados apenas orbitais s), a corrente 
de tunelamento é

$$
I_{t}=\frac{8 \pi \hbar^{3}}{m} V R^{2} \rho_{t}\left(E_{F}\right) \exp \left(\frac{\sqrt{8 m \varphi}}{\hbar} R\right) \sum_{\nu}\left|\psi_{\nu}\left(\mathbf{r}_{0}\right)\right|^{2} \delta\left(E_{\nu}-E_{F}\right)
$$

onde $R$ é o raio da ponta, $\varphi$ é a função trabalho da superfície e $\mathbf{r}_{0}$ é a distância da amostra ao centro da ponta. Notando que a LDOS da superfície é dada por

$$
\rho_{s}(\mathbf{r}, E)=\sum_{\nu}\left|\psi_{\nu}(\mathbf{r})\right|^{2} \delta\left(E_{\nu}-E\right)
$$

e que no resto da expressão para $I_{t}$ (Eq. 3.26) aparecem apenas constantes e termos relacionados à estrutura da ponta, temos que

$$
I_{t} \propto V \rho_{s}\left(\mathbf{r}_{0}, E_{F}-e V\right)
$$

Assim, dentro deste modelo, uma imagem de STM a altura constante é proporcional a um plano de corte da LDOS da superfície, enquanto que uma imagem a corrente constante corresponde à uma isosuperfície da LDOS. 


\section{Capítulo 4}

\section{Simulação computacional}

A simulação computacional é uma ferramenta muito útil (às vezes é a única) na obtenção de informações em casos no quais a realização de experimentos é muito cara, perigosa, impossível, ou, simplesmente, quando se quer verificar e/ou confrontar diferentes modelos teóricos com resultados experimentais.

“... o resto, é química." A famosa frase, proferida por Dirac após a formulação da mecânica quântica, expressava a crença de que, tendo sido estabelecidos os fundamentos da mecânica quântica, i.e. a equação de Schrödinger, tudo o que restava era aplicar a mesma aos problemas de interesse. No entanto, a tarefa de encontrar soluções analíticas para esta equação, com exceção de alguns poucos casos, revelou-se extremamente difícil, restando apenas a possibildade de se obter soluções numéricas (em geral, com o uso de aproximações), o que também se configura como um problema de porte na maioria dos casos. É por esta razão que o avanço no poder computacional experimentado nas últimas décadas possibilitou um grande crescimento na área de física dos materiais (e na ciência como um todo).

Hoje em dia, dependendo, é claro, do método e aproximações empregadas e da precisão desejada, já é possível estudar sistemas com um número de átomos da ordem de $10^{3}$. No presente trabalho, são tratados sistemas de até 528 elétrons com cálculos ab initio, algo impensável há uma década, por exemplo. 


\subsection{VASP}

Todos os cálculos apresentados neste trabalho foram realizados com o código VASP (Vienna Ab-initio Simulation Package) [63]. O VASP é um programa desenhado para realizar cálculos de estrutura eletrônica e dinâmica molecular. Ele é baseado em DFT, usando uma base de ondas planas para expandir as funções de onda, pseudopotenciais (veja apêndice C) para tratar os elétrons de caroço e condições periódicas de contorno (veja apêndice D). Os núcleos são tratados clássicamente, pela aproximação de Born-Oppenheimer (apêndice A).

Este programa foi escolhido por ser altamente confiável e pelo uso de ondas planas como base. Este último fato elimina problemas com erros de superposição de base ao se calcular energias de formação, embora, por outro lado, eleve o custo computacional para descrever regiões de vácuo ${ }^{1}$.

\subsection{Detalhes dos cálculos}

Nos cálculos apresentados nesta dissertação ${ }^{2}$ foi usada uma energia de corte de 525 eV. A zona de Brillouin foi amostrada com 3 pontos $\mathrm{k}$ para as nanofitas e $3 \times 3$ para o grafeno, segundo o esquema de Monkhorst-Pack [64].

A aproximação de supercélula (apêndice D) foi empregada para o cálculo de defeitos, usando-se $11 \AA$ de vácuo para separar tanto as folhas de grafeno quando as nanofitas. Assim, as dimensões das supercélulas usadas foram de $21.35 \AA \times$ $22.17 \AA \times 11.00 \AA$, contendo 180 átomos, para o grafeno e $28.80 \AA \times 19.67 \AA \times 11.00 \AA$, contendo 144 átomos, para as nanofitas. Um detalhe a ser notado é que o tamanho da supercélula não foi relaxado, o que pode resultar em energias mais altas para os defeitos se estes alterarem o parâmetro de rede local do sistema.

A energia de troca e correlação é calculada com o funcional GGA proposto por

\footnotetext{
${ }^{1}$ Com uma base de ondas planas todas as regiões do espaço são tratadas uniformemente.

${ }^{2}$ Para uma descrição dos procedimentos adotados para a otimização dos parâmetros veja o apêndice B.
} 
Perdew e Wang (PW91) [56] e os elétrons de caroço são tratados com pseudopotenciais ultrasoft de Vanderbilt [65]. As geometrias foram consideradas relaxadas quando todas as forças atuantes nos átomos fossem menores que $1 \mathrm{meV} / \AA$.

As simulações de imagens STM foram feitas graficando isosuperfícies da densidade parcial de carga para cada defeito. 


\section{Capítulo 5}

\section{Resultados}

Vamos agora apresentar os resultados obtidos neste trabalho, onde fizemos um estudo de defeitos do tipo vacância, divacância e Stone-Wales em nanofitas de grafeno zigzag com uma largura de $1.56 \mathrm{~nm}$ (correspondente a sete hexágonos de largura).

A razão de focarmos em fitas com borda zigzag é devido ao fato de que estas apresentam uma maior riqueza de comportamentos, podendo ser condutoras ou semi-condutoras dependendo da orientação dos momentos magnéticos das bordas (conforme mencionado no Cap. 2). A largura foi escolhida de forma a permitir diferenciar com clareza as regiões de borda e centrais. Vale ressaltar também que fitas com esta largura já estão bem próximas das produzidas experimentalmente (lembre que já foram produzidas fitas de $\sim 2.5 \mathrm{~nm}$ ), conforme mostrado na Fig. 2.7. Também, para efeitos de comparação, os mesmos defeitos foram calculados em grafeno, que fornece um limite para fitas muito largas.

As energias de formação dos defeitos foram calculadas por

$$
E_{f}=E_{\text {defeito }}-E_{\text {pristino }}+N \mu_{C}
$$

onde $E_{\text {defeito }}$ é a energia total do sistema com defeito, $E_{\text {pristino }}$ é a energia total do sistema (grafeno ou nanofita) puro, $\mu_{C}$ é o potencial químico do carbono e $N$ é o número de átomos de carbono retirados para formar o defeito. O potencial químico 
do carbono foi tomado em referência ao grafeno e foi calculado dividindo a energia total de uma célula de grafeno pelo número de átomos contidos na mesma,

$$
\mu_{C}=\frac{E_{\text {grafeno }}}{N_{\text {atomos }}}=-9.27 \mathrm{eV}
$$

\subsection{Grafeno}

Os cálculos apresentados adiante foram realizados conforme os parâmetros especificados na seção 4.2. O tamanho da supercélula, que pode ser vista na figura 5.1, é de $21.35 \AA \times 22.17 \AA \times 11.00 \AA$ (veja também os apêndices B e D).

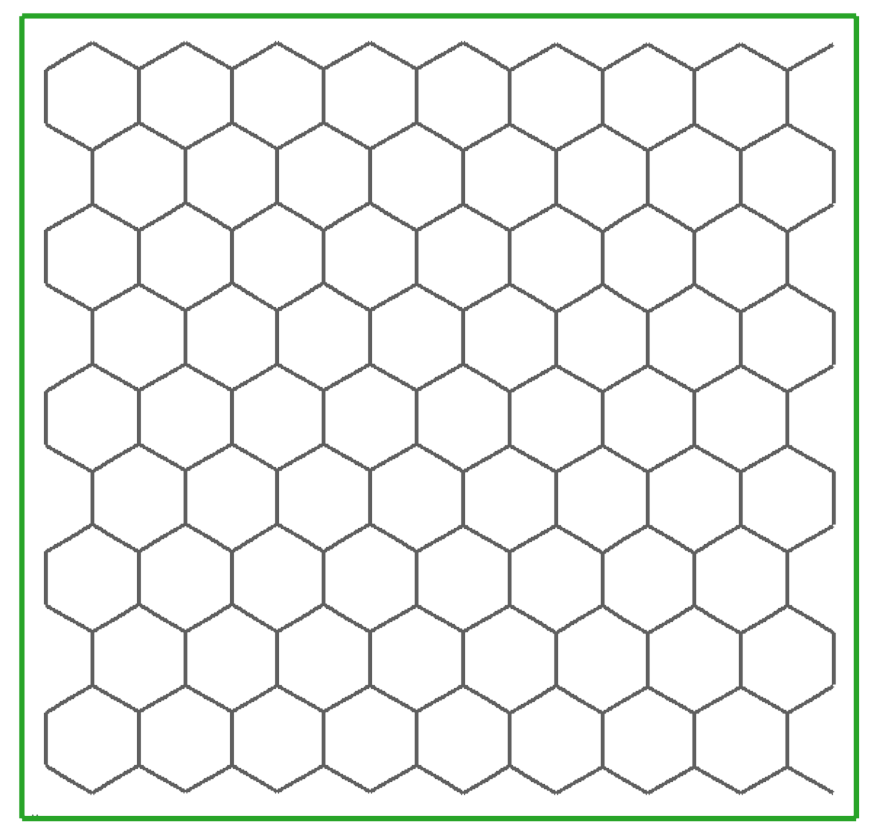

Figura 5.1: Grafeno puro na supercélula empregada pra realizar os cálculos, com tamanho de $21.35 \AA \times 22.17 \AA \times 11.00 \AA$.

\subsubsection{Divacância (V2)}

A divacância, como o próprio nome diz, é o defeito formado ao se retirar dois átomos de uma folha de grafeno. A reconstrução deste defeito, mostrada na figura 5.2a, forma dois pentágonos e um octágono, sendo chamada de 585. Na figura 5.2b 
podem-se ver duas isosuperfícies da densidade de carga do defeito, que permitem analisar a natureza das ligações entre os átomos. Como podemos ver, no defeito 585, há duas ligações nos pentágonos "quase quebradas" (indicadas por setas na Fig. $5.2 \mathrm{a})$, apresentando um comprimento de $1.73 \AA$, enquanto que o comprimento de ligação de equilíbrio no grafeno é de $1.42 \AA$. A energia de formação calculada para este defeito é de $7.45 \mathrm{eV}$.

a)

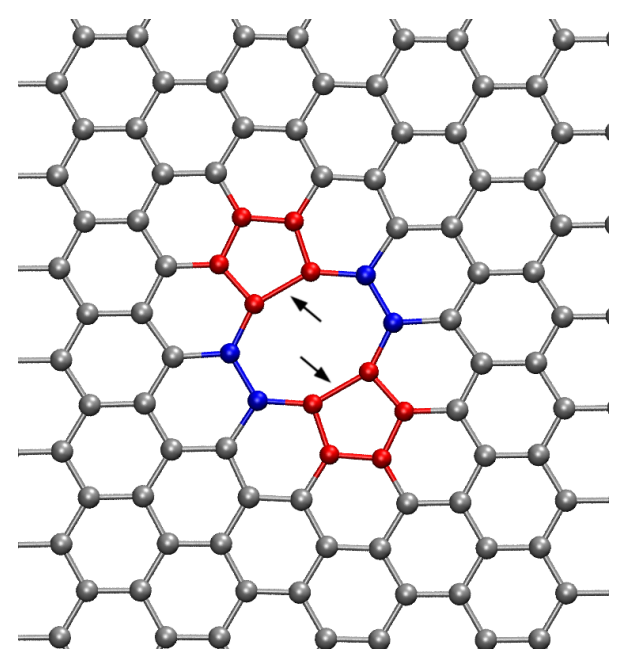

b)

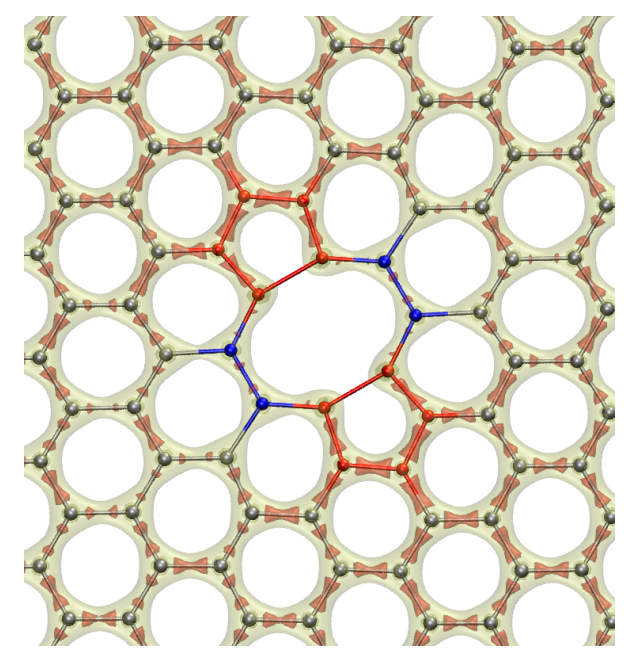

Figura 5.2: V2 na reconstrução 585 em uma folha de grafeno: (a) Geometria e (b) duas isosuperfícies da densidade de carga, com $1.5 \mathrm{e} / \AA^{3}$ (amarelo) e $2 \mathrm{e} / \AA^{3}$ (vermelho). Note as duas ligações "quase quebradas" nos pentágonos.

A divacância, além da reconstrução 585, possui uma outra reconstrução, formada por três pentágonos e três heptágonos, chamada de 555777 (Fig. 5.3a). Esta, com uma energia de formação de $6.97 \mathrm{eV}$, é mais estável que a 585 por uma diferença de $0.62 \mathrm{eV}$. Nesta reconstrução, conforme pode-se ver na figura 5.3b, as ligações nos pentágonos (indicadas por setas na figura) que estão voltadas para o centro do defeito (o átomo de carbono em cor verde) são mais fracas que as outras do defeito, apresentando um comprimento de $1.52 \AA$, mas são mais fortes que no defeito 585 .

É interessante notar que no grafeno ${ }^{1}$ há uma inversão de estabilidade dos defeitos 555777 e 585 em relação à nanotubos com diâmetro pequeno, onde a recontrução 585 é mais estável que a 555777 [66]. Isto acontece porque nos nanotubos não

\footnotetext{
${ }^{1} \mathrm{O}$ grafeno pode ser visto como o limite de um nanotubo com diâmetro infinito.
} 
a)

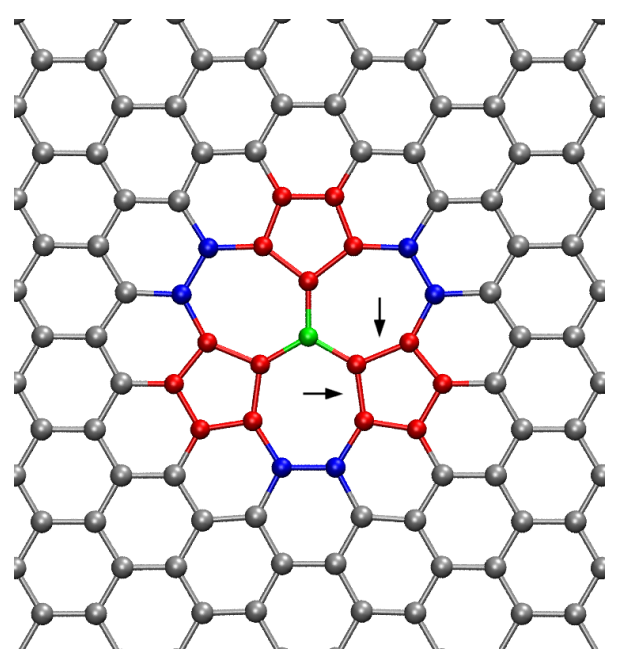

b)

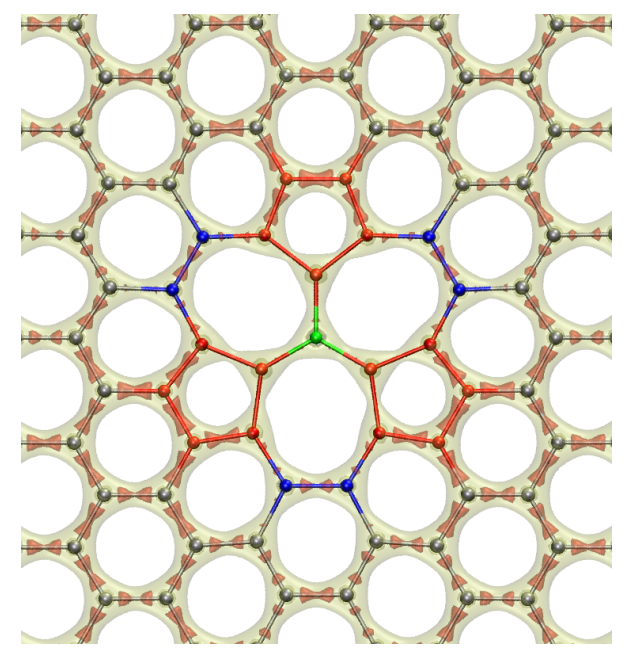

Figura 5.3: V2 na reconstrução 555777 em uma folha de grafeno: (a) Geometria e (b) duas isosuperfícies da densidade de carga, com $1.5 e / \AA^{3}$ (amarelo) e $2 e / \AA^{3}$ (vermelho). Note as ligações enfraquecidas nos pentágonos, mas mais intensas que no defeito 585 .

há o vinculo planar existente no grafeno, e assim é possível uma melhor relaxação estrutural, o que diminui as distâncias das ligações nos pentágonos [66].

\subsubsection{Monovacância (V1)}

Uma monovacância é um defeito formado pela retirada de um átomo da rede. Na sua reconstrução, apresentada na figura 5.4a, dois dos átomos centrais do defeito se aproximam tentando fechar um pentágono (ficando a uma distância de 2.02), enquanto que o átomo restante sofre uma re-hibridização, adquirindo ligeiro caráter $s p^{3}$ e formando uma uma ligação pendente (dangling bond). Esta ligação pendente é altamente reativa. Logo, se a monovacância estiver exposta a uma atmosfera, é muito provável que qualquer molécula que passe perto do defeito seja adsorvida, algo muito bom para a construção de sensores [6, 7]. Como pode ser visto na figura 5.4c, este defeito também cria uma magnetização local ${ }^{2}[44,45]$ (o grafeno é intrinsecamente não-magnético), que foi definida aqui como a diferença entre as

\footnotetext{
${ }^{2}$ Em nossos cálculos, encontramos que a magnetização estabiliza a monovacância por $0.14 \mathrm{eV}$. Ou seja, a energia do defeito sem magnetização é $0.14 \mathrm{eV}$ maior.
} 
densidades de carga up e down,

$$
m(\mathbf{r})=n_{\uparrow}(\mathbf{r})-n_{\downarrow}(\mathbf{r}) .
$$

A energia de formação de uma monovacância é de $7.61 \mathrm{eV}$, valor em concordância com os valores nas Refs. [67, 43], e o maior entre os defeitos aqui estudados para o grafeno.

a)

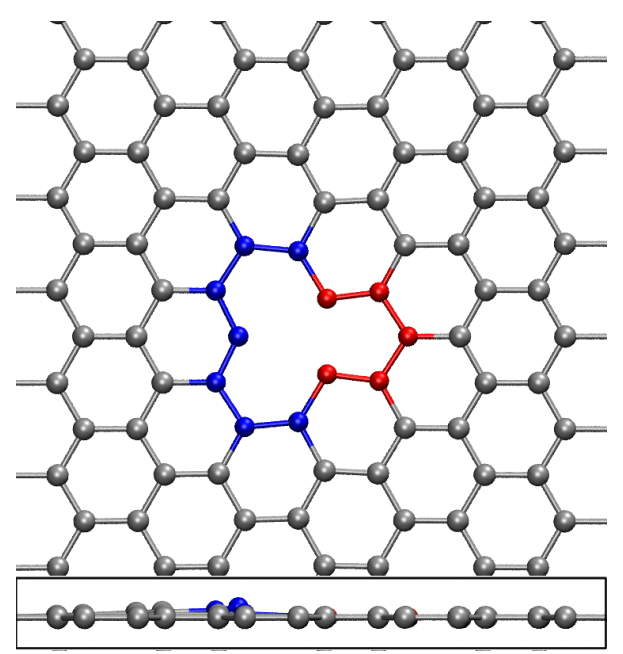

b)

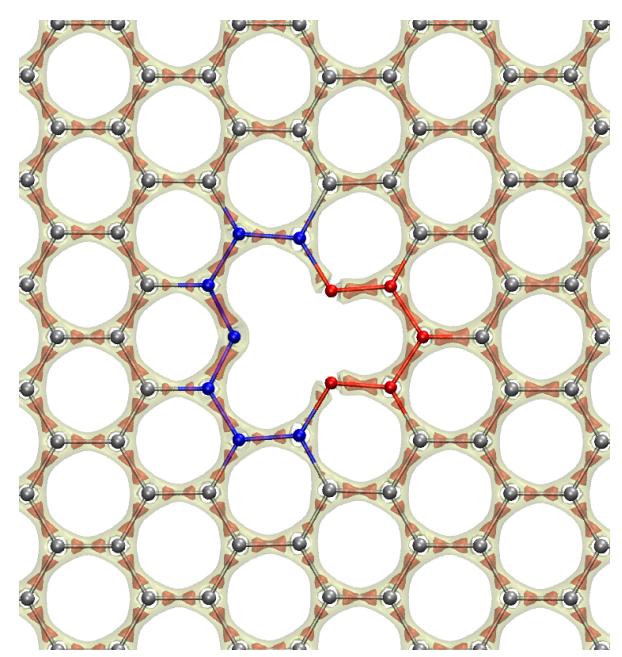

c)

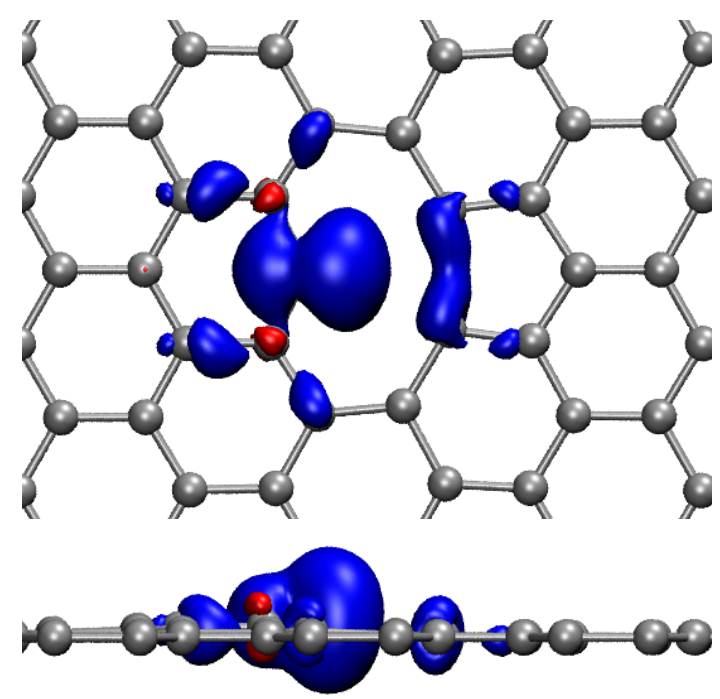

Figura 5.4: V1 em uma folha de grafeno: (a) Geometria, (b) duas isosuperfícies da densidade de carga, com $1.5 e / \AA^{3}$ (amarelo) e $2 e / \AA^{3}$ (vermelho) e (c) isosuperfícies da magnetização local $\left(0.02 e / \AA^{3}\right.$ em azul e $-0.02 e / \AA^{3}$ em vermelho.

Um resultado a ser notado é que é mais fácil (mais barato energeticamente) criar 
uma divacância do que uma monovacância no grafeno.

\subsubsection{Stone-Wales (SW)}

Defeitos do tipo Stone-Wales, diferentemente das vacâncias, não envolvem a retirada de átomos, mas sim a rotação de uma ligação (um par de átomos) por 90 graus.

Na sua reconstrução (figura 5.5a) este defeito apresenta dois pentágonos e dois heptágonos (5577) e sua energia de formação, a mais baixa entre os defeitos estudados no grafeno, é de $5.03 \mathrm{eV}$, valor em concordância com resultados anteriores [43]. Note que, como pode ser visto na figura 5.5b, e contrariamente ao que acontece com os defeitos anteriores, as ligações realizadas pelos átomos que compõem o defeito não são tão fracas, nem estão "quebradas". Os maiores comprimentos de ligação neste defeito, indicados por setas na Fig.5.5a, são de 1.47 .

a)

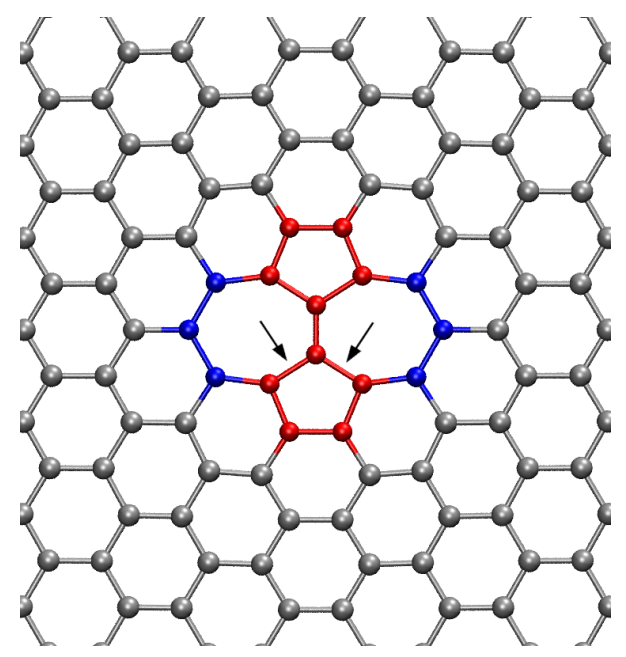

b)

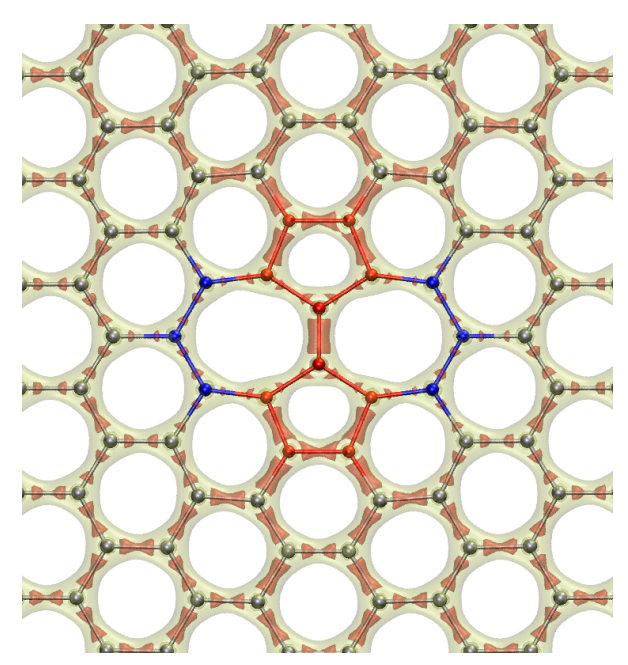

Figura 5.5: SW em uma folha de grafeno: (a) Geometria e (b) duas isosuperfícies da densidade de carga, com $1.5 e / \AA^{3}$ (amarelo) e $2 e / \AA^{3}$ (vermelho).

\subsubsection{Discussão}

Na tabela 5.1 mostramos as energias de formação e o comprimento da maior ligação, $d_{>}$, dos defeitos estudados, que como vimos até agora, se encontram sempre nos pentágonos. Como se pode ver, os defeitos que apresentam ligações pendentes 
ou "quase quebradas" (a monovacância e o 585) apresentam as energias de formação mais altas. Além disso, pode-se perceber uma correlação entre $d_{>}$e $E_{f}$.

\begin{tabular}{lcc}
\hline Defeito & $E_{f}(\mathrm{eV})$ & $d_{>}(\AA)$ \\
\hline \hline V2 585 & 7.45 & 1.73 \\
V2 555777 & 6.83 & 1.53 \\
V1 & 7.75 & 2.02 \\
SW & 5.03 & 1.47 \\
\hline
\end{tabular}

Tabela 5.1: Energias de formação e maior comprimento de ligação dos defeitos no grafeno.

Para ilustrar essa tendência, na figura 5.6 graficamos a energia de formação em função do maior comprimento de ligação, $d_{>}$, e também da média das três maiores ligações, $d_{3>}$. Como se pode notar no gráfico, quanto maior $d_{>}\left(\right.$ou $\left.d_{3>}\right)$, maior é a energia de formação do defeito. Isto sugere que a maior contribuição para energia de formação destes defeitos no grafeno advém da energia química necessária para "romper" as ligações [66]. Portanto, vemos que os átomos dos defeitos contidos nos pentágonos, especialmente através de suas distâncias de ligação, são determinantes para a energética dos defeitos.

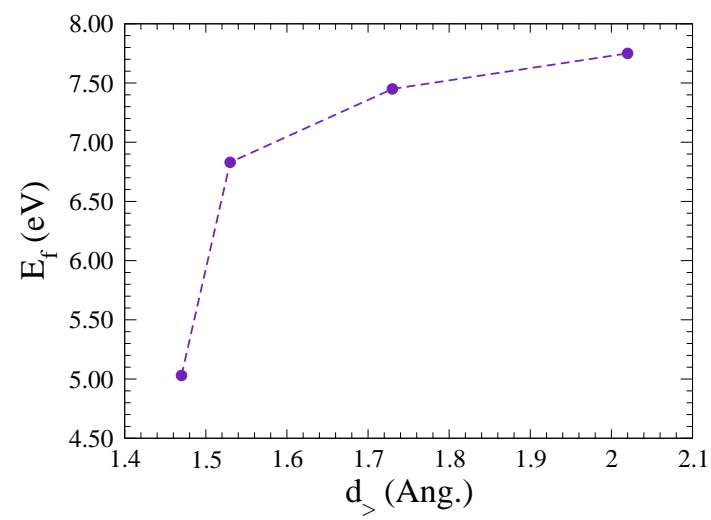

Figura 5.6: Energia de formação, $E_{f}$, em função do maior comprimento de ligação, $d_{>}$, e da média das três maiores ligações, $d_{3>}$, para os defeitos no grafeno. 


\section{$5.2 \quad$ Nanofitas}

A seguir, iremos apresentar os resultados obtidos nos cálculos realizados para os mesmos tipos de defeitos acima estudados, mas agora, em nanofitas de grafeno. Como veremos, a presença das bordas introduz fatores qualitativamente diferentes em relação ao grafeno, como magnetismo por exemplo. Assim, além de calcular a energia de formação $E_{f}$ nos exemplos abaixo, também calculamos as energias de formação antiferromagnética (AF) e ferromagnética $(\mathrm{F})$, dadas por

$$
E_{f}^{A F}=E_{\text {defeito }}^{A F}-E_{\text {pristino }}^{A F}+N \mu_{C}
$$

$\mathrm{e}$

$$
E_{f}^{F}=E_{\text {defeito }}^{F}-E_{\text {pristino }}^{F}+N \mu_{C}
$$

respectivamente.

Como mencionado anteriormente, as nanofitas estudadas aqui são do tipo zigzag com uma largura de $1.56 \mathrm{~nm}$ (sete hexágonos). Os átomos das bordas, que apresentam ligações pendentes, pois estão ligados a apenas dois vizinhos (o carbono na hibridização $s p^{2}$ faz três ligações), foram saturados com uma ligação de hidrogênio.

\section{4 átomos}

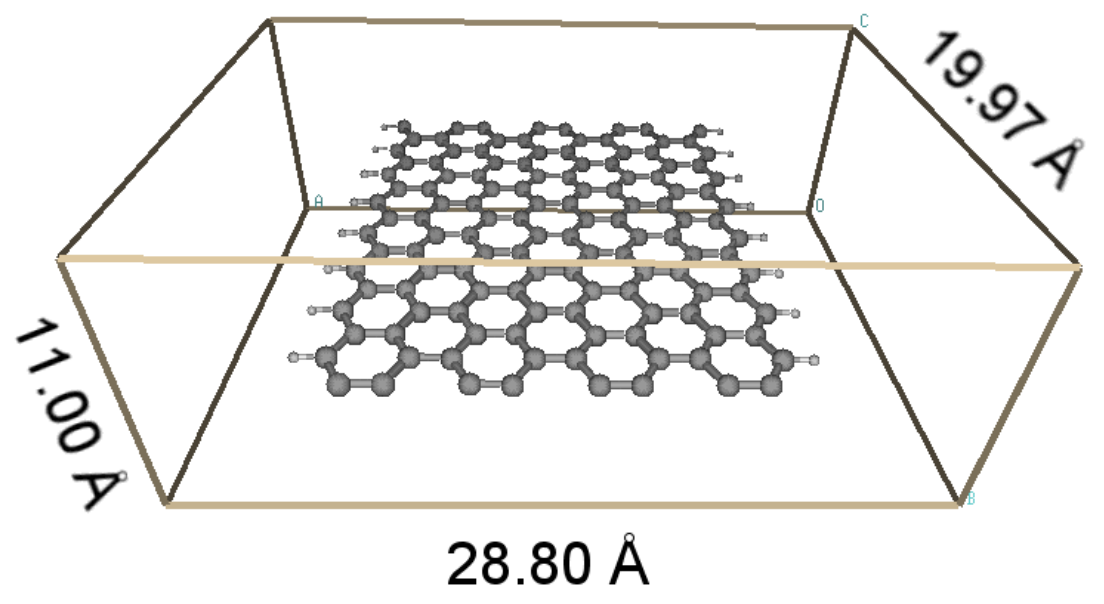

Figura 5.7: Supercélula empregada pra realizar os cálculos, com tamanho de $28.80 \AA \times 19.97 \AA \times 11.00 \AA$. 
A supercélula usada contém oito repetições de uma célula primitiva, com uma dimensão de $19.67 \AA$ na direção do eixo da fita. Todas as simulações de imagens STM mostradas são à corrente constante $\operatorname{com} V=-0.25 \mathrm{eV}$, ou seja, usando estados ocupados e correspondendo a uma isosuperfície de valor $7.11 \times 10^{-7} \mathrm{e} /{ }^{3}$.

\subsubsection{Pristina}

Para efeito de comparação, nas figuras 5.8a e 5.8b apresentamos (da mesma forma que nos defeitos para o grafeno) a geometria relaxada da nanofita estudada e duas isosuperfícies da densidade de carga, que caracterizam qualitativamente a intensidade das ligações.

No entanto, agora, diferentemente do que acontece com o grafeno, os estados de mais baixa energia apresentam magnetização (figuras $5.8 \mathrm{c}$ e 5.8d), resultante dos elétrons nos obitais $p_{z}$.

O estado mais estável é o que apresenta configuração antiferromagnética (AF) entre as bordas (Fig. 5.8c), isto é, tem bordas com momentos magnéticos alinhados em direções opostas, apresentando uma diferença de energia em relação ao estado fundamental não-magnético dada por $E_{A F}-E_{0}=-0.47 \mathrm{eV}(-0.06 \mathrm{eV}$ por célula unitária), onde $E_{A F}$ é a energia total do estado fundamental AF e $E_{0}$ é a energia total do estado fundamental não-polarizado. Este valor, que resulta numa diferença de $-0.03 \mathrm{eV}$ por átomo de borda, concorda com resultados já publicados [29, 28].

A configuração ferromagnética $(\mathrm{F})$, mostrada na Fig. 5.8d, também é mais estável que o estado não-magnético, por uma diferença dada por $E_{F}-E_{0}=-0.42 \mathrm{eV}$.

Note também que as configurações F e AF podem ser diferenciadas pelo padrão na imagem STM deixado no centro da fita. 
a)

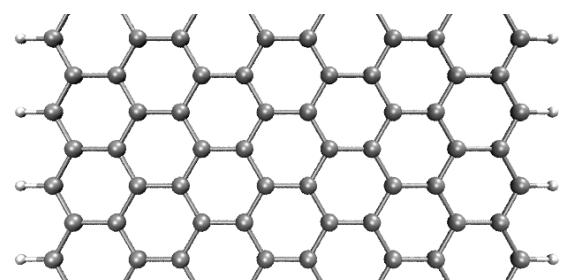

c)

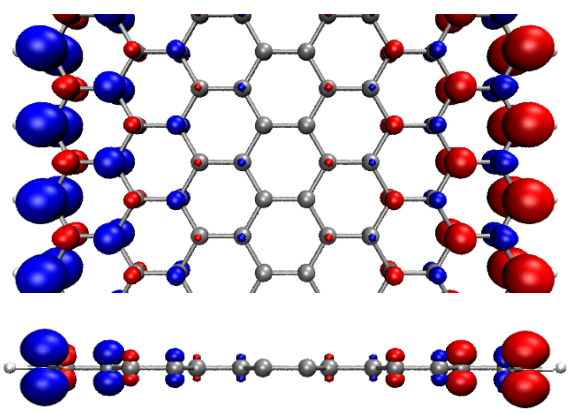

e)

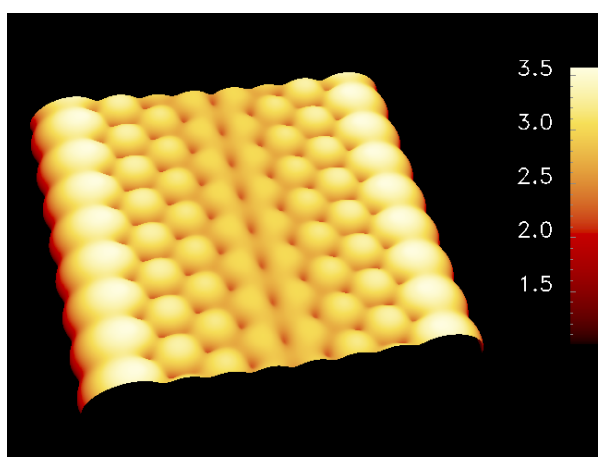

b)

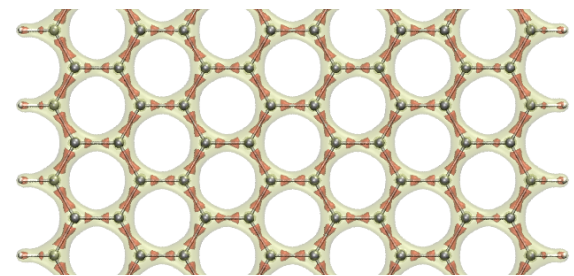

d)
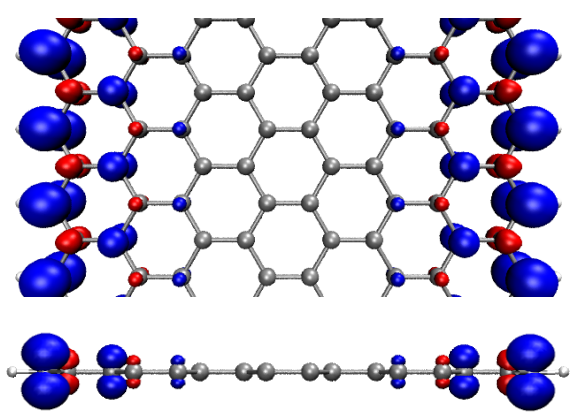

f)

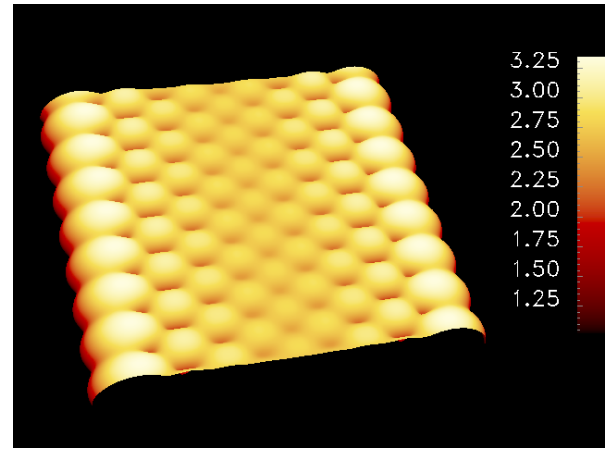

Figura 5.8: Nanofita de grafeno pristina: (a) Geometria; (b) duas isosuperfícies da densidade de carga, com $1.7 e / \AA^{3}$ (amarelo) e $2 e / \AA^{3}$ (vermelho); magnetização $\left( \pm 0.02 e_{\uparrow-\downarrow} / \AA^{3}\right)$ nas configurações AF (c) e F (d); simulações de imagens STM para as configurações AF (e) e F (f).

Analisando mais atentamente a geometria da fita (figura 5.9), podemos ver que os tamanhos das ligações variam ao longo da largura da fita. Ligações com orientação perpendicular ao eixo de crescimento da fita (vertical na página) são maiores que as que têm orientação paralela. Consistentemente, como podemos ver na Fig. 5.8b, as ligações orientadas paralemente ao eixo da fita são mais fortes que as perpendiculares. Outra observação que pode ser feita é que, no centro da nanofita, o comprimento das ligações é muito próximo ao de bulk (com pequenas diferenças de $\sim 0.003 \AA)$. 


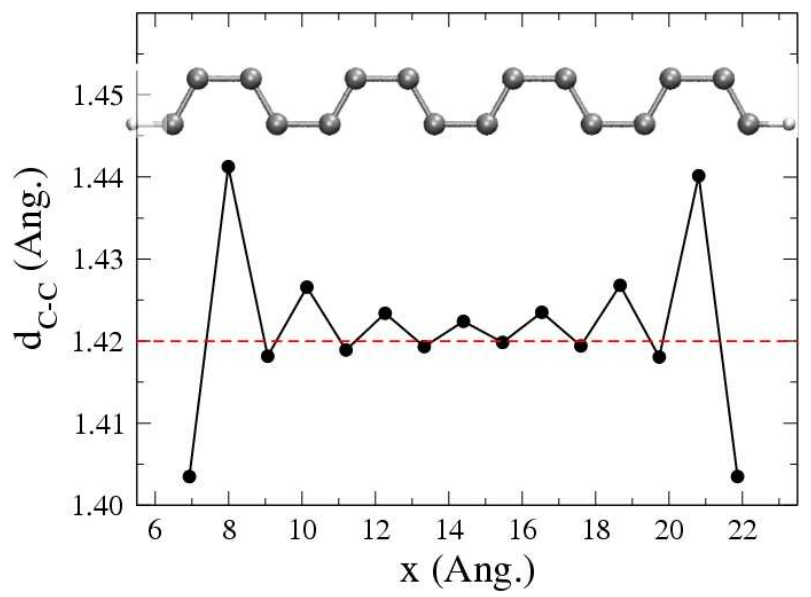

Figura 5.9: Comprimentos das ligações carbono-carbono, $d_{C-C}$, na nanofita. A linha tracejada indica o valor de $d_{C-C}$ no grafeno.

\subsubsection{Divacância}

Nas nanofitas, a reconstrução 585 pode ter duas orientações possíves, paralela e perpendicular ao eixo da fita, e também, diversas posições em relação à borda. No caso da 585 perpendicular no centro da fita (figura 5.10), podemos ver que, qualitativamente, temos o mesmo tipo de comportamento que na 585 no grafeno: há duas ligações "quase quebradas" nos pentágonos (indicadas por flechas na Fig. 5.10a), com um comprimento de ligação de $1.71 \AA$. Quanto à energética, o defeito apresenta uma energia de formação maior do que no grafeno. Como no caso da fita pura, as configurações F e AF são mais estáveis que a configuração não-magnética, sendo que os estados F e AF são praticamente degenerados.

Um fator que deve ser levado em conta é que não foi feita a relaxação da supercélula na direção do eixo da fita. Desta forma, é possível que as ligações indicadas na Fig. 5.10a, que são paralelas ao eixo da fita, não tenham relaxado completamente, resultando em energias de formação mais altas.

\begin{tabular}{cccccccc}
\hline Defeito & $E_{f}$ & $E_{f}^{A F}$ & $E_{f}^{F}$ & $E_{f}^{\text {graf }}$ & $E_{A F}-E_{0}$ & $E_{F}-E_{0}$ & $E_{A F}-E_{F}$ \\
\hline \hline V2 585 per. c & 7.76 & 7.62 & 7.57 & 7.45 & -0.48 & -0.47 & -0.01 \\
\hline
\end{tabular}

Tabela 5.2: Energias de formação não-magnética, AF, F e no grafeno; e estabilidades relativas para o V2 585 perpendicular no centro. Energias em eV. 
a)

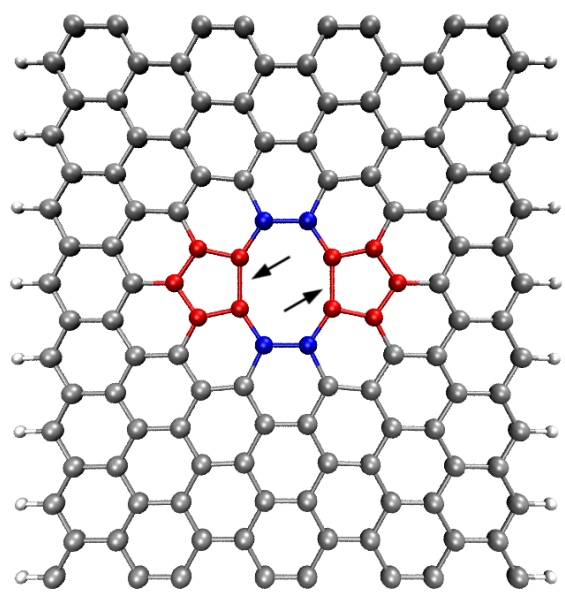

c)

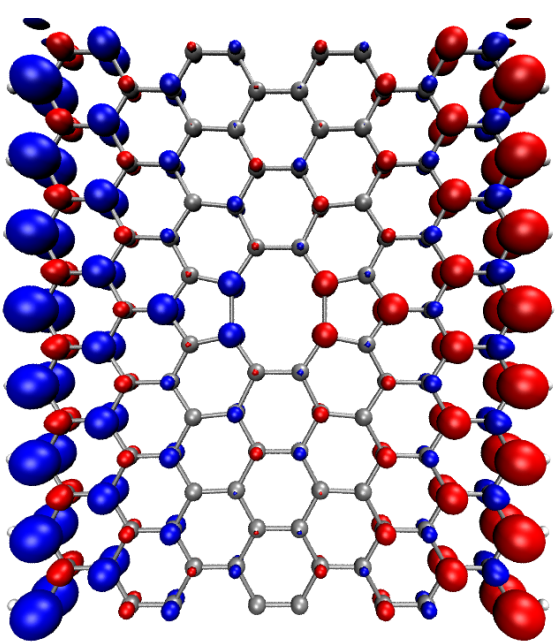

e)

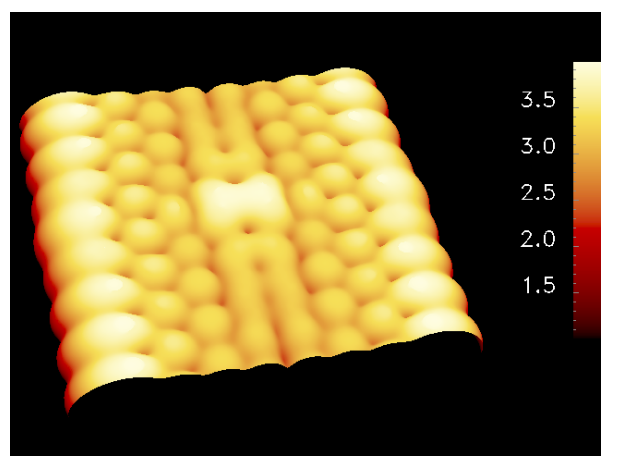

b)

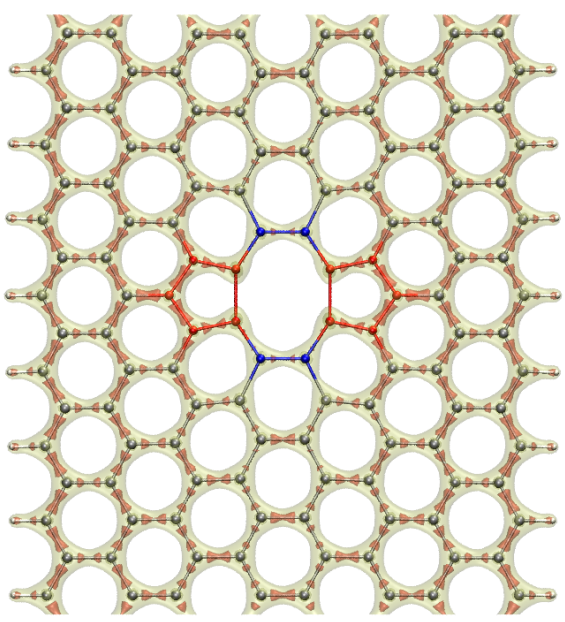

d)

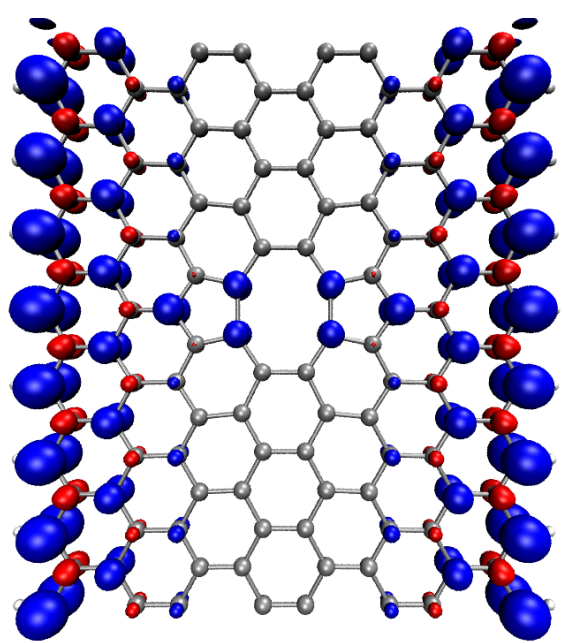

f)

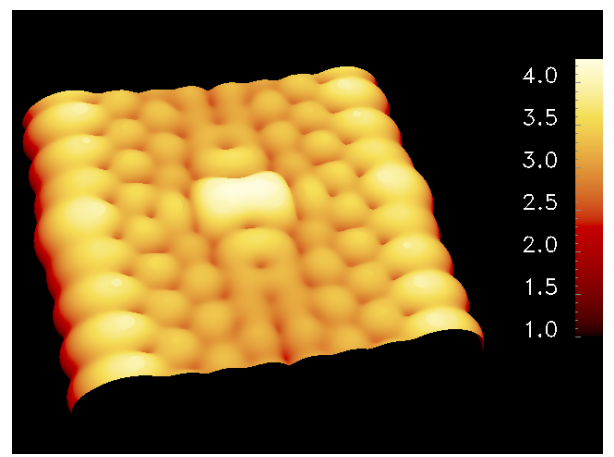

Figura 5.10: V2 585 com orientação perpendicular no centro de uma nanofita: (a) Geometria; (b) duas isosuperfícies da densidade de carga, com 1.5e/ $\AA^{3}$ (amarelo) e $2 e / \AA^{3}$ (vermelho); magnetização local $\left(0.02 e / \AA^{3}\right.$ em azul e $-0.02 e / \AA^{3}$ em vermelho) nas configurações AF (c) e F (d); simulações de imagens STM para as configurações AF (e) e F (f). 
a)

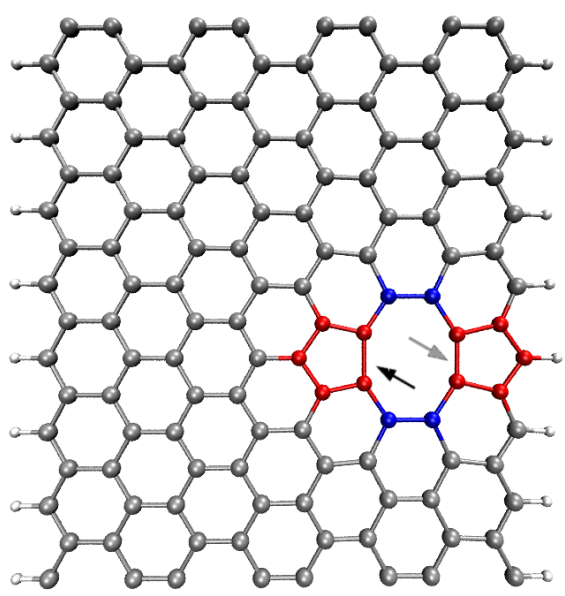

c)

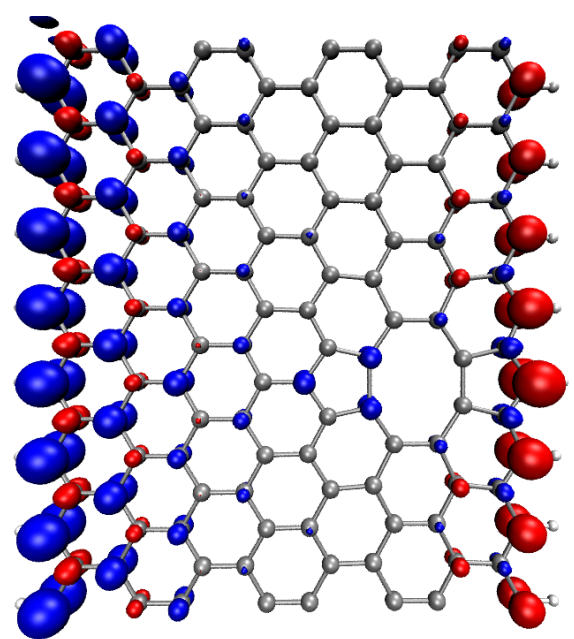

e)

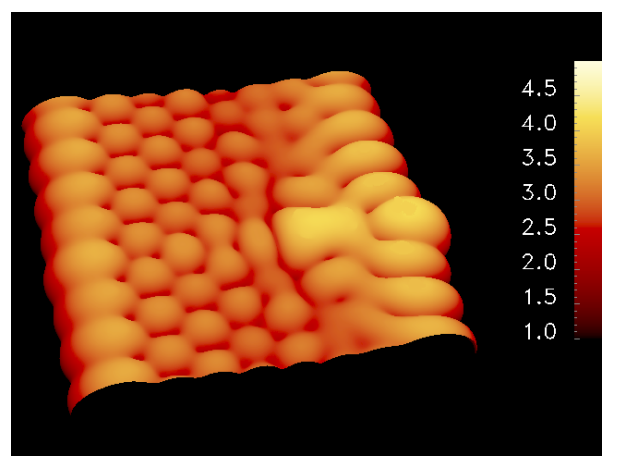

b)

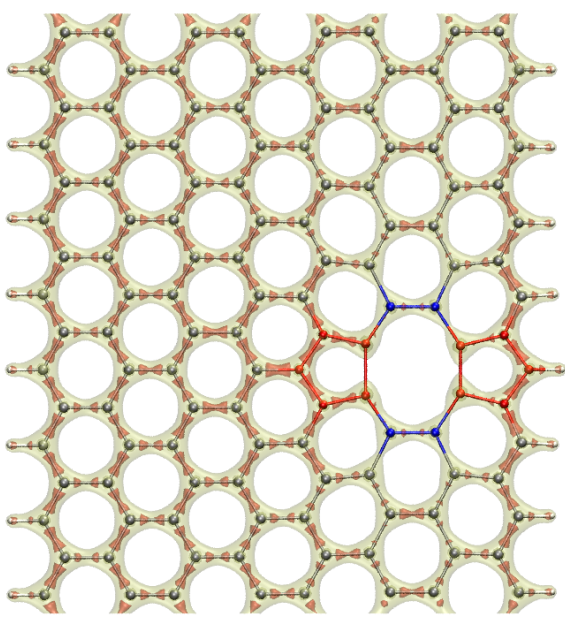

d)

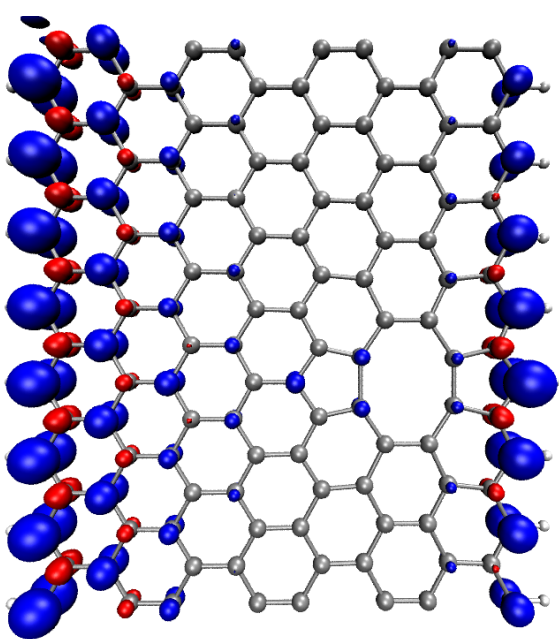

f)

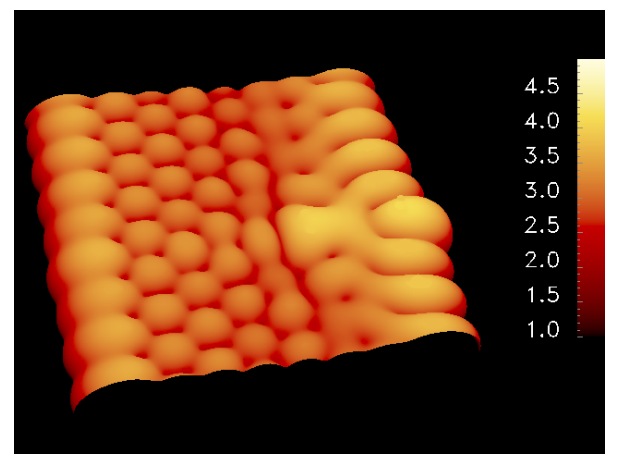

Figura 5.11: V2 585 com orientação perpendicular na borda de uma nanofita: (a) Geometria; (b) duas isosuperfícies da densidade de carga, com $1.5 e / \AA^{3}$ (amarelo) e $2 e / \AA^{3}$ (vermelho); magnetização local $\left(0.02 e / \AA^{3}\right.$ em azul e $-0.02 e / \AA^{3}$ em vermelho) nas configurações AF (c) e F (d); simulações de imagens STM para as configurações AF (e) e F (f). 
Para a V2 585 perpendicular na borda (figura 5.11), pode-se observar que os átomos que formam a ligação do pentágono "quase quebrada" que está mais próxima da borda (indicada pela seta cinza), estão ligeiramente mais ligados, com uma distância de $1.57 \AA$, em comparação à ligação indicada pela seta preta, com $1.70 \AA$. Assim, como pode ser visto na tabela ${ }^{3} 5.3$, as energias de formação deste defeito são ligeiramente menores que as do grafeno, apresentando o estados F e AF degenerados e ambos mais estáveis que o não-magnético.

\begin{tabular}{cccccccc}
\hline Defeito & $E_{f}$ & $E_{f}^{A F}$ & $E_{f}^{F}$ & $E_{f}^{\text {graf }}$ & $E_{A F}-E_{0}$ & $E_{F}-E_{0}$ & $E_{A F}-E_{F}$ \\
\hline \hline V2 585 per. b & 7.42 & 7.44 & 7.38 & 7.45 & -0.32 & -0.32 & 0.00 \\
\hline
\end{tabular}

Tabela 5.3: Energias de formação não-magnética, AF, F e no grafeno; e estabilidades relativas para o V2 585 perpendicular na borda. Energias em eV.

O defeito V2 585 paralelo no centro (figura 5.12), da mesma forma que o seu homólogo perpendicular, apresenta as duas ligações "quase quebradas" nos pentágonos, indicadas por flechas na Fig 5.12a, com comprimentos de $1.63 \AA$ e $1.62 \AA$ (esta última é a que está mais perto da borda), que são sensivelmente menores que no 585 perpendicular no centro da fita $(1.71 \AA)$ e o 585 no grafeno (1.73 $\AA$ ). Assim, como mostrado na tabela 5.4, este defeito possui energias de formação em torno de $1.1 \mathrm{eV}$ mais baixas que no grafeno e $1.3 \mathrm{eV}$ mais baixas que no 585 perpendicular centrado. Também, como nos casos anteriores as configurações F e AF são quase-degeneradas.

\begin{tabular}{cccccccc}
\hline Defeito & $E_{f}$ & $E_{f}^{A F}$ & $E_{f}^{F}$ & $E_{f}^{\text {graf }}$ & $E_{A F}-E_{0}$ & $E_{F}-E_{0}$ & $E_{A F}-E_{F}$ \\
\hline \hline V2 585 par. c & 6.36 & 6.30 & 6.25 & 7.45 & -0.40 & -0.39 & -0.01 \\
\hline
\end{tabular}

Tabela 5.4: Energias de formação não-magnética, AF, F e no grafeno; e estabilidades relativas para o V2 585 paralelo no centro. Energias em eV.

\footnotetext{
${ }^{3}$ Por motivo de espaço, daqui em diante usaremos a abreviação c para identificar defeitos no centro e b para defeitos na borda.
} 
a)

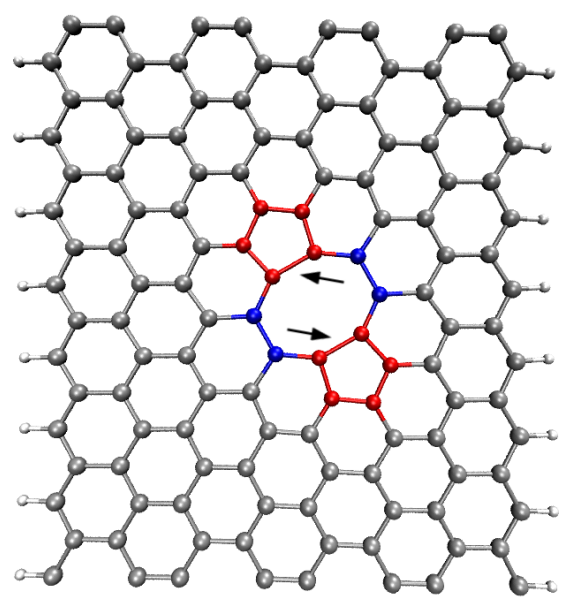

c)

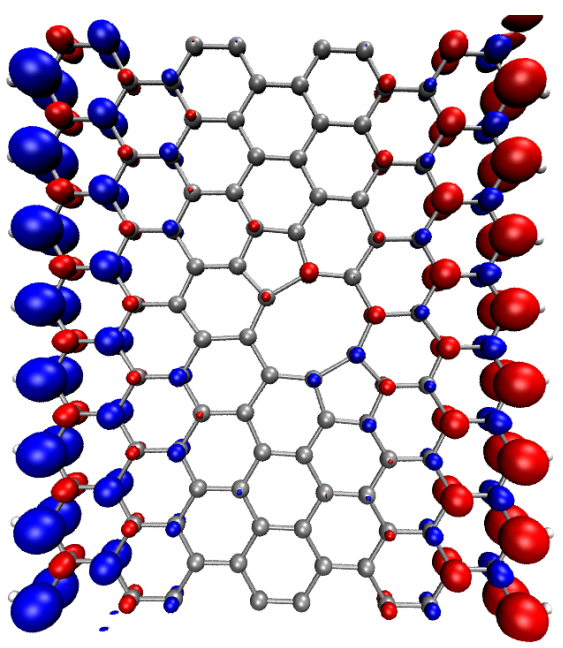

e)

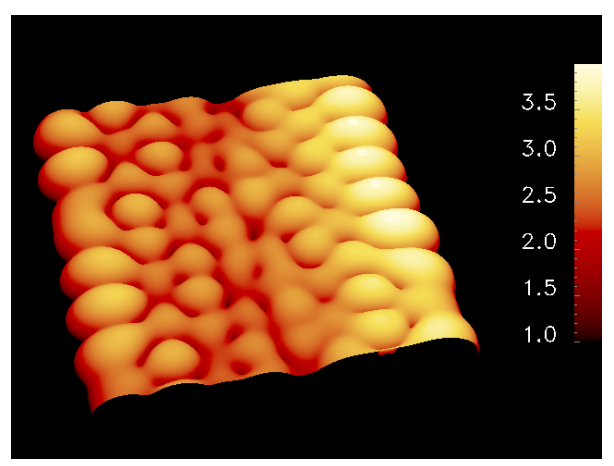

b)

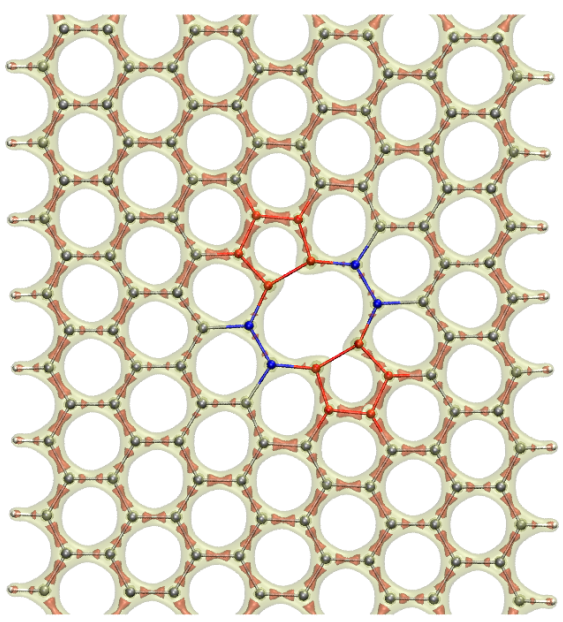

d)

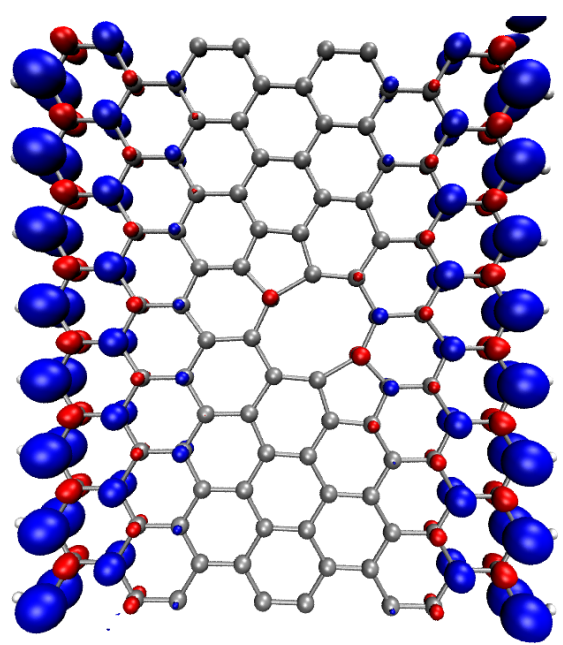

f)

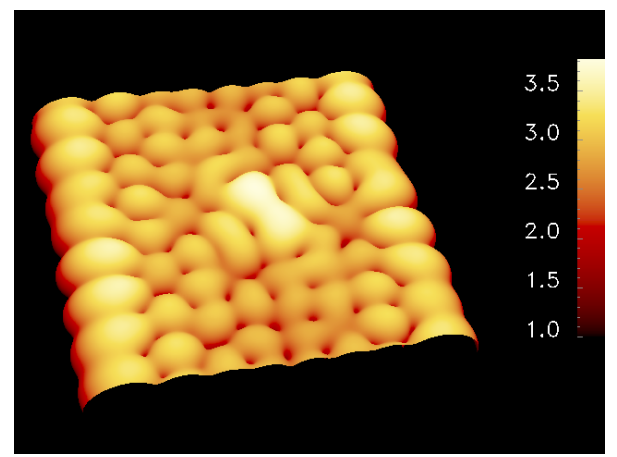

Figura 5.12: V2 585 com orientação paralela no centro de uma nanofita: (a) Geometria; (b) duas isosuperfícies da densidade de carga, com $1.5 e / \AA^{3}$ (amarelo) e $2 e / \AA^{3}$ (vermelho); magnetização local $\left(0.02 e / \AA^{3}\right.$ em azul e $-0.02 e / \AA^{3}$ em vermelho) nas configurações AF (c) e F (d); simulações de imagens STM para as configurações AF (e) e F (f). 
Já no caso do V2 585 paralelo na borda (Fig. 5.13), é possível notar uma mudança mais marcante na intensidade das ligações, caracterizadas pela densidade de carga (Fig. 5.13b), sendo que práticamente todos os átomos que compõem o defeito estão mais ligados do que nos outros defeitos 585. Em particular, os comprimentos das ligações indicadas por setas na Fig.5.13a são $1.51 \AA$ (seta cinza) e $1.53 \AA$ (seta preta). Conseqüentemente, as energias de formação para este defeito são muito mais baixas, em torno de $3 \mathrm{eV}$ a menos que no grafeno. Também para este defeito as configurações F e AF tem, aproximadamente, a mesma energia.

Nas figuras 5.13e e 5.13f, apresentamos as imagens STM simuladas para este defeito. Pode-se perceber que os padrões das configurações F e AF são diferentes, podendo ser diferenciados via STM.

\begin{tabular}{cccccccc}
\hline Defeito & $E_{f}$ & $E_{f}^{A F}$ & $E_{f}^{F}$ & $E_{f}^{g r a f}$ & $E_{A F}-E_{0}$ & $E_{F}-E_{0}$ & $E_{A F}-E_{F}$ \\
\hline \hline V2 585 par. b & 4.49 & 4.55 & 4.48 & 7.45 & -0.28 & -0.30 & 0.02 \\
\hline
\end{tabular}

Tabela 5.5: Energias de formação não-magnética, AF, F e no grafeno; e estabilidades relativas para o V2 585 paralelo na borda. Energias em eV. 
a)

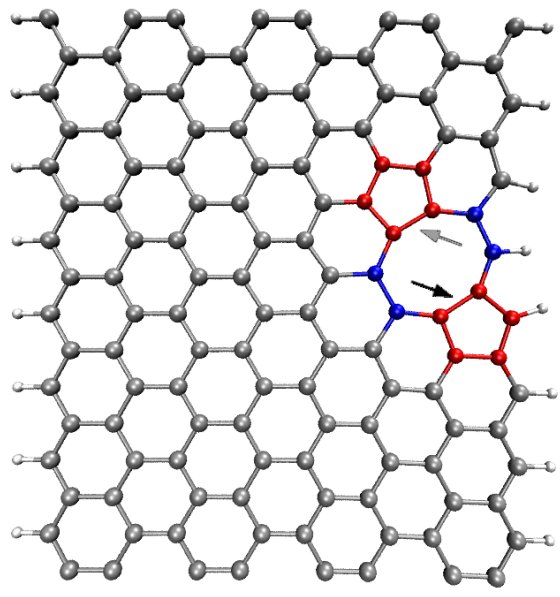

c)

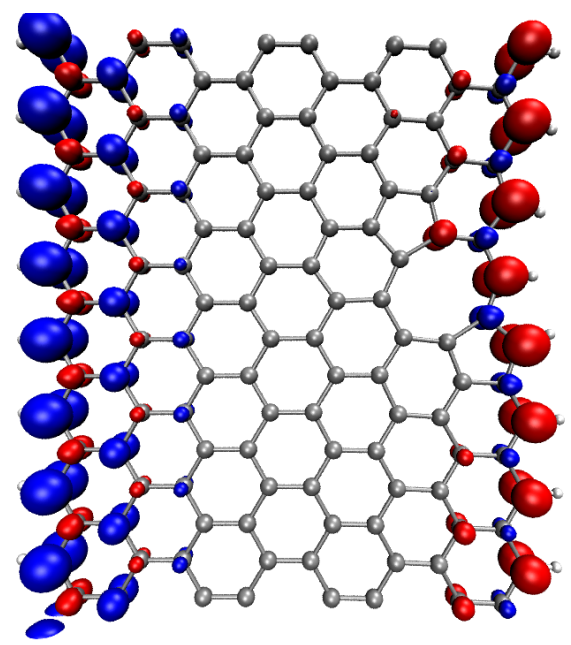

e)

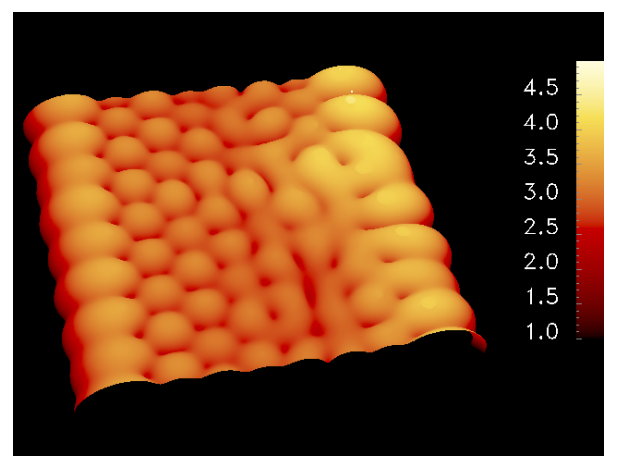

b)

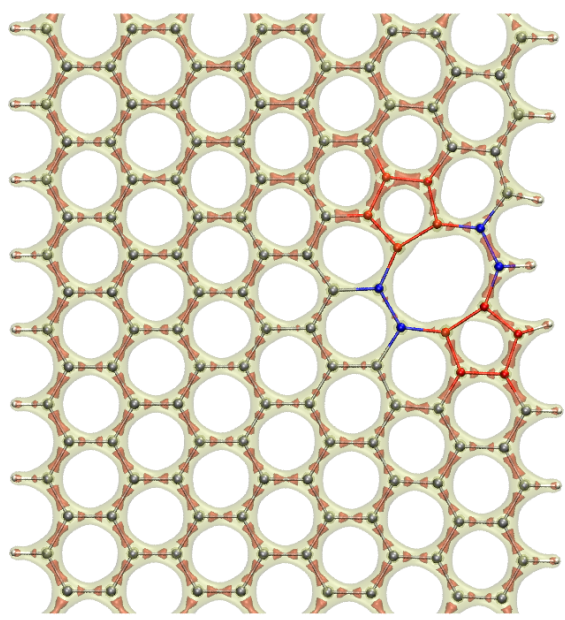

d)

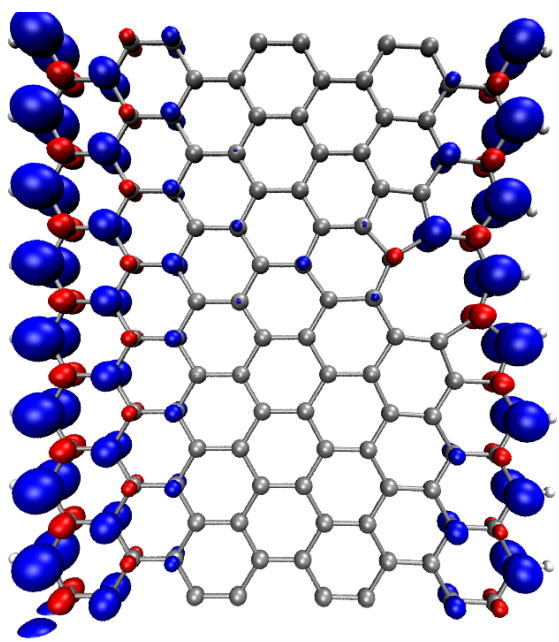

f)

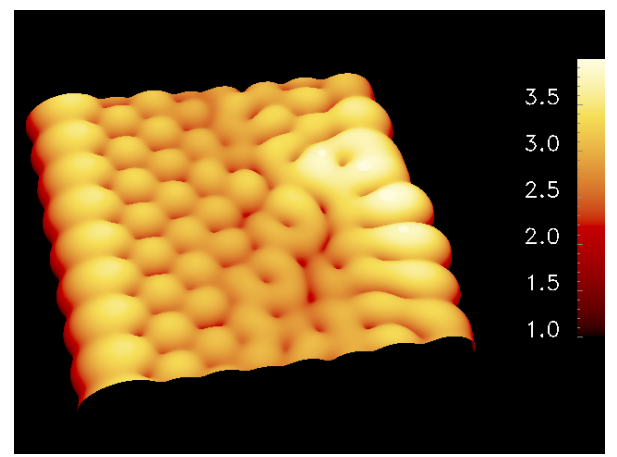

Figura 5.13: V2 585 com orientação paralela na borda de uma nanofita: (a) Geometria; (b) duas isosuperfícies da densidade de carga, com $1.5 e / \AA^{3}$ (amarelo) e $2 e / \AA^{3}$ (vermelho); magnetização local $\left(0.02 e / \AA^{3}\right.$ em azul e $-0.02 e / \AA^{3}$ em vermelho) nas configurações AF (c) e F (d); simulações de imagens STM para as configurações AF (e) e F (f). 
a)

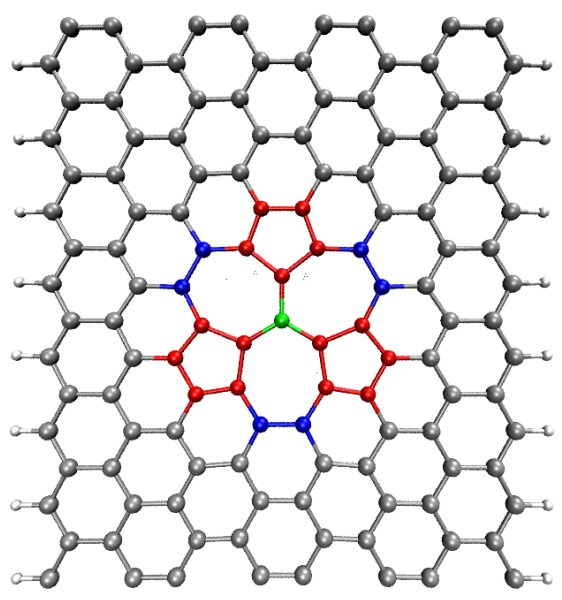

c)

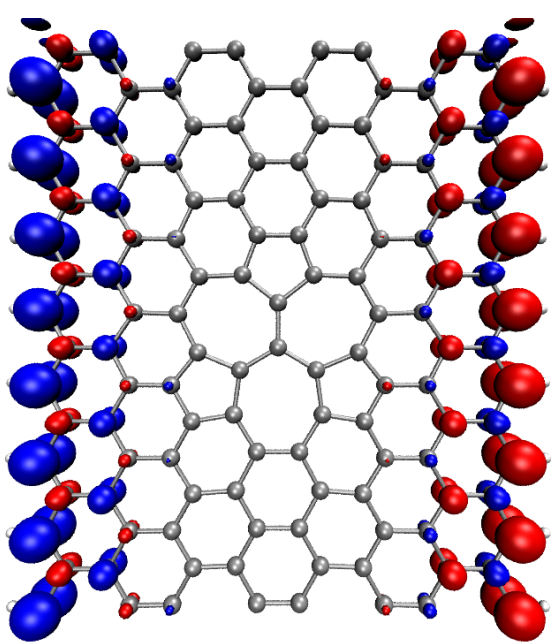

e)

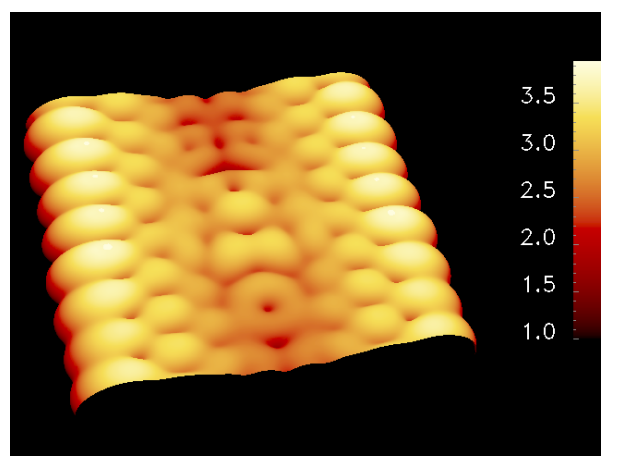

b)

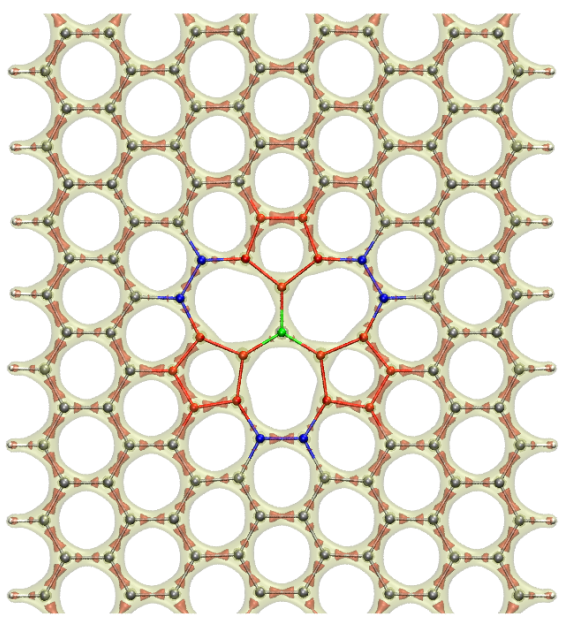

d)

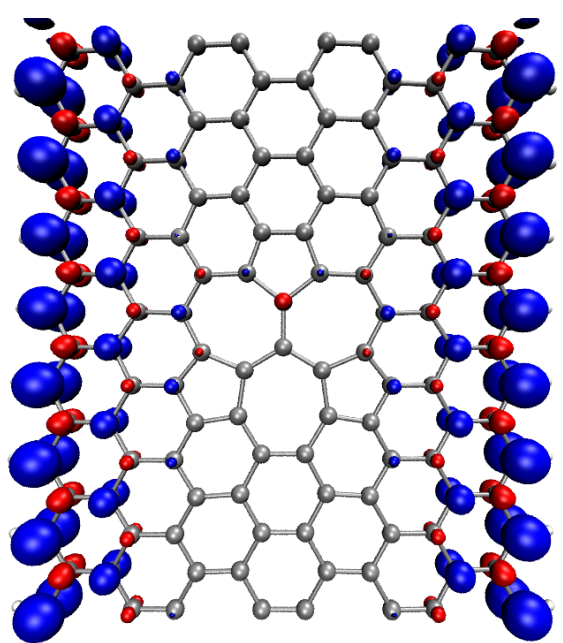

f)

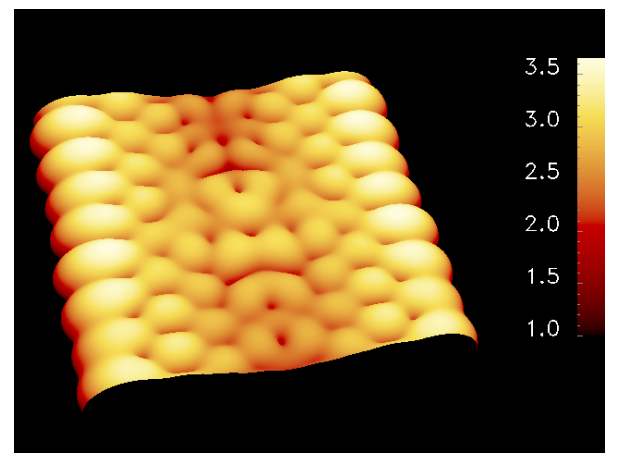

Figura 5.14: V2 555777 no centro de uma nanofita: (a) Geometria; (b) duas isosuperfícies da densidade de carga, com $1.5 e / \AA^{3}$ (amarelo) e $2 e / \AA^{3}$ (vermelho); magnetização local (0.02e/ $\AA^{3}$ em azul e $-0.02 e / \AA^{3}$ em vermelho) nas configurações AF (c) e F (d); simulações de imagens STM para as configurações AF (e) e F (f). 
Na figura 5.14 mostramos a reconstrucão 555777 de uma divacância no centro de uma nanofita, que apresenta comportamento semelhante ao 555777 no grafeno do ponto de vista das ligações (Fig. 5.14b). O comprimento das ligações indicadas por setas negras é de $1.53 \AA$ e as indicadas por setas cinzas é $1.51 \AA$, valores quase idênticos aos do 555777 no grafeno (1.52 A).

Energeticamente, este defeito é mais estável no centro da nanofita do que no grafeno por, aproximadamente, $0.7 \mathrm{eV}$. Também podemos notar que as energias dos estados F e AF, como em todos os casos até agora, são praticamente degenerados, diferindo por apenas $0.04 \mathrm{eV}$. Em comparação às divacâncias 585 no centro, o 555777 é mais estável.

\begin{tabular}{cccccccc}
\hline Defeito & $E_{f}$ & $E_{f}^{A F}$ & $E_{f}^{F}$ & $E_{f}^{\text {grafeno }}$ & $E_{A F}-E_{0}$ & $E_{F}-E_{0}$ & $E_{A F}-E_{F}$ \\
\hline \hline V2 555777 c & 6.29 & 6.27 & 6.19 & 6.97 & -0.35 & -0.39 & 0.04 \\
\hline
\end{tabular}

Tabela 5.6: Energias de formação não-magnética, AF, F e no grafeno; e estabilidades relativas para o V2 555777 no centro. Energias em eV.

A geometria relaxada da divacância 555777 na borda é apresentada na figura 5.7a. Na figura 5.15b, onde podemos ver duas isosuperfícies da densidade de carga, podemos notar que as ligações formadas pelos átomos do defeito próximos às bordas são mais fortes. Este defeito apresenta uma energia de formação mais baixa que o 555777 no centro, por uma diferença de $\sim 0.7 \mathrm{eV}$, e mais baixa que no grafeno, por mais ou menos $1.6 \mathrm{eV}$.

\begin{tabular}{cccccccc}
\hline Defeito & $E_{f}$ & $E_{f}^{A F}$ & $E_{f}^{F}$ & $E_{f}^{g r a f}$ & $E_{A F}-E_{0}$ & $E_{F}-E_{0}$ & $E_{A F}-E_{F}$ \\
\hline \hline V2 $555777 \mathrm{~b}$ & 5.40 & 5.45 & 5.38 & 6.97 & -0.29 & -0.30 & 0.01 \\
\hline
\end{tabular}

Tabela 5.7: Energias de formação não-magnética, AF, F e no grafeno; e estabilidades relativas para o V2 555777 na borda. Energias em eV. 
a)

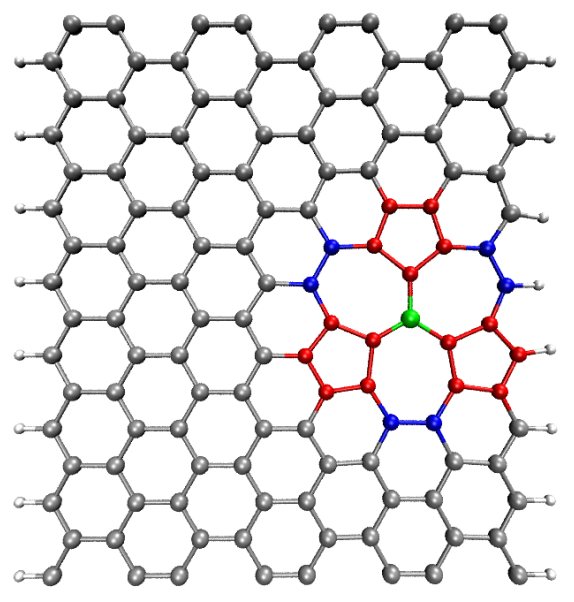

c)

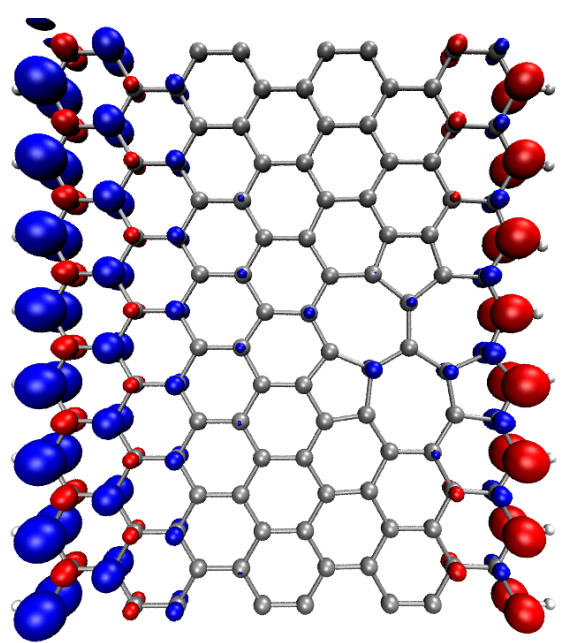

e)

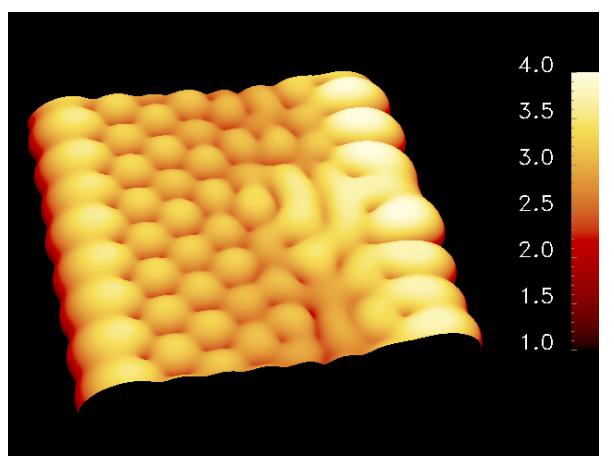

b)

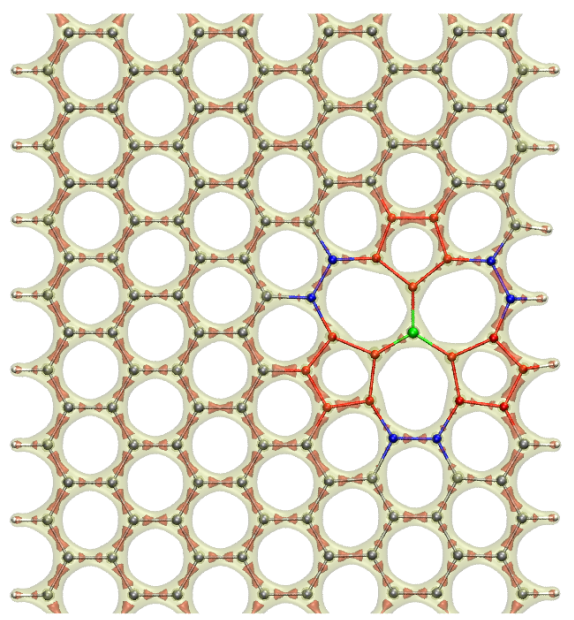

d)

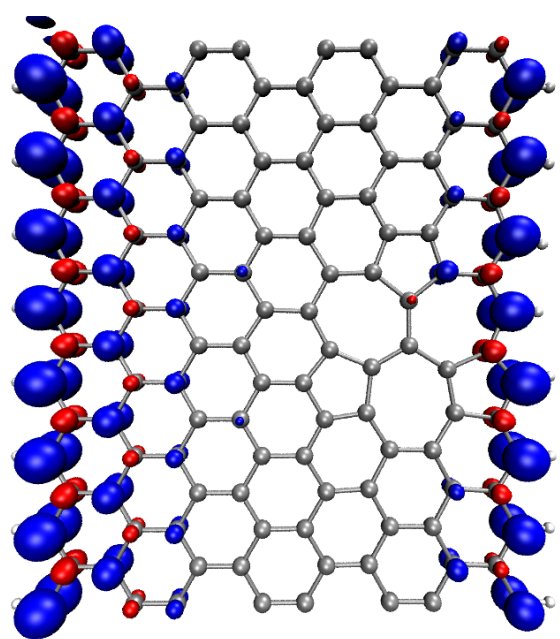

f)

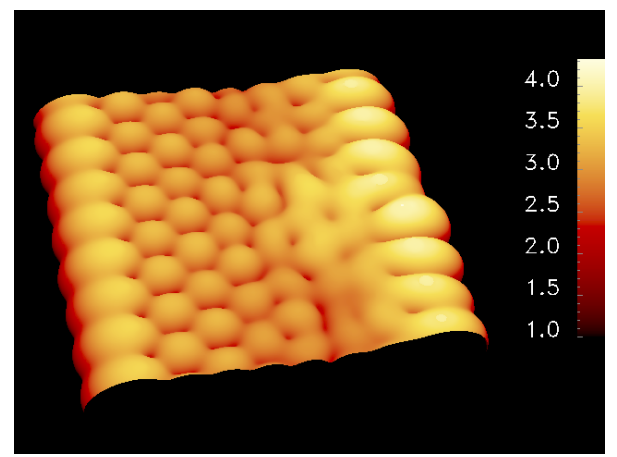

Figura 5.15: V2 555777 na borda de uma nanofita: (a) Geometria; (b) duas isosuperfícies da densidade de carga, com $1.5 e / \AA^{3}$ (amarelo) e $2 e / \AA^{3}$ (vermelho); magnetização local (0.02e $/ \AA^{3}$ em azul e $-0.02 e / \AA^{3}$ em vermelho) nas configurações AF (c) e F (d); simulações de imagens STM para as configurações AF (e) e F (f). 


\subsubsection{Monovacância}

A reconstrução de uma monovacância com orientação perpendicular no centro da nanofita, conforme ilustrado na figura 5.16a, é semelhante a do grafeno. Dois átomos do centro se aproximam, ficando a uma distância de $1.89 \AA$, tentando fechar um pentágono (em vermelho na Fig. 5.16a) e o átomo que sobra sofre uma reibridização, adquirindo caráter $s p^{3}$. Como se pode ver no inset este átomo sai do plano do grafeno e fica com uma ligação pendente. Esta apresenta uma magnetização (figuras 5.16c e 5.16d) bastante alta se comparada aos outros átomos da fita.

\begin{tabular}{cccccccc}
\hline Defeito & $E_{f}$ & $E_{f}^{A F}$ & $E_{f}^{F}$ & $E_{f}^{g r a f}$ & $E_{A F}-E_{0}$ & $E_{F}-E_{0}$ & $E_{A F}-E_{F}$ \\
\hline \hline V1 per. c & 7.79 & 7.49 & 7.39 & 7.61 & -0.64 & -0.68 & 0.04 \\
\hline
\end{tabular}

Tabela 5.8: Energias de formação não-magnética, AF, F e no grafeno; e estabilidades relativas para o V1 perpendicular no centro. Energias em eV.

Seguindo o modelo do custo das ligações químicas, este defeito apresenta energias de formação altas (tabela 5.8), ligeiramente menores $(\sim 0.1-0.2 \mathrm{eV})$ que a da monovacância no grafeno. Também podemos perceber que, neste defeito, a diferença de energia entre as configurações F e AF com a configuração não-magnética é duas vezes maior que nos outros tipos de defeito. Ou seja, a estabilização do defeito devido à polarização de spin é muito maior para monovacâncias, que apresentam uma ligação pendente. Esta ligação pendente, como já mencionado antes, é altamente reativa e provalvelmente não deve ser encontrada se a fita se encontrar exposta a uma atmosfera qualquer.

As imagens de STM simuladas para este defeito (Figs. 5.16e e 5.16f) mostram a alta densidade de estados locais na ligação pendente, criando uma assinatura para este tipo de defeito. 
a)

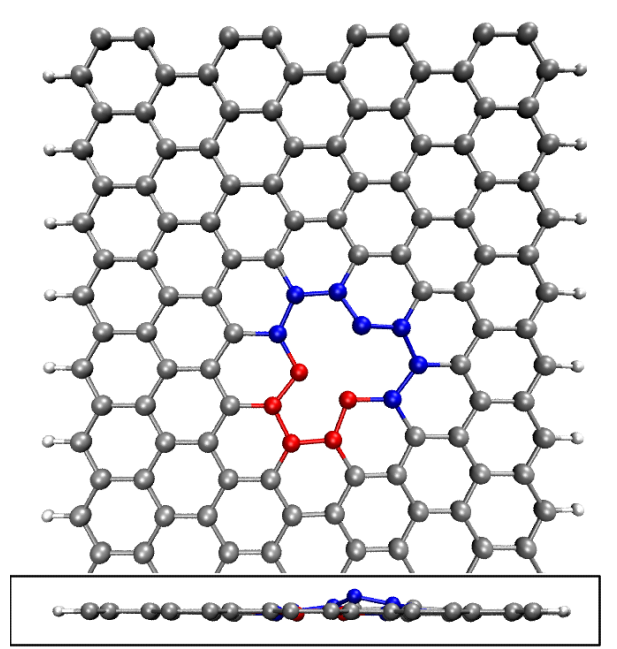

c)

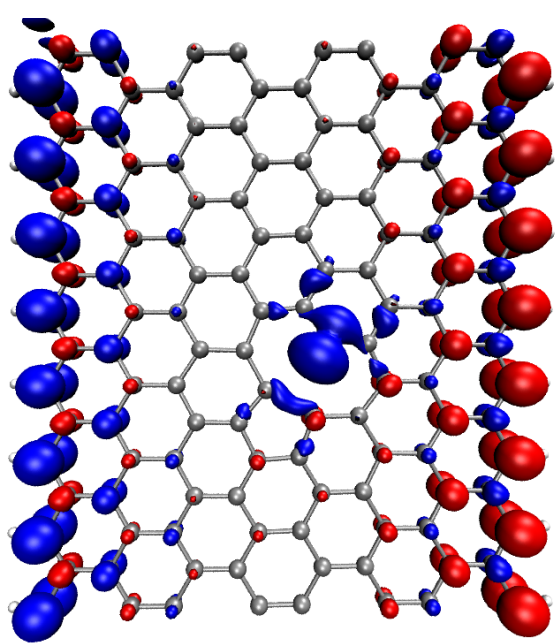

e)

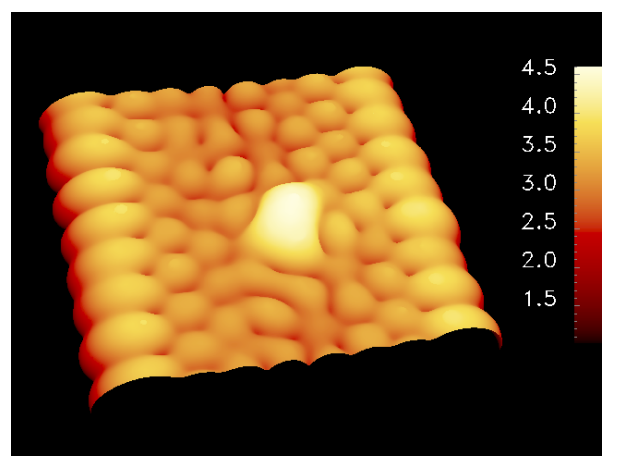

b)

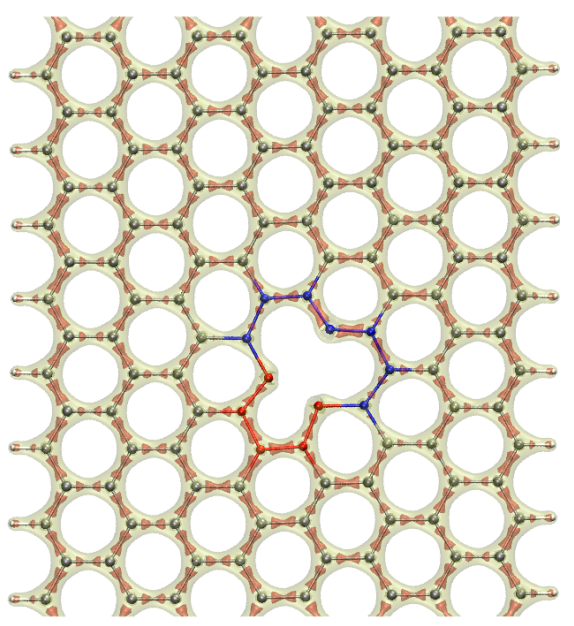

d)

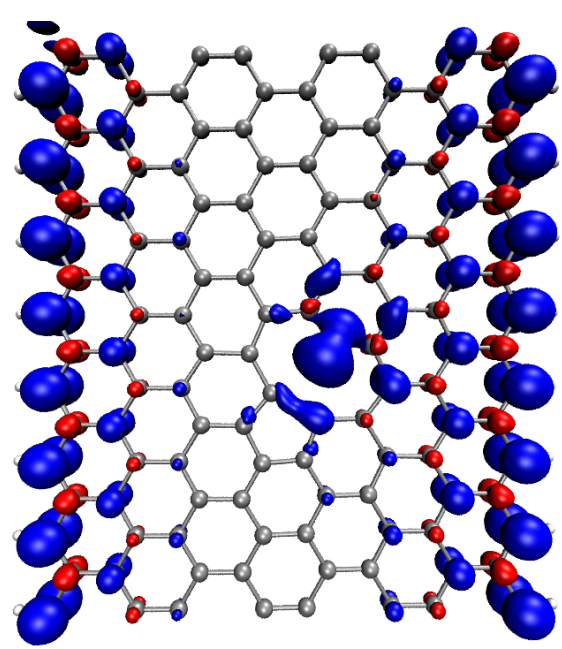

f)

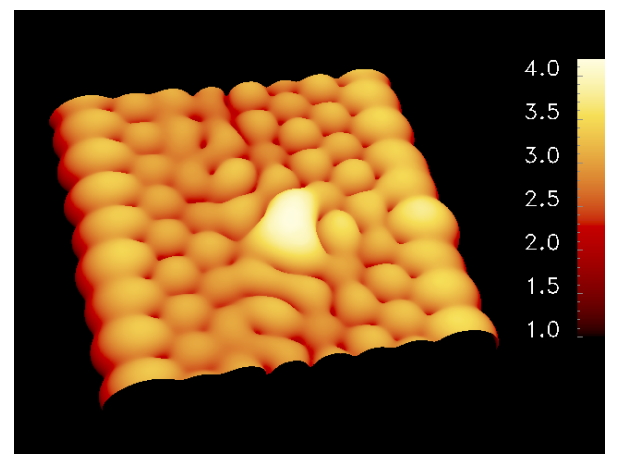

Figura 5.16: V1 com orientação perpendicular no centro de uma nanofita: (a) Geometria; (b) duas isosuperfícies da densidade de carga, com $1.5 \mathrm{e} / \AA^{3}$ (amarelo) e $2 e / \AA^{3}$ (vermelho); magnetização local $\left(0.02 e / \AA^{3}\right.$ em azul e $-0.02 e / \AA^{3}$ em vermelho) nas configurações AF (c) e F (d); simulações de imagens STM para as configurações $\mathrm{AF}(\mathrm{e})$ e $\mathrm{F}$ (f). 
No caso da monovacância com orientação paralela ao eixo da fita, as características do defeito se mantém. No entanto, é interessante notar que a ligação "quase rompida" do pentágono é paralela ao eixo da fita. Como vimos na seção 5.2.1, as ligações nessa direção são mais fortes (e portanto mais duras). Assim, o pentágono não consegue fechar tanto quanto na orientação perpendicular, ficando com uma distância de $2.04 \AA$, resultando em energias de ligação mais altas.

Da mesma forma que na orientação perpendicular, a presença da ligação pendente induz uma magnetização local (figura 5.17) no defeito, que também possui uma alta densidade local de estados, conforme pode ser visto nas imagens STM simuladas. Note que esta orientação da monovacância pode ser diferenciada da anterior pelo padrão triangular da imagem.

\begin{tabular}{cccccccc}
\hline Defeito & $E_{f}$ & $E_{f}^{A F}$ & $E_{f}^{F}$ & $E_{f}^{g r a f}$ & $E_{A F}-E_{0}$ & $E_{F}-E_{0}$ & $E_{A F}-E_{F}$ \\
\hline \hline V1 par. c & 8.01 & 7.68 & 7.60 & 7.61 & -0.67 & -0.69 & -0.02 \\
\hline
\end{tabular}

Tabela 5.9: Energias de formação não-magnética, AF, F e no grafeno; e estabilidades relativas para o V1 paralelo no centro. Energias em eV.

Também, como podemos ver na tabela 5.9, a estabilização do defeito devido à polarização de spin é grande neste defeito. 
a)

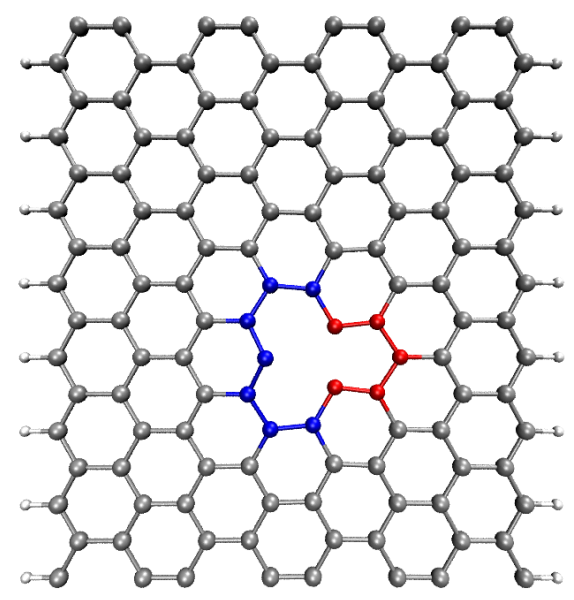

c)

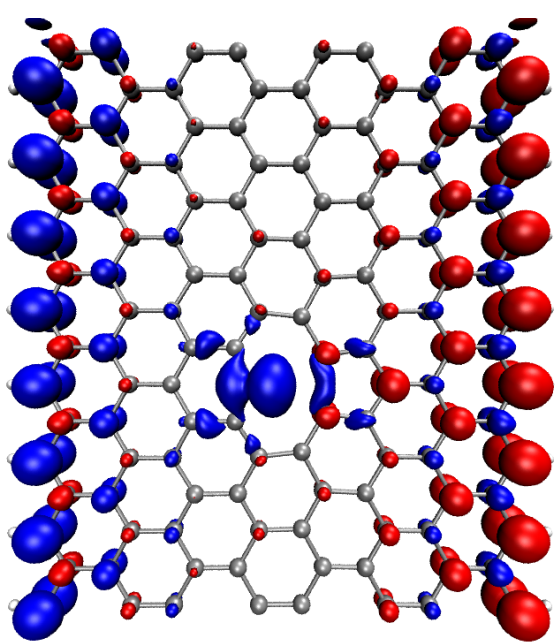

e)

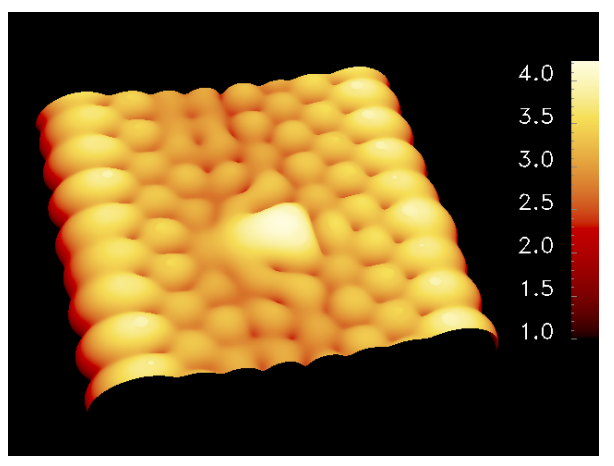

b)

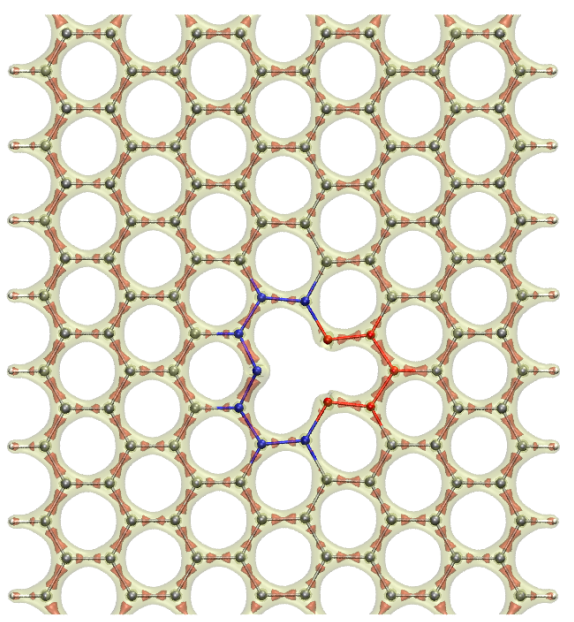

d)

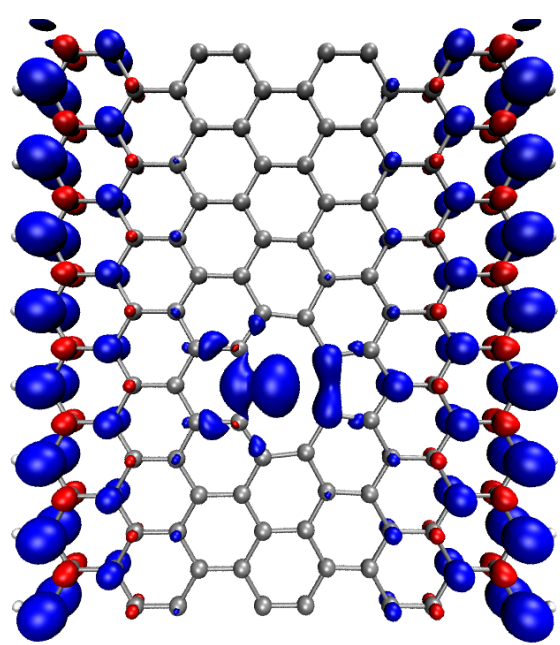

f)

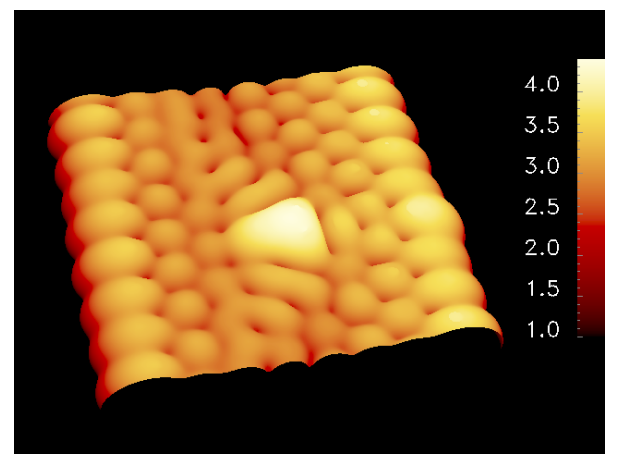

Figura 5.17: V1 com orientação paralela no centro de uma nanofita: (a) Geometria; (b) duas isosuperfícies da densidade de carga, com $1.5 e / \AA^{3}$ (amarelo) e $2 e / \AA^{3}$ (vermelho); magnetização local $\left(0.02 e / \AA^{3}\right.$ em azul e $-0.02 e / \AA^{3}$ em vermelho) nas configurações AF (c) e F (d); simulações de imagens STM para as configurações AF (e) e F (f). 
A monovacância na borda da nanofita, apresenta uma reconstrução bem diferente quando comparada à monovacância no centro. Como pode ser visto na figura 5.18a, o pentágono consegue se fechar, sendo que as maiores ligações do defeito, indicadas por flechas na Fig. 5.18a têm 1.49 A. No entanto, o que seria o eneágono fica aberto agora. Também, como nos casos anteriores, um átomo de carbono sai do plano da folha de grafeno. Olhando para isosuperfícies da densidade de carga (figura 5.18), nota-se que, de forma geral, as ligações entre os átomos que compõem o defeito estão mais fortes. Outro fato que deve ser notado é que o defeito "mata" localmente a magnetização da borda (figura 5.18c).

As energias de formação deste defeito (veja a tabela 5.10) são significativamente mais baixas $(\sim 1.8 \mathrm{eV})$ que no grafeno, em concordância com a análise das ligações. Para este defeito não apresentamos nenhuma energia relacionada a $\mathrm{F}$ porque todas as tentativas para realizar os cálculos na configuração F convergiram para a AF.

\begin{tabular}{cccccccc}
\hline Defeito & $E_{f}$ & $E_{f}^{A F}$ & $E_{f}^{F}$ & $E_{f}^{\text {grafeno }}$ & $E_{A F}-E_{0}$ & $E_{F}-E_{0}$ & $E_{A F}-E_{F}$ \\
\hline \hline V1 b & 5.13 & 5.22 & - & 7.61 & -0.25 & - & - \\
\hline
\end{tabular}

Tabela 5.10: Energias de formação não-magnética, AF e no grafeno; e estabilidades relativas para o V1 na borda. Energias em eV. 
a)

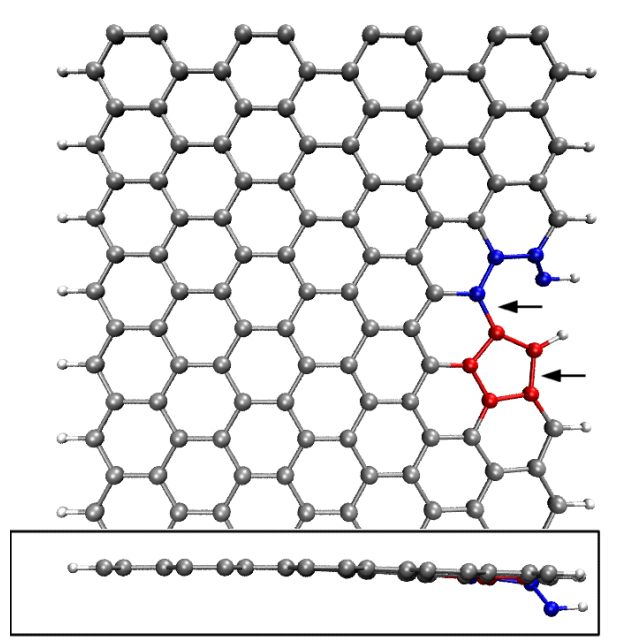

c)

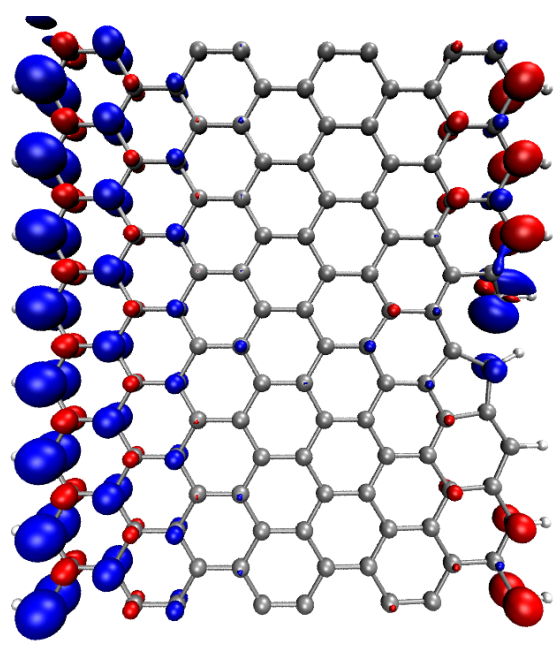

b)

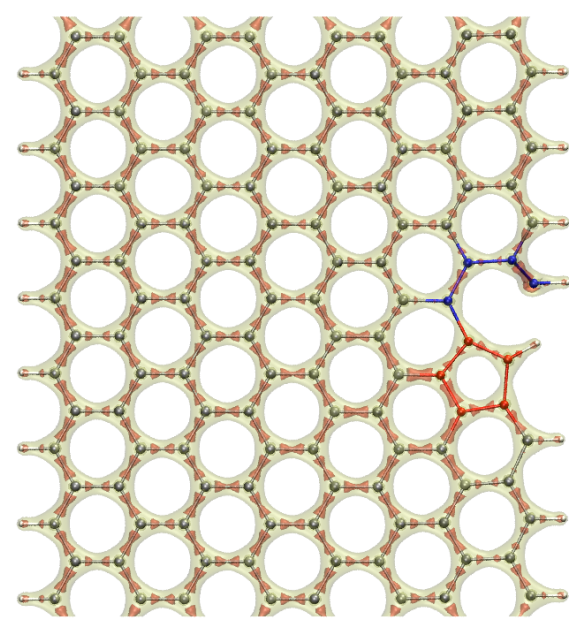

d)

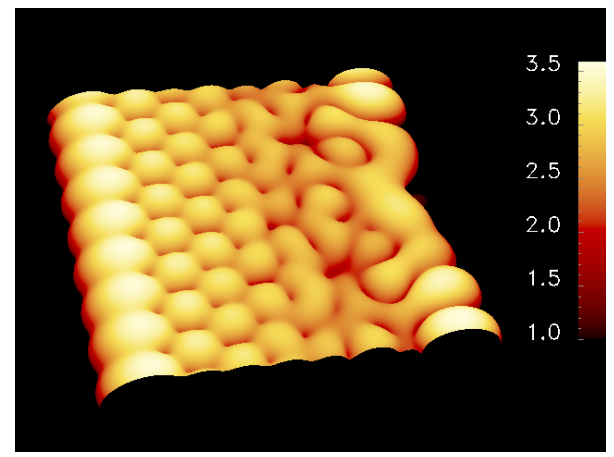

Figura 5.18: V1 na borda de uma nanofita: (a) Geometria; (b) duas isosuperfícies da densidade de carga, com $1.5 e / \AA^{3}$ (amarelo) e $2 e / \AA^{3}$ (vermelho); (c) magnetização local $\left(0.02 e / \AA^{3}\right.$ em azul e $-0.02 e / \AA^{3}$ em vermelho) e (d) simulação de imagem STM para a configuração AF. 


\subsubsection{Stone-Wales}

A reconstrução de um defeito SW com orientação perpendicular (definida pelos heptágonos) no centro de uma nanofita é mostrada na figura 5.19a. Como se pode ver, o defeito apresenta dois pentágonos e dois heptágonos (5577), da mesma forma que um SW no grafeno (Fig. 5.5a). Olhando para as isosuperfícies da densidade de carga nota-se que nenhum dos átomos do defeito participam de ligações muito fracas, nem "quase rompidas". Inclusive, o contrário acontece, os dois átomos dos pentágonos opostos participam de uma ligação bem forte. Note também que esta ligação é paralela ao eixo da fita, o que favorece ligações fortes. As maiores ligações do defeito, que são as quatro equivalentes à indicada na Fig. 5.5a, apresentam um comprimento de $1.45 \AA$.

Outro aspecto deste defeito diz respeito à magnetização. Analisando as figuras 5.19c e 5.19d, percebemos que este defeito, principalmente na sua configuração AF, aumenta a magnetização da fita consideravelmente.

Conforme mostrado na tabela 5.11, as energias de formação do SW perpendicular no centro de uma nanofita são próximas à energia de formação do SW no grafeno, sendo que as energias de formação AF e F, são, aproximadamente, $0.17 \mathrm{eV}$ maiores. Também, como em todos os defeitos em nanofitas vistos até agora, as configurações F e AF são mais estáveis que a configuração não-magnética e praticamente degeneradas, embora as diferenças de energias $E_{A F}-E_{0}$ e $E_{F}-E_{0}$ sejam as menores (maiores em módulo) vistas até agora.

\begin{tabular}{cccccccc}
\hline Defeito & $E_{f}$ & $E_{f}^{A F}$ & $E_{f}^{F}$ & $E_{f}^{\text {graf }}$ & $E_{A F}-E_{0}$ & $E_{F}-E_{0}$ & $E_{A F}-E_{F}$ \\
\hline \hline SW per. c & 5.05 & 5.20 & 5.19 & 5.03 & -0.19 & -0.14 & -0.05
\end{tabular}

Tabela 5.11: Energias de formação não-magnética, AF, F e no grafeno; e estabilidades relativas para o SW perperpendicular no centro. Energias em eV. 
a)

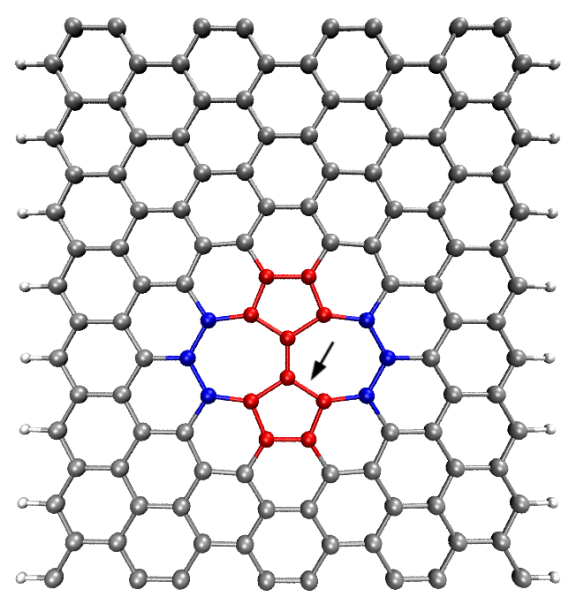

c)

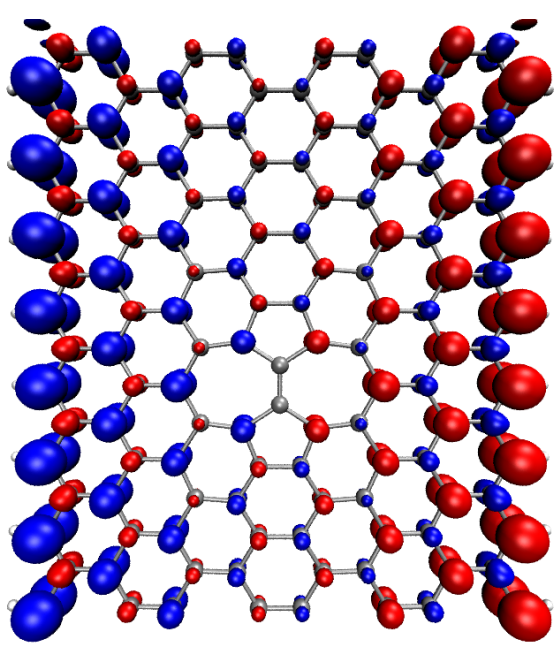

e)

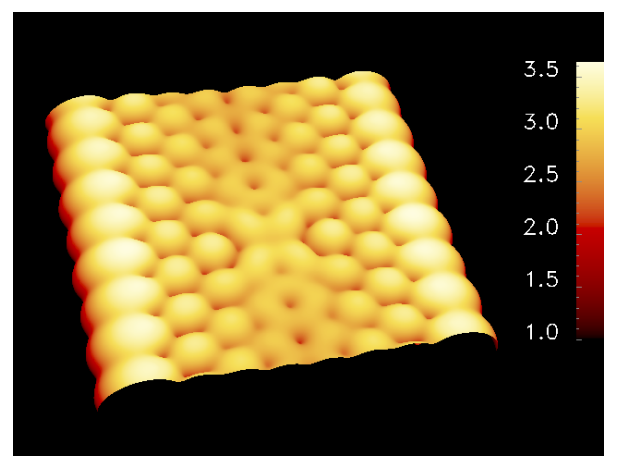

b)

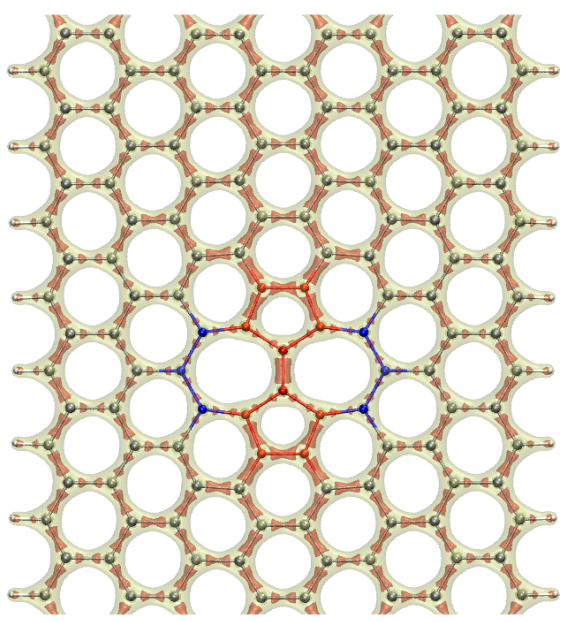

d)

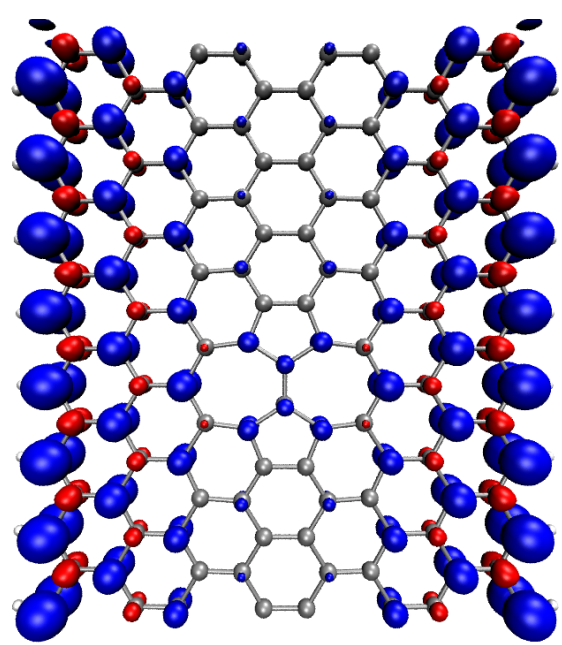

f)

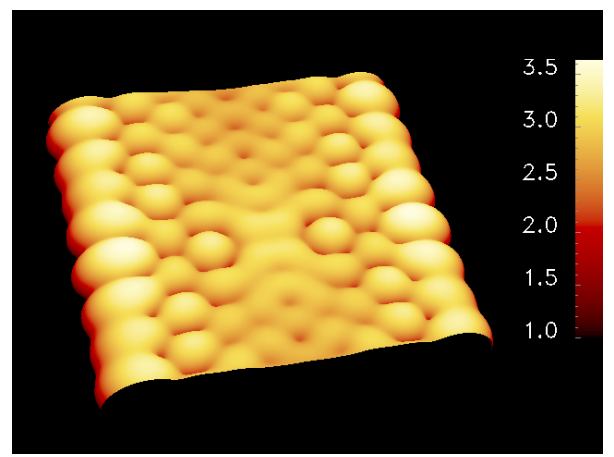

Figura 5.19: SW com orientação perpendicular no centro de uma nanofita: (a) Geometria; (b) duas isosuperfícies da densidade de carga, com 1.5e/ $\AA^{3}$ (amarelo) e $2 e / \AA^{3}$ (vermelho); magnetização local $\left(0.02 e / \AA^{3}\right.$ em azul e $-0.02 e / \AA^{3}$ em vermelho) nas configurações AF (c) e F (d); simulações de imagens STM para as configurações AF (e) e F (f). 
Além da orientação perpendicular, o SW pode ser orientado paralelamente ao eixo da nanofita. A geometria de equilíbrio para este caso, formada também por dois pentágonos e dois heptágonos (5577), pode ser vista na figura 5.20a. Da mesma forma que para o caso do SW com orientação perpendicular e no centro, pode-se ver na figura 5.20b que não há nenhuma ligação muito fraca entre os átomos que compõem o defeito. Também o comprimento das maiores ligações do defeito não se altera muito, sendo de $1.46 \AA$ para as ligações indicadas pelas setas cinzas e de 1.47 A para as ligações indicadas pelas setas pretas.

No entanto, no caso da magnetização (figuras 5.20c e 5.20e), não há mais um aumento na magnetização dos átomos, como acontecia com o SW perpendicular centrado.

As energias de formação deste defeito são aproximadamente $1 \mathrm{eV}$ menores do que no grafeno, como pode ser visto na tabela 5.12. Também as energias da configurações F e AF são mais estáveis que a configuração não-magnética, sendo que o estado AF é mais estavel que o $\mathrm{F}$ por $0.06 \mathrm{eV}$.

\begin{tabular}{cccccccc}
\hline Defeito & $E_{f}$ & $E_{f}^{A F}$ & $E_{f}^{F}$ & $E_{f}^{\text {graf }}$ & $E_{A F}-E_{0}$ & $E_{F}-E_{0}$ & $E_{A F}-E_{F}$ \\
\hline \hline SW par. c & 4.19 & 4.08 & 4.08 & 5.03 & -0.44 & -0.39 & -0.06
\end{tabular}

Tabela 5.12: Energias de formação não-magnética, AF, F e no grafeno; e estabilidades relativas para o SW paralelo no centro de uma nanofita. Energias em eV. 
a)

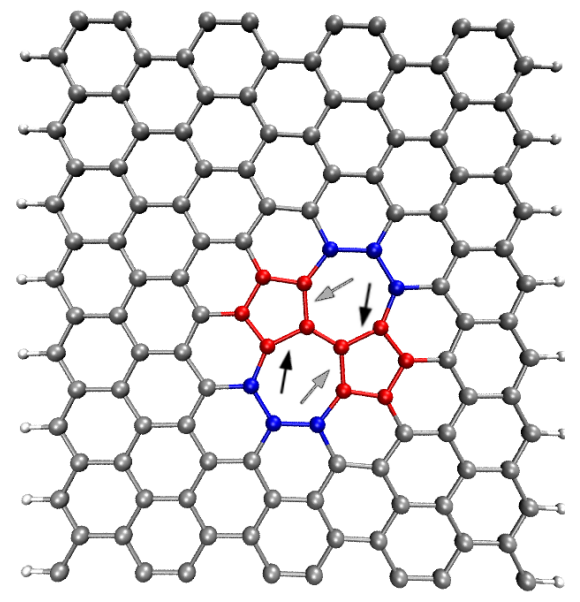

c)

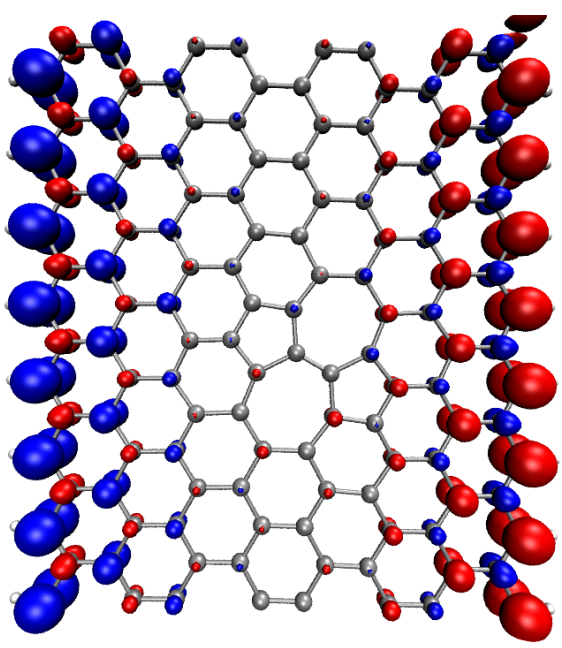

e)

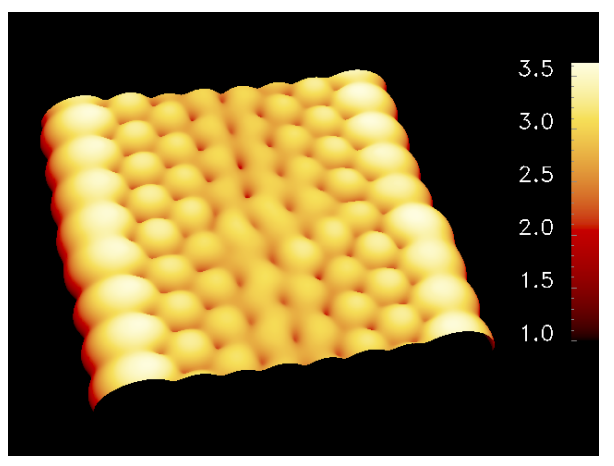

b)

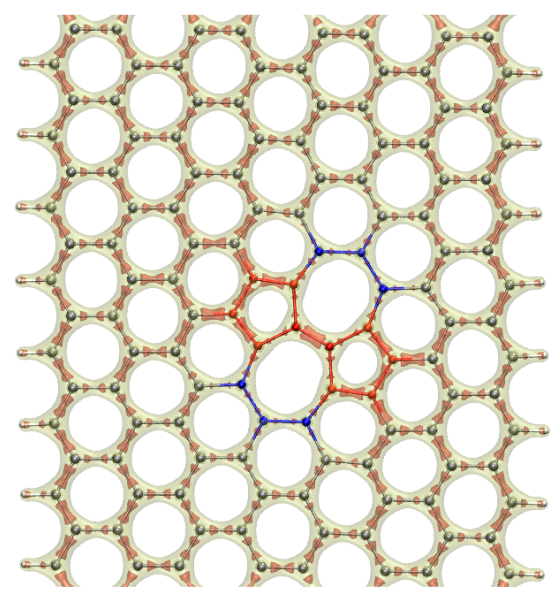

d)

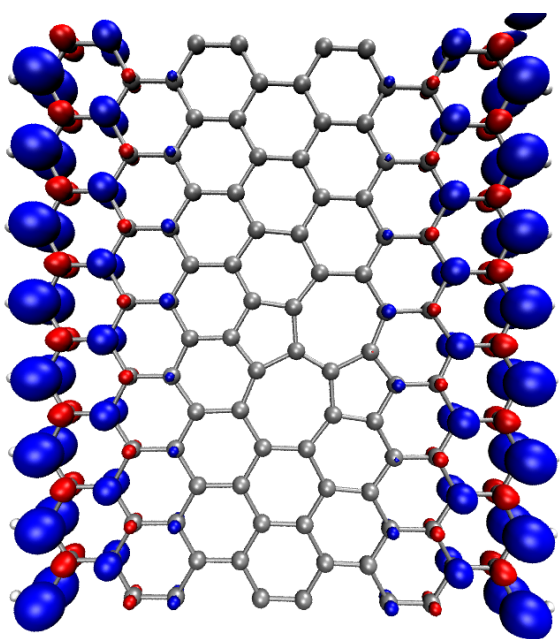

f)

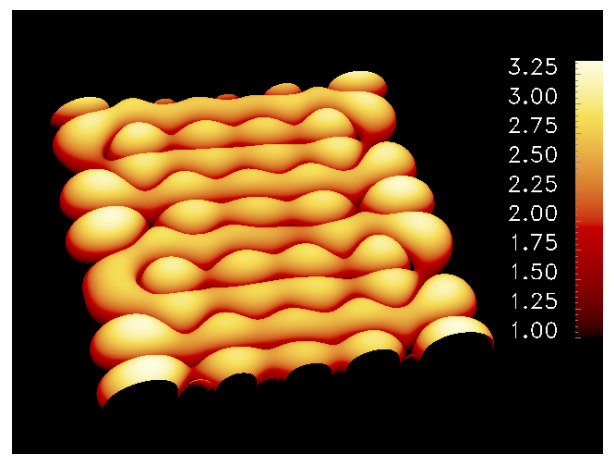

Figura 5.20: SW com orientação paralela no centro de uma nanofita: (a) Geometria; (b) duas isosuperfícies da densidade de carga, com $1.5 e / \AA^{3}$ (amarelo) e $2 e / \AA^{3}$ (vermelho); magnetização local $\left(0.02 e / \AA^{3}\right.$ em azul e $-0.02 e / \AA^{3}$ em vermelho) nas configurações AF (c) e F (d); simulações de imagens STM para as configurações AF (e) e F (f). 
Agora, vamos analisar o defeito SW na borda da nanofita e com orientação paralela. A relaxação da geometria deste defeito pode ser observada na figura 5.21a. Esta continua sendo formada por dois pentágonos e dois heptágonos (5577), mas agora, já se pode notar uma maior perturbação causada pelo defeito na borda. A análise das isosuperfícies da densidade de carga (figura 5.21b) revela que uma das ligações, a indicada na Fig.5.21a e que apresenta um comprimento de $1.44 \AA$, é ligeiramente mais intensa.

As magnetizações para as configurações AF e F podem ser vistas nas figuras 5.21c e 5.21d. Aqui também não encontramos nenhuma característica marcante.

Quanto às energias de formação, descritas na tabela 5.13, vemos que o SW paralelo na borda apresenta a menor energia de formação entre o defeitos já vistos, tanto em nanofitas quanto em grafeno. Novamente observamos também que as configurações F e AF são praticamente degeneradas e que estas são mais estáveis que a configuração não magnética.

\begin{tabular}{cccccccc}
\hline Defeito & $E_{f}$ & $E_{f}^{A F}$ & $E_{f}^{F}$ & $E_{f}^{\text {grafeno }}$ & $E_{A F}-E_{0}$ & $E_{F}-E_{0}$ & $E_{A F}-E_{F}$ \\
\hline \hline SW par. b & 3.37 & 3.33 & 3.30 & 5.03 & -0.38 & -0.35 & -0.03 \\
\hline
\end{tabular}

Tabela 5.13: Energias de formação não-magnética, AF, F e no grafeno; e estabilidades relativas para o SW paralelo na borda. Energias em eV. 
a)

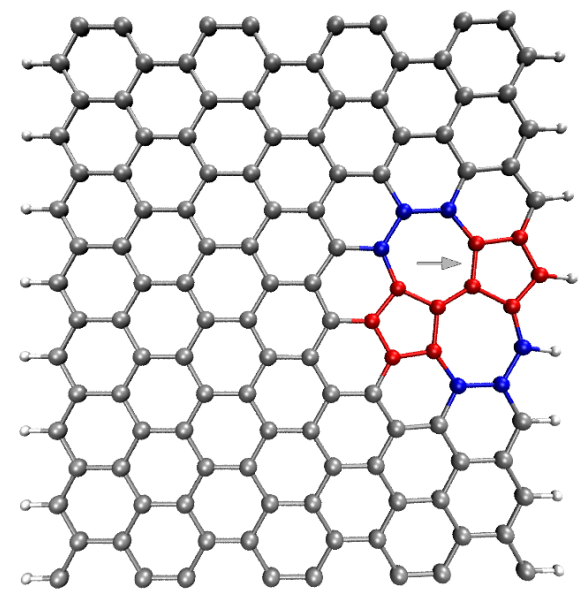

c)

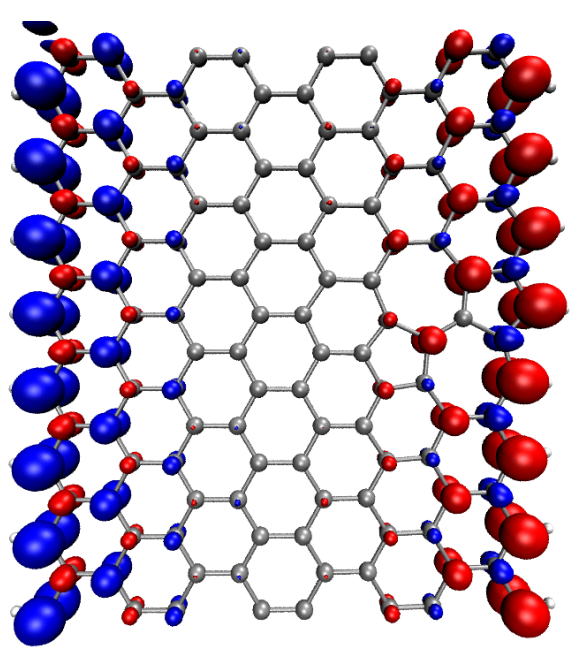

e)

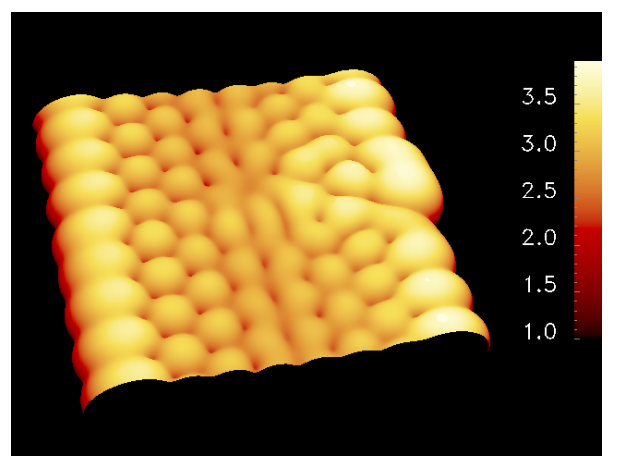

b)

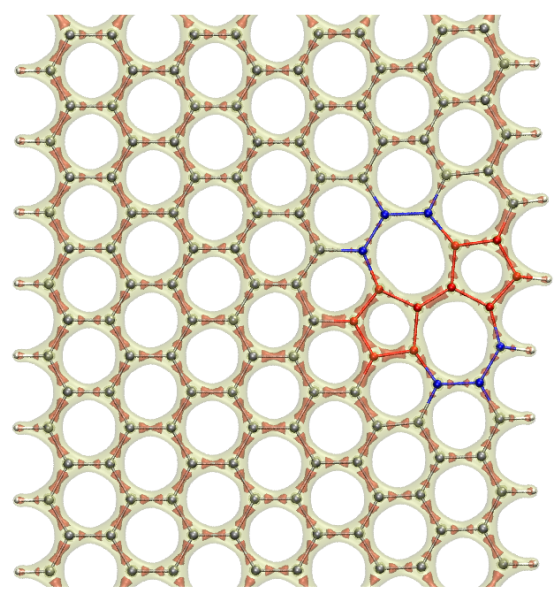

d)

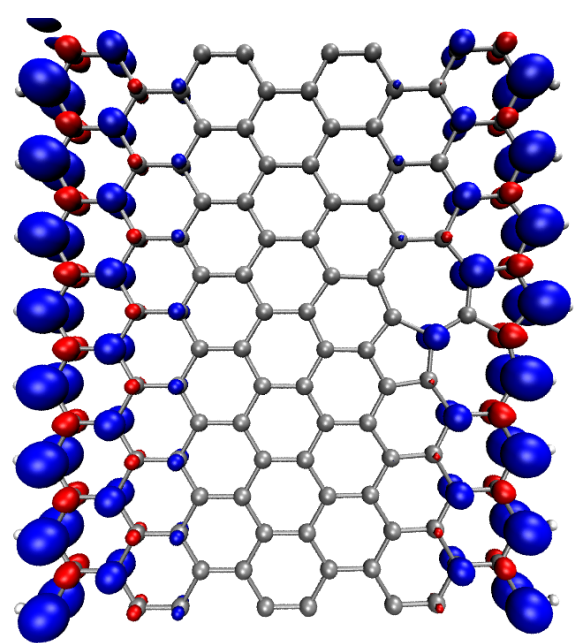

f)

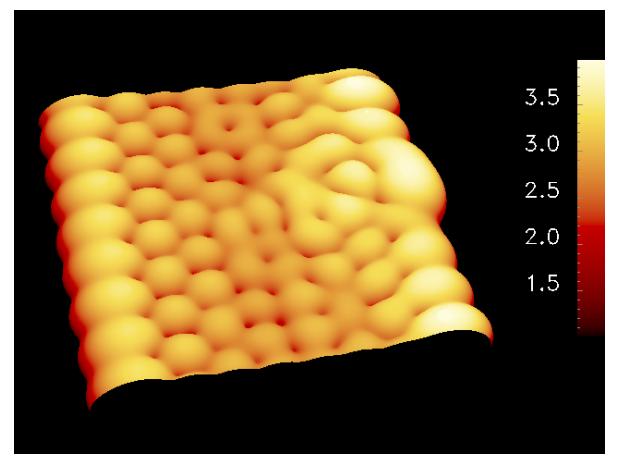

Figura 5.21: SW com orientação paralela na borda de uma nanofita: (a) Geometria; (b) duas isosuperfícies da densidade de carga, com $1.5 e / \AA^{3}$ (amarelo) e $2 e / \AA^{3}$ (vermelho); magnetização local $\left(0.02 e / \AA^{3}\right.$ em azul e $-0.02 e / \AA^{3}$ em vermelho) nas configurações AF (c) e F (d); simulações de imagens STM para as configurações AF (e) e F (f). 
Como vimos anteriormente, defeitos SW são formados através de rotações de ligaçoes (por $90^{\circ}$ ), resultando em defeitos do tipo 5577. No entanto, se a rotação for aplicada numa ligação muito perto da borda, a geometria do defeito fica diferente. O defeito que vamos tratar agora é criado aplicando uma rotação na ligação perpendicular ao eixo da fita mais próxima da borda. A geometria relaxada deste defeito pode ser vista na figura 5.22a, onde pode-se ver que o defeito é formado por dois pentágonos e apenas um heptágono. Por esse motivo este defeito foi chamado neste trabalho de SW 557. Note que este defeito induz uma curvatura considerável na fita.

Outro aspecto que chama bastante a atenção é a forte supressão da magnetização na borda que contem o defeito (figura 5.22c). Em relação à energética, também vemos (tabela 5.14) que as energias de formação são as mais baixas encontradas até agora, quase metade da energia de formação de uma SW no grafeno. Isto pode ser entendido pelo fato de que, além de estar localizado na borda, este defeito apresenta menos anéis (apenas dois pentágonos e dois heptágonos) e portanto menos átomos, o que facilita sua relaxação estrutural. Também, a configuração AF é mais estável que a não-magnética. Energias envolvendo a configuração F não são mostradas porque todos os cálculos onde se tentou encontrar a configuração F, convergiram para a AF.

\begin{tabular}{cccccccc}
\hline Defeito & $E_{f}$ & $E_{f}^{A F}$ & $E_{f}^{F}$ & $E_{f}^{g r a f}$ & $E_{A F}-E_{0}$ & $E_{F}-E_{0}$ & $E_{A F}-E_{F}$ \\
\hline \hline SW 557 b & 2.65 & 2.74 & - & 5.03 & -0.24 & - & - \\
\hline
\end{tabular}

Tabela 5.14: Energias de formação não-magnética, AF, F e no grafeno; e estabilidades relativas para o SW 557 na borda de uma nanofita. Energias em eV. 
a)

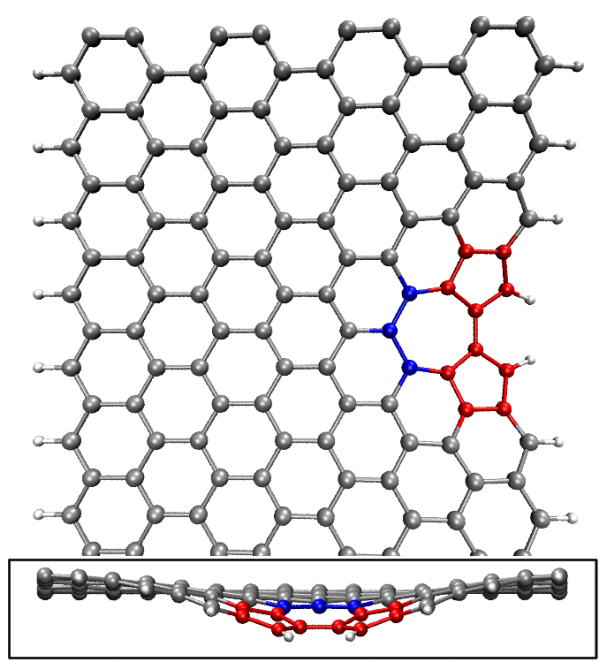

c)

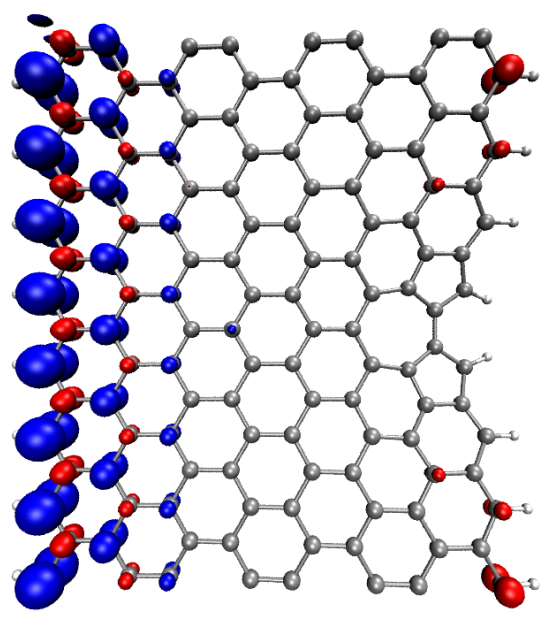

b)

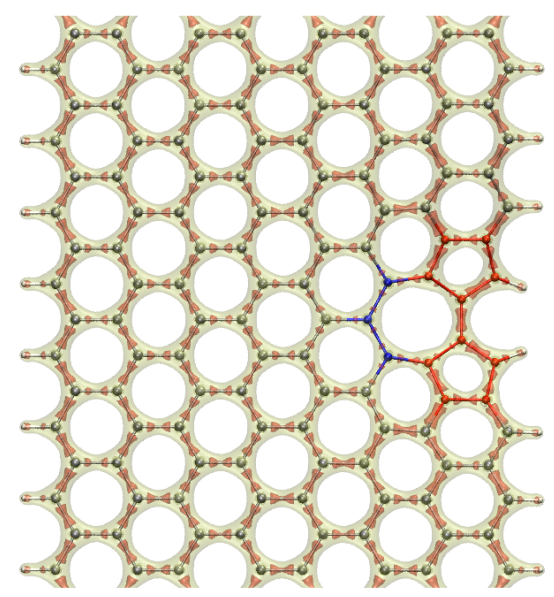

e)

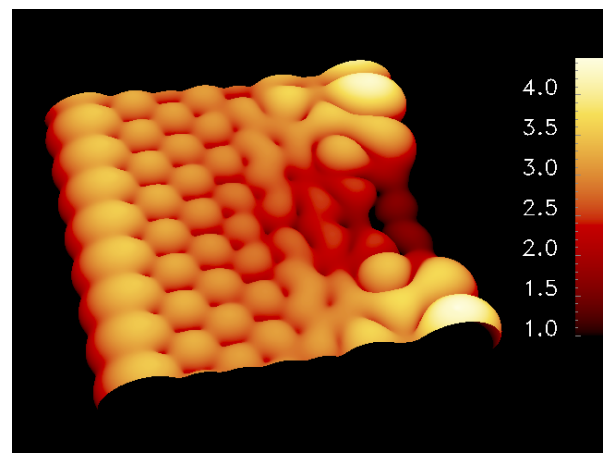

Figura 5.22: SW com orientação paralela na borda de uma nanofita: (a) Geometria; (b) duas isosuperfícies da densidade de carga, com $1.5 e / \AA^{3}$ (amarelo) e $2 e / \AA^{3}$ (vermelho); (c) magnetização local $\left(0.02 e / \AA^{3}\right.$ em azul e $-0.02 e / \AA^{3}$ em vermelho) e (d) simulação de imagem STM para a configuração AF.

Agora, depois de ter visto que uma rotação em uma ligação perto da borda resulta num defeito com energia de formação muito baixa, surge a pergunta: E se aplicarmos a rotação numa ligação da propria borda? A resposta é dada a seguir.

Na figura 5.23a, podemos ver o defeito gerado por essa rotação da ligação da borda. Este defeito é formado por um par pentágono-heptágono, e será chamado de SW 57. Olhando as isosuperfícies da densidade de carga, apresentadas na figura 
5.23b, pode-se notar que a ligação do pentágono que está mais proxima da borda é um tanto fraca, se comparada às outras ligações do pentágono.

Note também que este defeito, conforme mostrado na figura 5.23c, causa uma inversão local na magnetização dos átomos da borda. Em termos de estabilidade, como se pode ver na tabela 5.15, a energia de formação da configuração não magnética é de $1.74 \mathrm{eV}$, e a da configuração AF, $1.82 \mathrm{eV}$. Assim, este defeito é mais estável entre os estudados neste trabalho, apresentando energias de formação extremamente baixas. Também, da mesma forma que para todos os outros defeitos estudados, a configuração de mais baixa energia é a AF. Para este defeito, os cálculos tentando obter configurações $\mathrm{F}$ também convergiram para AF.

\begin{tabular}{cccccccc}
\hline Defeito & $E_{f}$ & $E_{f}^{A F}$ & $E_{f}^{F}$ & $E_{f}^{g r a f}$ & $E_{A F}-E_{0}$ & $E_{F}-E_{0}$ & $E_{A F}-E_{F}$ \\
\hline \hline SW 57 b & 1.74 & 1.82 & - & 5.03 & -0.25 & - & -
\end{tabular}

Tabela 5.15: Energias de formação não-magnética, AF e no grafeno; e estabilidades relativas para o SW 57 na borda de uma nanofita. Energias em eV. 
a)

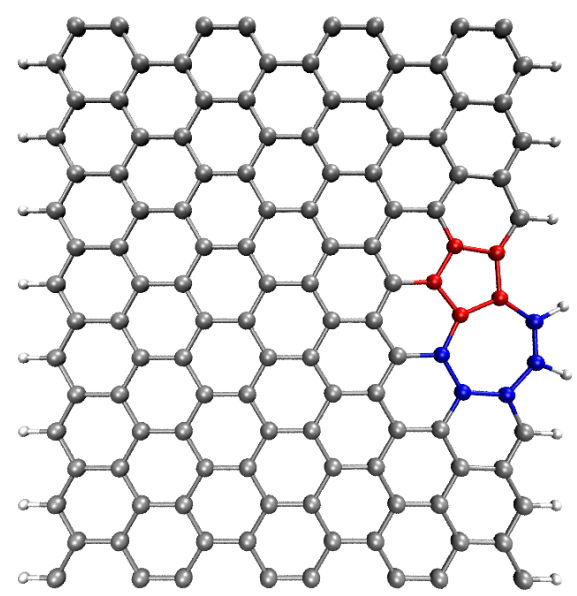

c)

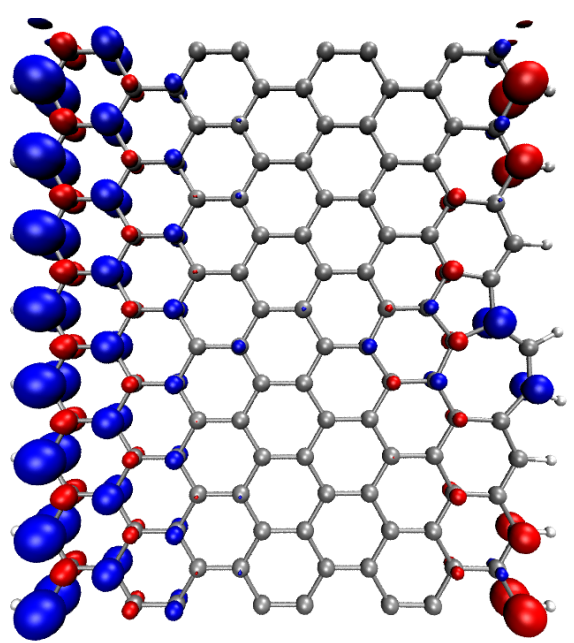

b)

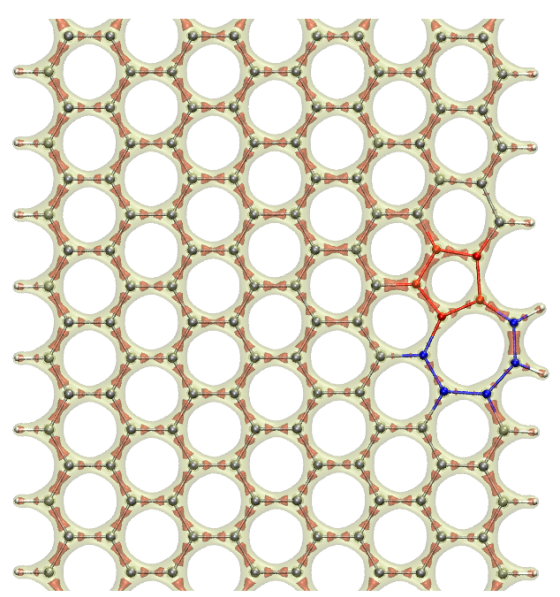

e)

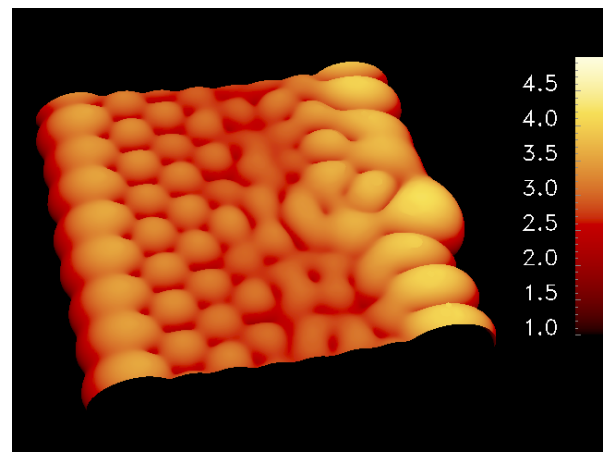

Figura 5.23: SW com orientação paralela na borda de uma nanofita: (a) Geometria; (b) duas isosuperfícies da densidade de carga, com $1.5 e / \AA^{3}$ (amarelo) e $2 e / \AA^{3}$ (vermelho); (c) magnetização local $\left(0.02 e / \AA^{3}\right.$ em azul e $-0.02 e / \AA^{3}$ em vermelho) e (d) simulação de imagem STM para a configuração AF.

Tendo em vista a baixissima energia de formação do SW 57, fizemos um cálculo da sua energia de formação usando nove repetições de uma célula unitária (nos cálculos apresentados até aqui usamos oito) e relaxando o tamanho da supercélula também. Todos os outros parâmetros do cálculo foram mantidos iguais, conforme descritos na seção 4.2. A energia de formação (para a configuração não-magnética) calculada desta forma foi de $1.57 \mathrm{eV}$. A razão de ter-se encontrado um valor 0.17 
$\mathrm{eV}$ mais baixo resulta de que, primeiro, aumentando o tamanho da supercélula a interação entre as imagens do defeito diminui (veja o apêndice D) e, segundo, relaxando o tamanho da supercélula é possível uma melhor relaxação do defeito que pode "preferir" um parâmetro de rede local diferente de que o sistema pristino.

\subsubsection{Discussão}

Nas tabelas 5.16 e 5.17 sumarizamos os resultados encontrados para as energias de formação não-magnética, AF e $\mathrm{F}$ dos defeitos estudados para a nanofita e a energia de formação dos defeitos no grafeno; e para a estabilidade relativa entre as configurações não-magnética, F e AF para os defeitos na nanofita, respectivamente.

Analisando os valores das energias de formação na tabela 5.16, podemos observar uma tendência: que as energias de formação são sempre mais baixas na borda da nanofita para um mesmo tipo de defeito. Isto é devido ao fato de que a ausência de vínculos nos átomos das bordas permite que os defeitos relaxem melhor, se tornando mais estáveis. Também pode-se notar que, de forma geral, defeitos do tipo StoneWales são os mais fáceis de serem criados (tem uma energia de formação menor) e monovacâncias, os mais difíceis.

Vimos anteriormente que para os defeitos no grafeno, quanto maior o valor do comprimento da maior ligação do defeito, $d_{>}$, maior é a energia de formação. Para os defeitos estudados em nanofitas, o mesmo também acontece, como pode ser visto na figura 5.24, confirmando que a maior contribuição para a energia de formação dos defeitos advém da energia química necessária para "romper" as ligações. 


\begin{tabular}{lcccc}
\hline Defeito & $E_{f}$ & $E_{f}^{A F}$ & $E_{f}^{F}$ & $E_{f}^{\text {grafeno }}$ \\
\hline \hline V2 585 per. centro & 7.76 & 7.62 & 7.57 & 7.45 \\
V2 585 per. borda & 7.42 & 7.44 & 7.38 & 7.45 \\
V2 585 par. centro & 6.36 & 6.30 & 6.25 & 7.45 \\
V2 585 par. borda & 4.49 & 4.55 & 4.48 & 7.45 \\
\hline V2 555777 centro & 6.29 & 6.27 & 6.19 & 6.97 \\
V2 555777 borda & 5.40 & 5.45 & 5.38 & 6.97 \\
\hline V1 per. centro & 7.79 & 7.49 & 7.39 & 7.61 \\
V1 par. centro & 8.01 & 7.68 & 7.60 & 7.61 \\
V1 borda & 5.13 & 5.22 & - & 7.61 \\
\hline SW per. centro & 5.05 & 5.20 & 5.19 & 5.03 \\
SW par. centro & 4.19 & 4.08 & 4.08 & 5.03 \\
SW par. borda & 3.37 & 3.33 & 3.30 & 5.03 \\
SW 557 & 2.65 & 2.74 & - & 5.03 \\
SW 57 & $1.74(1.57)$ & 1.82 & - & 5.03
\end{tabular}

Tabela 5.16: Energias de formação não-magnética, AF, F e no grafeno (em eV). $\mathrm{O}$ valor entre parênteses para o defeito SW 57 corresponde à energia de formação calculada com a supercélula relaxada com 9 repetições.

\begin{tabular}{lccc}
\hline Defeito & $E_{A F}-E_{0}$ & $E_{F}-E_{0}$ & $E_{A F}-E_{F}$ \\
\hline \hline Pristina & -0.47 & -0.42 & -0.06 \\
\hline V2 585 per. centro & -0.48 & -0.47 & -0.01 \\
V2 585 per. borda & -0.32 & -0.32 & 0.00 \\
V2 585 par. centro & -0.40 & -0.39 & -0.01 \\
V2 585 par. borda & -0.28 & -0.30 & 0.02 \\
\hline V2 555777 centro & -0.35 & -0.39 & 0.04 \\
V2 555777 borda & -0.29 & -0.30 & 0.01 \\
\hline V1 per. centro & -0.64 & -0.68 & 0.04 \\
V1 par. centro & -0.67 & -0.69 & -0.02 \\
V1 borda & -0.25 & - & - \\
\hline SW per. centro & -0.19 & -0.14 & -0.05 \\
SW par. centro & -0.44 & -0.39 & -0.06 \\
SW par. borda & -0.38 & -0.35 & -0.03 \\
SW 557 & -0.24 & - & - \\
SW 57 & -0.25 & - & -
\end{tabular}

Tabela 5.17: Estabilidade relativa entre as configurações não-magnética, AF e F $(\mathrm{em} \mathrm{eV})$. 


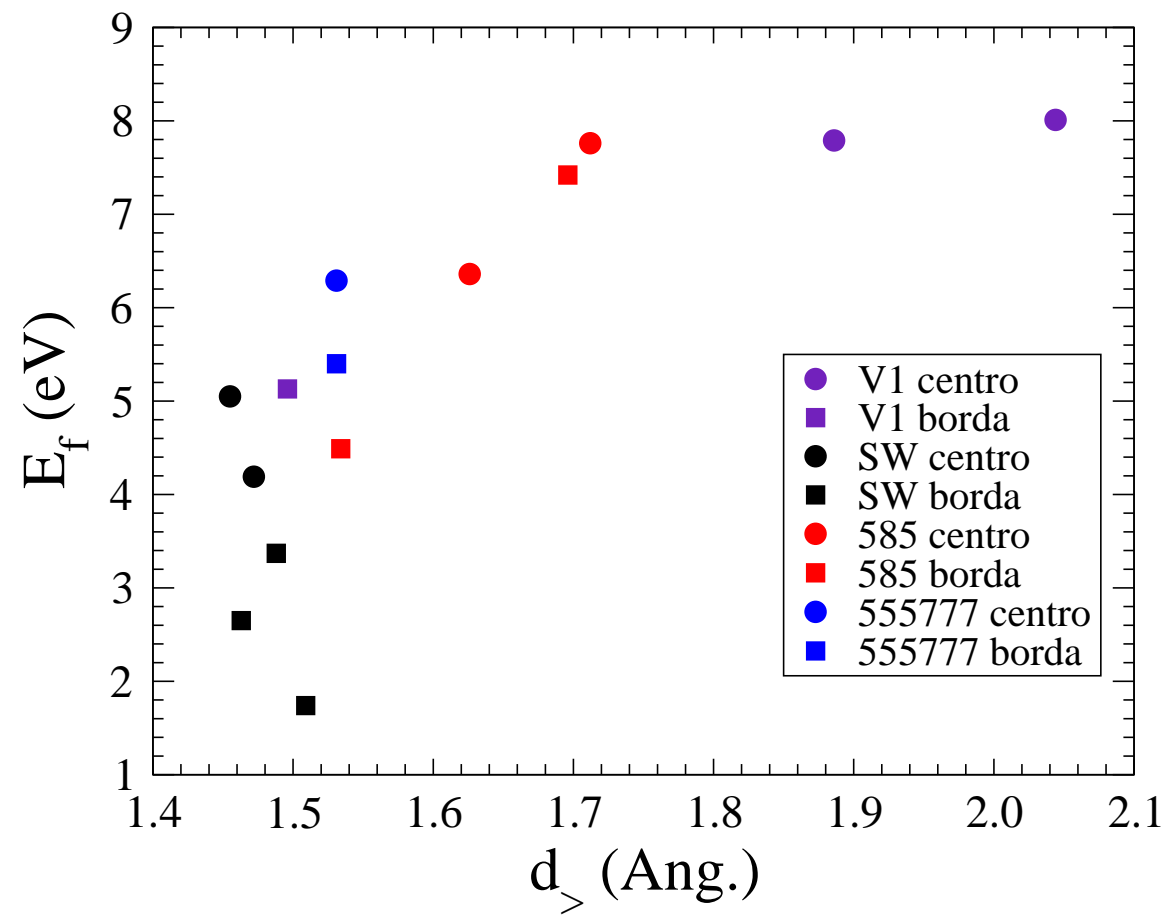

Figura 5.24: Energias de formação não-magnéticas, $E_{f}$, em função do maior comprimento de ligação no defeito, $d_{>}$. Os quadrados indicam defeitos na borda e círculos, no centro da fita. As cores diferenciam os tipos de defeitos. Note que, quanto maior $d_{>}$, maior é a energia de formação. Também percebe-se que defeitos na borda são mais estáveis que no centro. 


\section{Capítulo 6}

\section{Conclusão}

Grafeno e nanofitas de grafeno são sistemas muito estudados e de grande relevância atualmente, devido ao seu grande potencial para aplicações. Assim, saber quais são os defeitos mais encontrados nestes sistemas e como eles alteram suas propriedades é importante.

Em nanotubos de carbono e grafeno defeitos mais estáveis são do tipo divacância, vacância e Stone-Wales. Para nanofitas de grafeno, no entanto, estes defeitos ainda não haviam sido investigados.

Neste trabalho, preenchemos esse vazio estudando as propriedades energéticas e estruturais de defeitos do tipo divacância, vacância e Stone-Wales, verificando que estes também são importantes para nanofitas de grafeno zigzag. Em especial, encontramos dois novos defeitos, que chamamos de SW 557 e SW 57, com energias de formação muito baixas. Particularmente, dada sua baixíssima energia de formação, é muito provável que o defeito SW 57 seja criado nos processos de fabricação e corte das nanofitas.

Também apresentamos simulações de imagens STM para os defeitos nas fitas, que podem servir como guia para a caracterização experimental de defeitos em nanofitas. Como perspectivas futuras para este trabalho estão:

- Continuar a análise das propriedades eletrônicas dos defeitos (a estrutura de 
bandas dos defeitos já foi calculada);

- Estudar como os defeitos alteram as propriedades de transporte de carga de nanofitas;

- Investigar como a presença de desordem (distribuição aleatória de defeitos) altera as propriedades de transporte das fitas;

- Adsorção de moléculas, como $\mathrm{O}_{2}$ e $C O$, nos defeitos.

Algumas das perspectivas citadas já estão em andamento. 


\section{Apêndice A}

\section{Aproximação de Born-Oppenheimer}

A Hamiltoniana de um sistema composto por elétrons e núcleos (eq. 3.1) pode ser reescrita como

$$
\begin{aligned}
H & =T_{N}+T_{e}+U \\
& =T_{N}+H_{e}
\end{aligned}
$$

onde $T_{N}$ é a energia cinética dos núcleos, dada por

$$
T_{N}=-\sum_{I} \frac{\hbar^{2}}{2 M_{I}} \nabla_{I}^{2}
$$

$H_{e}$ é a hamiltoniana eletrônica, composta dos termos $T_{e}$, a energia cinética eletrônica,

$$
T_{e}=-\frac{\hbar^{2}}{2 m_{e}} \sum_{i} \nabla_{i}^{2}
$$

e $U=V_{e N}+V_{e e}+V_{N N}$, que agrupa as energias potenciais,

$$
V_{e N}=-\sum_{I, i} \frac{Z_{I} e^{2}}{\left|\mathbf{R}_{I}-\mathbf{r}_{i}\right|}
$$




$$
\begin{aligned}
V_{e e} & =-\frac{1}{2} \sum_{i \neq j} \frac{e^{2}}{\left|\mathbf{r}_{i}-\mathbf{r}_{j}\right|} \\
V_{N N} & =\frac{1}{2} \sum_{I \neq J} \frac{Z_{I} Z_{J} e^{2}}{\left|\mathbf{R}_{I}-\mathbf{R}_{J}\right|} .
\end{aligned}
$$

A solução para este sistema, que acopla as variáveis eletrônicas e nucleares através de $V_{e N}$, é dada por

$$
H \Psi_{s}(\mathbf{r}, \mathbf{R})=E_{s} \Psi_{s}(\mathbf{r}, \mathbf{R}) .
$$

Vamos supor que as soluções da parte eletrônica são conhecidas,

$$
H_{e} \psi_{i}(\mathbf{r} ; \mathbf{R})=E_{i}(\mathbf{R}) \psi_{i}(\mathbf{r} ; \mathbf{R})
$$

onde $\psi_{i}$ e $E_{i}$ dependem parametricamente das coordenadas nucleares R. Então, para cada $\mathbf{R}$ as autofunções $\psi_{i}$ formam uma base completa ( $H_{e}$ é hermitiano) para os estados eletrônicos. Logo, podemos escrever a solução para o sistema acoplado como uma combinação linear das funções de onda eletrônicas,

$$
\Psi_{s}(\mathbf{r}, \mathbf{R})=\sum_{i} \chi_{s i}(\mathbf{R}) \psi_{i}(\mathbf{r} ; \mathbf{R})
$$

Inserindo esta expressão em (A.7), multiplicando $\psi_{j}^{*}(\mathbf{r} ; \mathbf{R})$ e integrando nas variáveis eletrônicas, obtemos

$$
\left[T_{N}+E_{i}(\mathbf{R})-E_{s}\right] \chi_{s i}(\mathbf{R})=-\sum_{j} C_{i j}(\mathbf{R}) \chi_{s j}(\mathbf{R})
$$

onde $C_{i j}=A_{i j}+B_{i j}$ com

$$
A_{i j}(\mathbf{R})=\sum_{I} \frac{1}{M_{I}} \int \psi_{i}^{*}(\mathbf{r} ; \mathbf{R}) \nabla_{I} \psi_{j}(\mathbf{r} ; \mathbf{R}) d \mathbf{r} \nabla_{I}
$$


e

$$
B_{i j}(\mathbf{R})=\sum_{I} \frac{1}{2 M_{I}} \int \psi_{i}^{*}(\mathbf{r} ; \mathbf{R}) \nabla_{I}^{2} \psi_{j}(\mathbf{r} ; \mathbf{R}) d \mathbf{r} .
$$

A aproximação de Born-Oppenheimer consiste em desprezar os termos não diagonais $C_{i j}, i \neq j$, que acoplam diferentes estados eletrônicos. Ou seja, é assumido que os elétrons permanecem num mesmo estado enquanto os núcleos se movem. Esta aproximação é justificada pela grande diferença de massa entre os núcleos e os elétrons $\left(m_{e} / M \ll 1\right)$.

Assim, na aproximação BO, o movimento nuclear é descrito por

$$
\left[-\sum_{I} \frac{1}{2 M_{I}} \nabla_{I}^{2}+U_{i}(\mathbf{R})\right] \chi_{n i}(\mathbf{R})=E_{n i} \chi_{n i}(\mathbf{R}),
$$

onde $U_{i}(\mathbf{R})=E_{i}(\mathbf{R})+B_{i i}(\mathbf{R})$ determina um potencial para os núcleos ${ }^{1}$ e o índice $n$ se refere a estados nucleares.

\footnotetext{
${ }^{1} \mathrm{O}$ requerimento de que $\psi_{i}$ seja normalizado implica $A_{i i}=0$.
} 


\section{Apêndice B}

\section{Otimização de parâmetros}

Simulações computacionais de primeiros princípios podem gerar informações relevantes que ajudem no entendimento de um dado sistema, ou apenas lixo numérico sem sentido. A diferença entre esses dois extremos reside em, por um lado, assegurar que as aproximações físicas realizadas (como a aproximação de Born-Oppenheimer ou o funcional de troca e correlação escolhido) sejam válidas, e por outro, garantir a convergência das aproximações numéricas empregadas. Em suma, é necessário garantir que os resultados obtidos nas simulações são confiáveis dentro dos propósitos almejados.

\section{B.1 Energia de Corte}

Através do teorema de Bloch, uma função de onda de um sistema periódico pode ser expandida numa base de ondas planas

$$
\psi_{j}(\mathbf{r})=\sum_{\mathbf{G}} c_{k, \mathbf{G}} \exp [i(\mathbf{G}+\mathbf{k}) \cdot \mathbf{r}]
$$

onde $\mathbf{G}$ é um vetor da rede recíproca e $\mathbf{k}$ é um ponto dentro da primeira zona de Brillouin. 
A Energia de corte, definida como

$$
E_{\text {corte }}=\frac{\hbar^{2}}{2 m} \mathbf{K}_{\text {corte }}^{2}
$$

é usada então para determinar o tamanho da base na qual as funções de onda são expandidas. Apenas serão incluídas ondas com

$$
|\mathbf{G}+\mathbf{k}| \leq K_{\text {corte }}
$$

Inicialmente, para assegurar que a base usada para realizar os cálculos descreve bem o sistema, isto é, fosse completa o suficiente, fizemos um estudo da convergência da energia total $E$ com $E_{\text {corte. }}$ Na figura B.1, pode-se ver a energia total por átomo de uma célula unitária de um fita 7,0 em função de $E_{\text {corte }}$. O critério de convergência empregado foi de uma diferença de energias menor que $1 \mathrm{meV}$ por átomo.

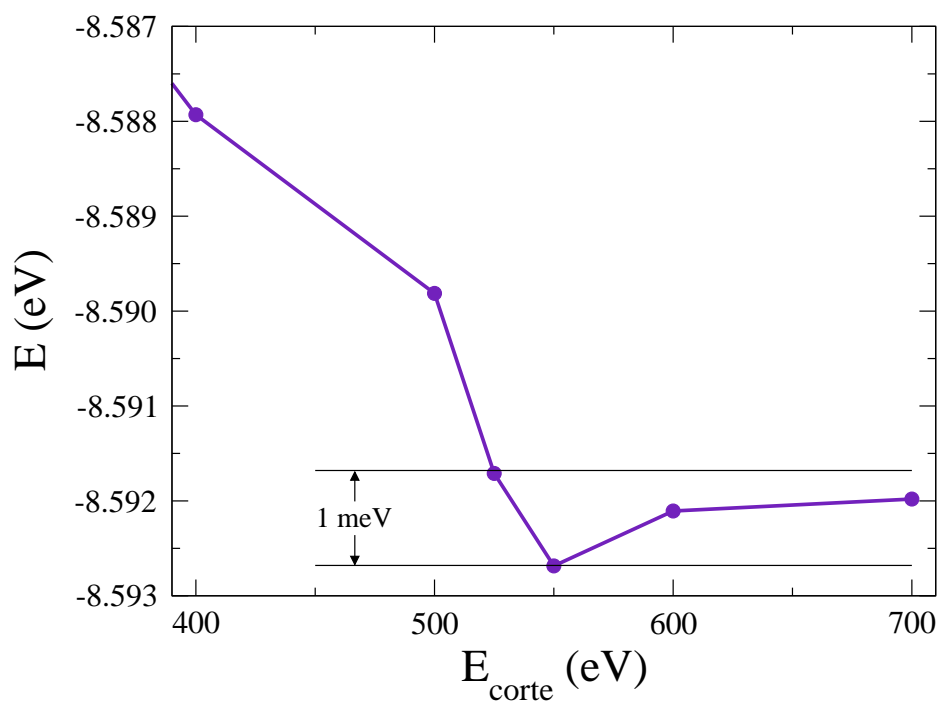

Figura B.1: Convergência da energia por átomo da célula unitária de uma nanofita 7,0 com a energia de corte. A energia converge dentro de $1 \mathrm{meV}$ por átomo a partir de $525 \mathrm{eV}$. 


\section{B.2 Pontos $\mathrm{k}$}

Muitos dos programas existentes atualmente para cálculo de estrutura eletrônica via DFT empregam condições periódicas de contorno nas três direções do espaço (o VASP, usado neste trabalho, é um deles). Através do teorema de Bloch [68] é possível tirar vantagem das simetrias de translação, transformando um problema com um número infinito de átomos noutro, com um número finito, mas com infinitos vetores de onda $\mathbf{k}$ (pontos $\mathbf{k}$ ) na zona de Brillouin (BZ).

Assim, por exemplo, para obter a energia total no estado fundamental é necessário calcular a integral

$$
\frac{1}{\Omega_{B Z}} \int_{B Z} d \mathbf{k} \sum_{n} \epsilon_{n}(\mathbf{k}) f\left(\epsilon_{n}(\mathbf{k})\right),
$$

onde $\Omega_{B Z}$ é o volume da BZ, $\epsilon_{n}(\mathbf{k})$ é a energia do orbital de Kohn-Sham e $f\left(\epsilon_{n}(\mathbf{k})\right)$, a ocupação do mesmo. Ao fazer o cálculo, a integral acima é aproximada por uma soma sobre um conjunto finito de pontos $\mathrm{k}$,

$$
\sum_{\mathbf{k}} w_{\mathbf{k}} \sum_{n} \epsilon_{n}(\mathbf{k}) f\left(\epsilon_{n}(\mathbf{k})\right)
$$

Para descobrir quantos pontos k são necessários para obter uma energia total convergida, foi realizado um estudo da energia em função do número de pontos k para uma fita 7,0 com oito repetições da célula unitária. É importante notar que a energia total não é variacional no número de pontos $\mathrm{k}$ e, portanto, não necessariamente decresce monotonicamente aumentanto o número de pontos k.

Como pode ser visto na figura B.2, convergência é atingida a partir de 3 pontos k. Este valor foi adotado para os cálculos com nanofitas. Para o grafeno, foram usados $3 \times 3$ pontos $\mathrm{k}$ na BZ. 


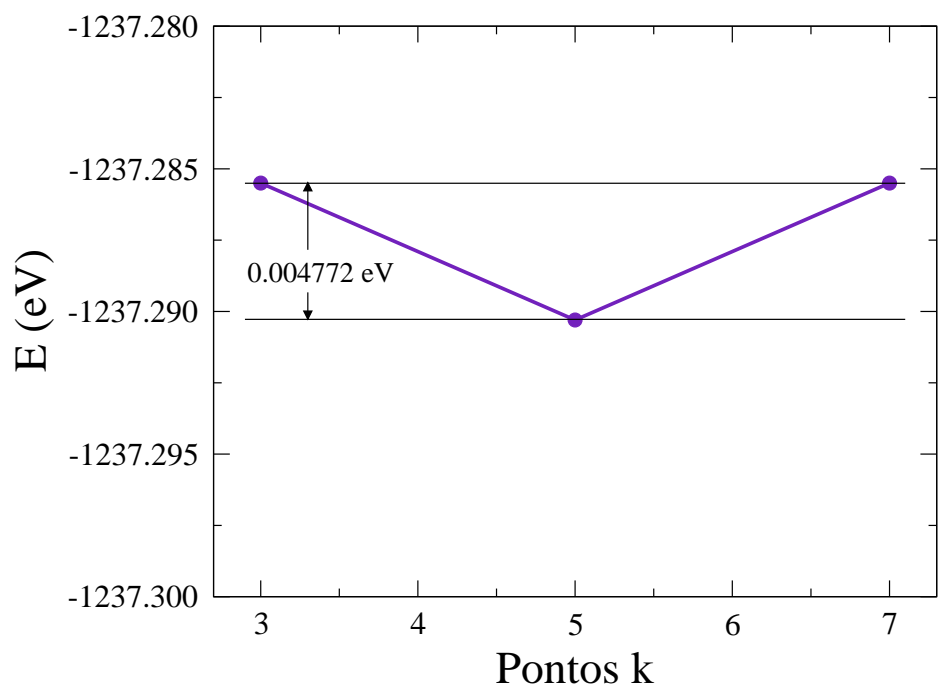

Figura B.2: Energia versus número de pontos k para uma fita 7,0.

\section{B.3 Parâmetro de rede}

Os parâmetros de rede foram obtidos fazendo-se pequenas variações do tamanho da caixa (os vetores que definem a célula unitária) em torno do valor experimental. As energias obtidas foram ajustadas por uma parábola ${ }^{1}$. O mínimo de energia corresponde então ao parâmetro de rede de equilíbrio.

O parâmetro de rede encontrado para o grafeno (figura B.3) foi de $2.46 \AA$, correspondente a uma distância carbono-carbono de $1.42 \AA$, em excelente acordo com valores experimentais $[39,69]$. Na figura B.4 podemos ver os resultados obtidos para a otimização de um parâmetro de rede de uma nanofita $(7,0)$. O valor encontrado para o parâmetro de rede é de $2.459 \AA$.

\footnotetext{
${ }^{1}$ Aproximações harmônicas são consistentes nas vizinhanças de um mínimo de energia.
} 


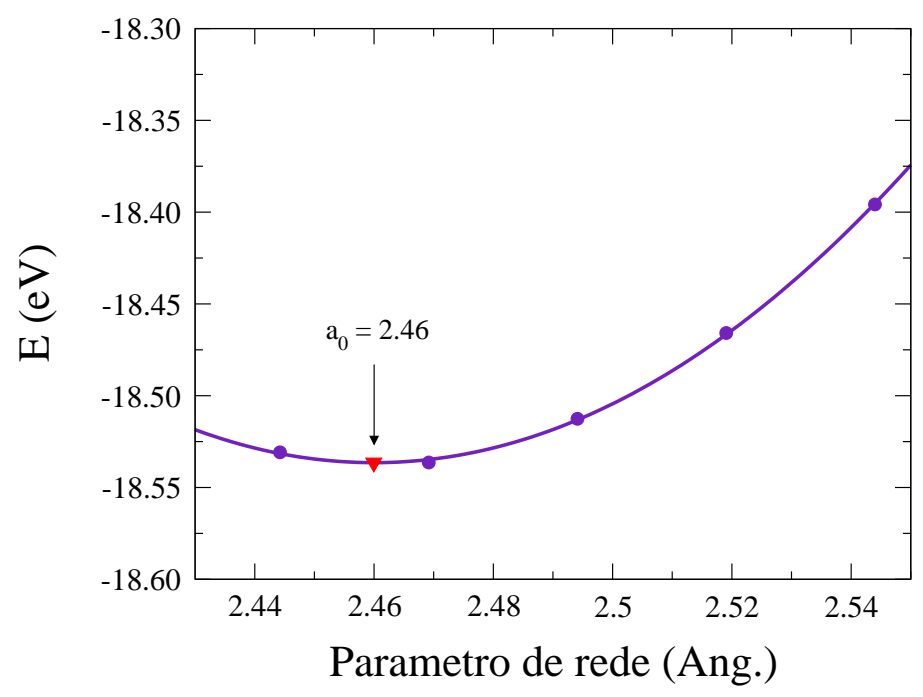

Figura B.3: Otimização do parâmetro de rede para o grafeno. Os pontos circulares indicam os valores calculados, a curva é o ajuste parabólico e o triângulo, o mínimo de energia, que corresponde ao parâmetro de rede de equilíbrio.

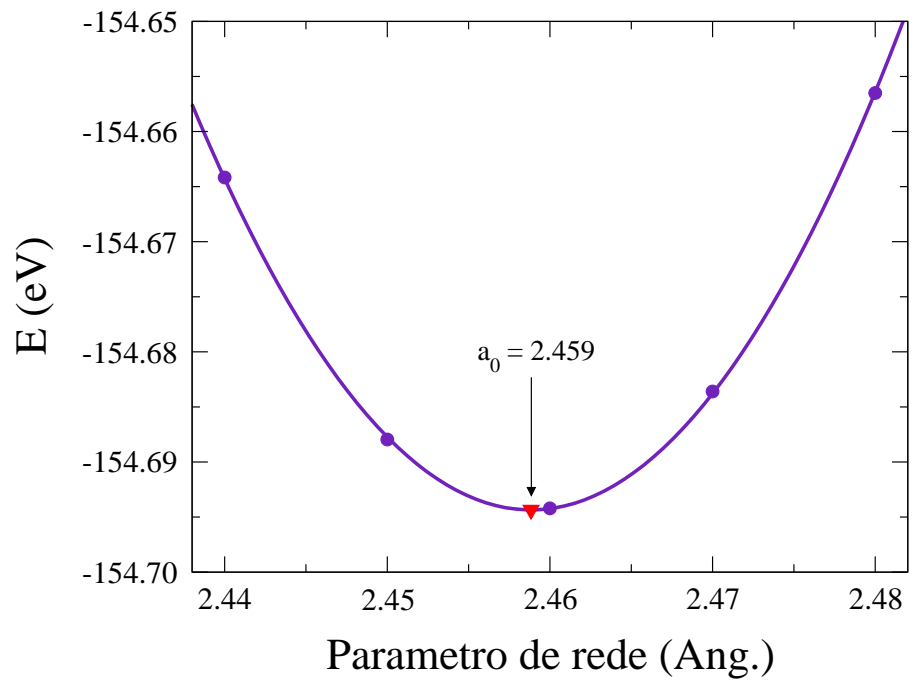

Figura B.4: Otimização do parâmetro de rede de uma nanofita $(7,0)$. Os pontos correspondem aos valores calculados para os diferentes parâmetros de rede, a linha sólida ao ajuste parabólico e o triângulo ao mínimo de energia, que corresponde a um parâmetro de rede de $2.459 \AA$. 


\section{Apêndice C}

\section{Pseudopotenciais}

Em geral, num átomo, apenas os elétrons da camada de valência são quimicamente ativos, participando da determinação das propriedades de sólidos e moléculas. Já os elétrons de caroço, que estão fortemente ligados ao núcleo, são quimicamente inertes, dependendo pouco do ambiente químico no qual o átomo se encontra.

Valendo-se disso, a aproximação de pseudopotencial consiste em subtituir o potencial gerado pelos elétrons de caroço mais o núcleo por um potencial efetivo dentro da região de caroço, definida por um raio de corte $r_{c}$ (veja a Fig. C.1). O pseudopotencial, $V_{P S}$, é mais fraco que o original na região $r<r_{c}$ porque os elétrons de caroço blindam o potencial nuclear. Fora da região de caroço $\left(r>r_{c}\right), V_{P S}=V$.

Desta forma, o número de elétrons é reduzido nos cálculos, diminuindo o custo computacional. Também, no caso de códigos que usam ondas planas para expandir as funções de onda (como o VASP), o uso de pseudopotenciais traz uma vantagem adicional. O número de ondas planas requeridas para descrever as funções de onda com estes programas seria muito grande na região de caroço, onde as funções de onda oscilam muito rapidamente. No entanto, as pseudo-funçoes de onda são muito mais suaves (Fig. C.1), requerendo energias de corte menores, isto é, menos funções base, o que torna os cálculos mais rápidos (em muitos casos os torna possíveis).

Um aspecto importante referente a pseudopotencias ao qual deve ser dada aten- 


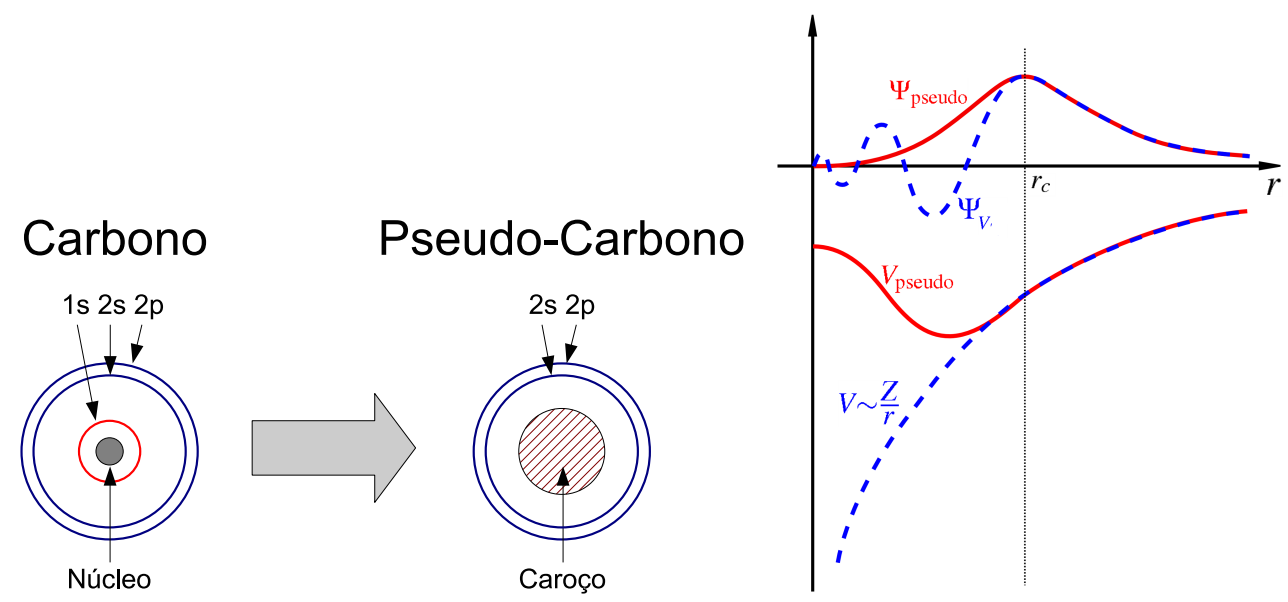

Figura C.1: Filosofia da aproximação de pseudopotencial. - Representação esquemática do pseudopotencial $V_{\text {pseudo }}$ e pseudo-função de onda $\Psi_{\text {pseudo }}$ (em vermelho), e do potencial $V(Z / r)$ e função de onda correspondente, $\Psi_{V}$ (azul). A partir do raio de corte $r_{c}$, as funções $\Psi_{\text {pseudo }}$ e $\Psi_{V}$ coincidem.

ção é sua tranferibilidade. Este é definido como a capacidade de descrever adequadamente ambientes químicos diferentes daqueles nos quais o pseudopotencial foi criado $^{1}$. Como regra, quanto maior o raio de corte de um pseudopotencial, mais suave este será, permitindo um ganho computacional maior. Por outro lado, ele se torna menos transferível. Assim, há uma competição entre performance e transferibilidade, dada pelo raio de corte $r_{c}$.

Os pseudopotenciais usados nos cálculos apresentados nesta dissertação são do tipo ultrasoft de Vanderbilt [65]. Neste tipo de pseudopotencias, o vínculo da conservação da norma é relaxado, fazendo com que as pseudo-funcões de onda resultantes sejam muito mais suaves na região de caroço do que em outros pseudopotenciais. Porém, as funções não são ortogonais e não há conservação da carga, que deve ser renormalizada. Estes problemas introduzem mais complexidade nos programas. Quanto à performance, o custo extra requerido é muito pequeno.

\footnotetext{
${ }^{1}$ Em geral, pseudopotenciais são gerados em cálculos atômicos.
} 


\section{Apêndice D}

\section{Aproximação de Supercélula}

Uma grande parte dos códigos desenvolvidos para cálculos de estrutura eletrônica, como o VASP, empregam condições périódicas de contorno (baseados no teorema de Bloch) nas três direções do espaço, x, y, e z. Isto, a princípio, impossibilitaria o cálculo em estruturas de baixa dimensionalidade, como grafeno, nanofitas e moléculas, ou em estruturas onde a simetria de translação é quebrada, como num material na presença de um defeito.

Este problema é contornado com a chamada aproximação de supercélula (figura D.1), que consiste simplesmente em construir, artificialmente, uma célula maior de forma a isolar a estrutura que se quer estudar. No caso do grafeno e das nanofitas, é incluída uma região de vácuo de $11 \AA$ entre as camadas de forma a garantir que não haja interação entre as imagens. Nas fitas também foram incluídos 11 A lateralmente. No caso do cálculos de defeitos nas nanofitas, foram incluídas 8 repetições da célula unitária original, resultando numa distância de aproximadamente $14 \AA$ entre os defeitos. Para os defeitos no grafeno a distância entre diferentes imagens é de aproximadamente $15 \AA$. 


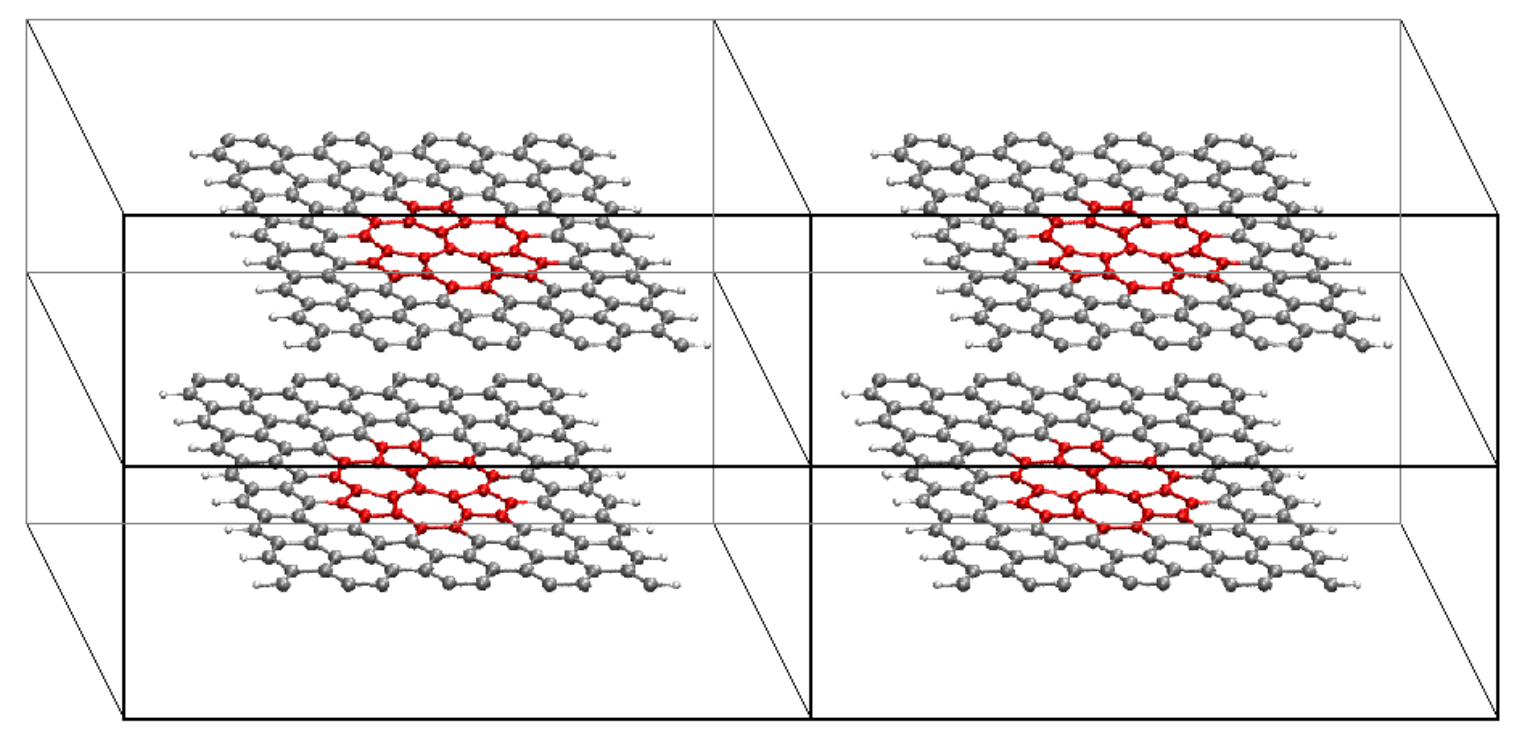

Figura D.1: Ilustração da aproximação de supercélula para uma nanofita de grafeno. Uma região de vácuo de 11 A é incluída entre as fitas. 


\section{Referências Bibliográficas}

[1] H. W. Kroto, J. R. Heath, S. C. O’Brien, R. F. Curl, and R. E. Smalley, "C60: Buckminsterfullerene," Nature, vol. 318, pp. 318-319, November 1985.

[2] S. Iijima, "Helical microtubules of graphitic carbon," Nature, vol. 354, pp. 5658, November 1991.

[3] A. K. Geim and K. S. Novoselov, "The rise of graphene," Nature Materials, vol. 6, pp. 183-191, Mar 2007.

[4] P. R. Wallace, "The band theory of graphite," Phys. Rev., vol. 71, pp. 622-634, May 1947.

[5] K. S. Novoselov, A. K. Geim, S. V. Morozov, D. Jiang, Y. Zhang, S. V. Dubonos, I. V. Grigorieva, and A. A. Firsov, "Electric Field Effect in Atomically Thin Carbon Films," Science, vol. 306, no. 5696, pp. 666-669, 2004.

[6] F. Schedin, A. K. Geim, S. V. Morozov, E. W. Hill, P. Blake, M. I. Katsnelson, and K. S. Novoselov, "Detection of individual gas molecules adsorbed on graphene," Nat. Mater., vol. 6, no. 9, pp. 652-655, 2007.

[7] J. T. Robinson, F. K. Perkins, E. S. Snow, Z. Wei, and P. E. Sheehan, "Reduced graphene oxide molecular sensors," Nano Letters, 2008.

[8] E. H. Hwang, S. Adam, and S. D. Sarma, "Transport in chemically doped graphene in the presence of adsorbed molecules," Physical Review B (Condensed Matter and Materials Physics), vol. 76, no. 19, p. 195421, 2007.

[9] X. Wang, L. Zhi, and K. Mullen, "Transparent, conductive graphene electrodes for dye-sensitized solar cells," Nano Letters, vol. 8, no. 1, pp. 323-327, 2008.

[10] M. C. Lemme, T. J. Echtermeyer, M. Baus, and H. Kurz, "A graphene fieldeffect device," IEEE Electron Device Lett., vol. 28, no. 4, pp. 282-284, 2007. 
[11] Z. H. Chen, Y. M. Lin, M. J. Rooks, and P. Avouris, "Graphene nano-ribbon electronics," Physica E, vol. 40, no. 2, pp. 228-232, 2007.

[12] B. Standley, W. Bao, H. Zhang, J. Bruck, C. N. Lau, and M. Bockrath, "Graphen-based atomic-scale switches," Nano Letters, 2008.

[13] T. J. Echtermeyer, M. C. Lemme, M. Baus, B. N. Szafranek, A. K. Geim, and H. Kurz, "Nonvolatile switching in graphene field-effect devices," IEEE Electron Device Lett., vol. 29, no. 8, pp. 952-954, 2008.

[14] M. Ohishi, M. Shiraishi, R. Nouchi, T. Nozaki, T. Shinjo, and Y. Suzuki, "Spin injection into a graphene thin film at room temperature," Jpn. J. Appl. Phys. Part 2 - Lett. Express Lett., vol. 46, no. 25-28, pp. L605-L607, 2007.

[15] C. Józsa, M. Popinciuc, N. Tombros, H. T. Jonkman, and B. J. van Wees, "Electronic spin drift in graphene field-effect transistors," Physical Review Letters, vol. 100, no. 23, p. 236603, 2008.

[16] E. W. Hill, A. K. Geim, K. Novoselov, F. Schedin, and P. Blake, "Graphene spin valve devices," IEEE Trans. Magn., vol. 42, no. 10, pp. 2694-2696, 2006.

[17] S. Cho, Y.-F. Chen, and M. S. Fuhrer, "Gate-tunable graphene spin valve," Applied Physics Letters, vol. 91, no. 12, p. 123105, 2007.

[18] D. Li and R. B. Kaner, "MATERIALS SCIENCE: Graphene-Based Materials," Science, vol. 320, no. 5880, pp. 1170-1171, 2008.

[19] A. V. Krasheninnikov, K. Nordlund, M. Sirviö, E. Salonen, and J. Keinonen, "Formation of ion-irradiation-induced atomic-scale defects on walls of carbon nanotubes," Phys. Rev. B, vol. 63, p. 245405, May 2001.

[20] C. Gomez-Navarro, P. J. D. Pablo, J. Gomez-Herrero, B. Biel, F. J. GarciaVidal, A. Rubio, and F. Flores, "Tuning the conductance of single-walled carbon nanotubes by ion irradiation in the Anderson localization regime," Nat. Mater., vol. 4, no. 7, pp. 534-539, 2005.

[21] A. Hashimoto, K. Suenaga, A. Gloter, K. Urita, and S. Iijima, "Direct evidence for atomic defects in graphene layers," Nature, vol. 430, no. 7002, pp. 870-873, 2004 .

[22] S. V. Morozov, K. S. Novoselov, M. I. Katsnelson, F. Schedin, D. C. Elias, J. A. Jaszczak, and A. K. Geim, "Giant intrinsic carrier mobilities in graphene and its bilayer," Physical Review Letters, vol. 100, no. 1, p. 016602, 2008. 
[23] C. Lee, X. Wei, J. W. Kysar, and J. Hone, "Measurement of the Elastic Properties and Intrinsic Strength of Monolayer Graphene," Science, vol. 321, no. 5887, pp. 385-388, 2008.

[24] A. A. Balandin, S. Ghosh, W. Z. Bao, I. Calizo, D. Teweldebrhan, F. Miao, and C. N. Lau, "Superior thermal conductivity of single-layer graphene," Nano Lett., vol. 8, no. 3, pp. 902-907, 2008.

[25] A. H. C. Neto, F. Guinea, N. M. R. Peres, K. S. Novoselov, and A. K. Geim, "The electronic properties of graphene," Rev. Mod. Phys., 2007.

[26] K. Nakada, M. Fujita, G. Dresselhaus, and M. S. Dresselhaus, "Edge state in graphene ribbons: Nanometer size effect and edge shape dependence," Phys. Rev. B, vol. 54, pp. 17954-17961, Dec 1996.

[27] Y.-W. Son, M. L. Cohen, and S. G. Louie, "Energy gaps in graphene nanoribbons," Physical Review Letters, vol. 97, no. 21, p. 216803, 2006.

[28] Y.-W. Son, M. L. Cohen, and S. G. Louie, "Half-metallic graphene nanoribbons," Nature, vol. 444, pp. 347-349, Nov 2006.

[29] L. Pisani, J. A. Chan, B. Montanari, and N. M. Harrison, "Electronic structure and magnetic properties of graphitic ribbons," Physical Review B (Condensed Matter and Materials Physics), vol. 75, no. 6, p. 064418, 2007.

[30] Y. Kobayashi, K. ichi Fukui, T. Enoki, K. Kusakabe, and Y. Kaburagi, "Observation of zigzag and armchair edges of graphite using scanning tunneling microscopy and spectroscopy," Phys. Rev. B, vol. 71, no. 19, p. 193406, 2005.

[31] Y. Kobayashi, K. ichi Fukui, T. Enoki, and K. Kusakabe, "Edge state on hydrogen-terminated graphite edges investigated by scanning tunneling microscopy," Phys. Rev. B, vol. 73, no. 12, p. 125415, 2006.

[32] C. Stampfer, E. Schurtenberger, F. Molitor, J. Guttinger, T. Ihn, and K. Ensslin, "Tunable graphene single electron transistor," Nano Lett., vol. 8, no. 8, pp. 2378-2383, 2008.

[33] L. A. Ponomarenko, F. Schedin, M. I. Katsnelson, R. Yang, E. W. Hill, K. S. Novoselov, and A. K. Geim, "Chaotic dirac billiard in graphene quantum dots," Science, vol. 320, no. 5874, pp. 356-358, 2008. 
[34] Z. F. Wang, Q. W. Shi, Q. Li, X. Wang, J. G. Hou, H. Zheng, Y. Yao, and J. Chen, "Z-shaped graphene nanoribbon quantum dot device," Applied Physics Letters, vol. 91, no. 5, p. 053109, 2007.

[35] B. Trauzettel, D. V. Bulaev, D. Loss, and G. Burkard, "Spin qubits in graphene quantum dots," Nat. Phys., vol. 3, no. 3, pp. 192-196, 2007.

[36] T. G. Pedersen, C. Flindt, J. Pedersen, N. A. Mortensen, A.-P. Jauho, and K. Pedersen, "Graphene antidot lattices: Designed defects and spin qubits," Physical Review Letters, vol. 100, no. 13, p. 136804, 2008.

[37] X. Li, X. Wang, L. Zhang, S. Lee, and H. Dai, "Chemically Derived, Ultrasmooth Graphene Nanoribbon Semiconductors," Science, vol. 319, no. 5867, pp. 1229-1232, 2008.

[38] L. Tapaszto, G. Dobrik, P. Lambin, and L. P. Biro, "Tailoring the atomic structure of graphene nanoribbons by scanning tunnelling microscope lithography," Nat. Nanotechnol., vol. 3, no. 7, pp. 397-401, 2008.

[39] J. C. Meyer, C. Kisielowski, R. Erni, M. D. Rossell, M. F. Crommie, and A. Zettl, "Direct imaging of lattice atoms and topological defects in graphene membranes," Nano Letters, 2008.

[40] H. Amara, S. Latil, V. Meunier, P. Lambin, and J.-C. Charlier, "Scanning tunneling microscopy fingerprints of point defects in graphene: A theoretical prediction," Physical Review B (Condensed Matter and Materials Physics), vol. 76, no. 11, p. 115423, 2007.

[41] G.-D. Lee, C. Z. Wang, E. Yoon, N.-M. Hwang, D.-Y. Kim, and K. M. Ho, "Diffusion, coalescence, and reconstruction of vacancy defects in graphene layers," Physical Review Letters, vol. 95, no. 20, p. 205501, 2005.

[42] G.-D. Lee, C. Z. Wang, E. Yoon, N.-M. Hwang, and K. M. Ho, "Vacancy defects and the formation of local haeckelite structures in graphene from tight-binding molecular dynamics," Physical Review B (Condensed Matter and Materials Physics), vol. 74, no. 24, p. 245411, 2006.

[43] M. T. Lusk and L. D. Carr, "Nanoengineering defect structures on graphene," Physical Review Letters, vol. 100, no. 17, p. 175503, 2008.

[44] J. J. Palacios, J. Fernández-Rossier, and L. Brey, "Vacancy-induced magnetism in graphene and graphene ribbons," Physical Review B (Condensed Matter and Materials Physics), vol. 77, no. 19, p. 195428, 2008. 
[45] O. V. Yazyev and L. Helm, "Defect-induced magnetism in graphene," Physical Review B (Condensed Matter and Materials Physics), vol. 75, no. 12, p. 125408, 2007.

[46] E. J. Duplock, M. Scheffler, and P. J. D. Lindan, "Hallmark of perfect graphene," Phys. Rev. Lett., vol. 92, p. 225502, Jun 2004.

[47] A. Szabo and N. S. Ostulnd, Modern Quantum Chemistry. Dover, 1996.

[48] L. H. Thomas, "The calculation of atomic fields," Proc. Cambridge Phil. Soc., vol. 23, pp. 542-548, 1927.

[49] E. Fermi, "Un metodo statistico per la determinazione di alcune priorieta dell'atome," Rend. Accad. Naz. Lincei, vol. 6, pp. 602-607, 1927.

[50] R. Martin, Electronic Structure: basic theory and practical methods. Cambridge University Press, 2004.

[51] P. Hohenberg and W. Kohn, "Inhomogeneous electron gas," Phys. Rev., vol. 136, pp. B864-B871, Nov 1964.

[52] W. Kohn and L. J. Sham, "Self-consistent equations including exchange and correlation effects," Phys. Rev., vol. 140, pp. A1133-A1138, Nov 1965.

[53] D. M. Ceperley and B. J. Alder, "Ground state of the electron gas by a stochastic method," Phys. Rev. Lett., vol. 45, pp. 566-569, Aug 1980.

[54] K. Capelle, "A bird's-eye view of density-functional theory," 2002.

[55] J. P. Perdew, K. Burke, and M. Ernzerhof, "Generalized gradient approximation made simple," Phys. Rev. Lett., vol. 77, pp. 3865-3868, Oct 1996.

[56] J. P. Perdew and Y. Wang, "Accurate and simple analytic representation of the electron-gas correlation energy," Phys. Rev. B, vol. 45, pp. 13244-13249, Jun 1992.

[57] A. D. Becke, "Density-functional exchange-energy approximation with correct asymptotic behavior," Phys. Rev. A, vol. 38, pp. 3098-3100, Sep 1988.

[58] C. Lee, W. Yang, and R. G. Parr, "Development of the colle-salvetti correlationenergy formula into a functional of the electron density," Phys. Rev. B, vol. 37, pp. 785-789, Jan 1988. 
[59] G. Binnig, H. Rohrer, C. Gerber, and E. Weibel, "Tunneling through a controllable vacuum gap," Applied Physics Letters, vol. 40, no. 2, pp. 178-180, 1982.

[60] E. Meyer, H. J. Hug, and R. Bennewitz, Scanning Probe Microscopy - The Lab on a Tip. Springer, 2004.

[61] J. Bardeen, "Tunnelling from a many-particle point of view," Phys. Rev. Lett., vol. 6, no. 2, pp. 57-59, 1961.

[62] J. Tersoff and D. R. Hamann, "Theory of the scanning tunneling microscope," Phys. Rev. B, vol. 31, no. 2, pp. 805-813, 1985.

[63] G. Kresse and J. Furthmuller, "Efficiency of ab-initio total energy calculations for metals and semiconductors using a plane-wave basis set," Comput. Mat. Sci., vol. 6, pp. 15-50, July 1996.

[64] H. J. Monkhorst and J. D. Pack, "Special points for brillouin-zone integrations," Phys. Rev. B, vol. 13, pp. 5188-5192, Jun 1976.

[65] D. Vanderbilt, "Soft self-consistent pseudopotentials in a generalized eigenvalue formalism," Phys. Rev. B, vol. 41, pp. 7892-7895, Apr 1990.

[66] R. Amorim, A. Fazzio, A. Antonelli, F. Novaes, and A. daSilva, "Divacancies in graphene and carbon nanotubes," Nano Letters, vol. 7, no. 8, pp. 2459-2462, 2007.

[67] K. Yamashita, M. Saito, and T. Oda, "Atomic geometry and stability of mono-, Di-, and trivacancies in graphene," Jpn. J. Appl. Phys. Part 1 - Regul. Pap. Brief Commun. Rev. Pap., vol. 45, no. 8A, pp. 6534-6536, 2006.

[68] A. E. Mattsson, P. A. Schultz, M. P. Desjarlais, T. R. Mattsson, and K. Leung, "Designing meaningful density functional theory calculations in materials science - a primer," Modelling and Simulation in Materials Science and Engineering, vol. 13, no. 1, pp. R1-R31, 2005.

[69] J. C. Meyer, A. K. Geim, M. I. Katsnelson, K. S. Novoselov, T. J. Booth, and S. Roth, "The structure of suspended graphene sheets," Nature, vol. 446, pp. 60-63, Mar 2007. 